\section{P 2.23}

\section{Automated Whole Blood Processing with the ATREUS 2C+ System Exceeds Conventional Preparation Method}

Lehmann C. ${ }^{I}$, Rummler S. ${ }^{2}$, Hildebrandt A. ${ }^{2}$, Lorenzen $T^{2}$, Barz D. ${ }^{2}$

${ }^{1}$ Universitätsklinikum Jena, Institut für Transfusionsmedizin, Jena, D, 'Jena, D

Objectives: The aim of the study was to evaluate the in-vitro quality of blood components processed by the Atreus $2 \mathrm{C}+$ System (AS) in comparison to results achieved using a conventional centrifugation method (CM). Design and Methods: The AS is an automated device for blood component filtration to separate a single unit of whole blood (WB) into a unit of red blood cells (RBCs), a plasma unit and a Buffy Coat (BC). The RBCs are leukoreduced (LR) offline through an integrated filter. Single BC units can be pooled together for further processing into a leukoreduced pooled platelet concentrate (PC). Using the CM whole blood is LR inline and the components are separated by centrifugation followed by a blood press process. By using a specific validation protocol, several in-vitro parameters of the blood components were tested. (1) BC-derived LR-PCs made out of 5 BCs: Volume, platelet count, residual white blood cells (WBCs), $\mathrm{RBCs}$ and $\mathrm{pH}$ at the beginning and end of storage. (2) LR-RBCs: Volume, hematocrit, free hemoglobin, residual WBCs, hemolysis at the beginning and end of storage, ATP/g hemoglobin. (3) Fresh Frozen Plasma (FFP), LR by plasmafilter PLAS1 (Maco Pharma): Volume, Factor VIII and residual cell contamination. Results:

\begin{tabular}{|l|l|l|l|l|l|}
\hline Parameter & $\begin{array}{l}\text { Platelet pool } \\
(\mathrm{AS}) \mathrm{n}=15\end{array}$ & $\begin{array}{l}\text { EK }(\mathrm{AS}) \\
\mathrm{n}=16\end{array}$ & $\begin{array}{l}\text { EK }(\mathrm{CM}) \\
\mathrm{n}=50\end{array}$ & $\begin{array}{l}\text { FFP (AS) } \\
\mathrm{n}=17\end{array}$ & $\begin{array}{l}\text { FFP }(\mathrm{CM}) \\
\mathrm{n}=50\end{array}$ \\
\hline WBC $\left(10^{6} / \mathrm{U}\right)$ & 0.02 & 0.02 & 0.08 & 0.0 & 0.06 \\
\hline RBC $\left(10^{9} / \mathrm{U}\right)$ & 1.0 & 1560 & 1602 & 0.0 & 0.1 \\
\hline PLT $\left(10^{9} / \mathrm{U}\right)$ & 322 & 0.7 & 1.0 & 0.0 & 0.0 \\
\hline Volume $(\mathrm{ml})$ & 251 & 254 & 255 & 248 & 246 \\
\hline pH - day $2 /$ day 6 & $6.9 / 7.1$ & & & & \\
\hline free Hb $(\mathrm{mmol} / 1)$ & & 0.01 & 0.04 & & \\
\hline Hematokrit $(1 / 1)$ & & 0.57 & 0.58 & & \\
\hline $\begin{array}{l}\text { Hemolysis }(\%)- \\
\text { day } 1 / \text { day } 42\end{array}$ & & $0.08 / 0.36$ & $\begin{array}{l}0.04 / 0.2 . \\
(\mathrm{n}=18)\end{array}$ & & \\
\hline$\mu$ mol ATP/g Hb & & 4.4 & $3.2(\mathrm{n}=18)$ & & \\
\hline $\begin{array}{l}\text { Factor VIII }(\%)- \\
\text { day 30 }\end{array}$ & & & & 100 & 96 \\
\hline
\end{tabular}

All blood products processed with the AS and the CM comply with the guide for the preparation, use and quality assurance of blood components. Conclusion: The AS enables us to improve the quality of LR-RBCs, LR-FFP and LR-BC-PCs out of WB through an automated and simple process

P 2.24

Reduction of the Plasma Content in Red Cell Units Using a New 5-Port-Technology in a Top/Top Blood Bag System

Volgmann . $^{l}$, Seltsam A. ${ }^{\prime}$, Zimmermann J. ${ }^{2}$, Koppitz G. ${ }^{2}$, Müller $T^{l}$

${ }^{1}$ Red Cross Blood Service NSTOB, Institute Springe, D, ${ }^{2}$ Maco Pharma International GmbH, Langen, D

Objectives: The major advantage of the Top/Top systems for blood component fractionation is the optimized yield of red blood cells (RBCs) and plasma. However, the preparation process in the standard blood bag systems causes an additional contamination of the packed RBCs with plasma resulting in a loss of plasma for therapeutic and fractionation purposes. A novel Top/Top blood bag design with a 5-port-technology was developed to furthe improve the purity of the blood components. Design and Methods: Whole blood donations $(500 \mathrm{~mL})$ from 37 healthy, randomized donors were paired according to the $\mathrm{ABO}$ blood groups, pooled and transferred in equal volumes to the standard and the new blood bag systems. Both blood bag systems were produced from Maco Pharma. Hematocrit, hemoglobin content and cell counts were measured using a Sysmex 200 device; protein content was determined by the Bradford method. Results: Blood component preparation using the newly developed bag system led to a significant lower plasma content in the RBC unit (mean $7.9 \pm 0.9 \mathrm{~g} / \mathrm{L}$ ) than the preparation in the standard Top/Top system (mean $10.5 \pm 1.1 \mathrm{~g} / \mathrm{L}$ ). Accordingly, a higher yield of plasma (mean $3 \mathrm{~mL}$ ) in the plasma unit was obtained with the new 5-porttechnology. Conclusion: The new Top/Top blood bag system with the 5port-outlet-design provides an optimal yield and separation of RBCs and plasma, fulfilling the requirements of a modern blood bag system. In particular, minimizing the plasma content in RBC units may help to reduce the incidence of transfusion-related acute lung injury (TRALI).

\section{P 2.25 \\ Filtration Times of Leukocyte Depleted Red Cell Concentrates}

Roehrig O. ${ }^{1}$, Sugg U. ${ }^{2}$, Luz B. ${ }^{2}$

${ }^{1}$ Klinikum Stuttgart, Katharinenhospital, Institut $\mathrm{f}$. Transfusionsmedizin, Stuttgart, D, ${ }^{2}$ Klinikum Stuttgart Katharinenhospital, Stuttgart, D

According to GMP regulations, all steps during processing of blood products should be defined and closely monitored. The objective of this study was to establish a method to record filtration times of leukocyte depleted red cell concentrates (RCC). A newly developed filtration device will be presented and the data obtained during routine processing of RCC. Design and Methods: After implementation of the device, filtration times (FT) were recorded during routine processing of RCC. Whole blood donations were obtained using two different blood collection systems. One was equipped with a hardshell filter (T3987, Fresenius Hemocare, EK-Inline Filter), the other with a soft shell filter (LQT2741, Maco-Pharma, LRC-5 Filter). In both systems PAGGS-M was used as additive solution. Filtration data spanning one year were analyzed retrospectively. Results: FT using the hard-shell filter were recorded correctly. Readings from the soft shell filter had to be corrected due to the void volume of the filter and the detection principle of the device. FT were $41.3 \pm 11$ min. $(M e a n \pm S D)$ for the T3987 system $(n=28.635)$ and $24.4 \pm 4.9 \mathrm{~min}$ for the LCR-5 system $(\mathrm{n}=9.523)$, respectively. Using the T3987 system, there was a substantial fraction $(3.9 \%)$ of RCC with FT of over 60 minutes. With the LCR-5 system, the respective fraction was only $0.27 \%$. No evidence of filter damage was found by leukocyte counts of RCC with very short FT. Time dependent analysis of FT of the T3987 system revealed a high variation from day to day, superposed by substantial intermediate term variations. The latter could partially be correlated to the use of different lots of the blood collection systems. FT of the LCR-5 system showed only little variation from day to day as well as between different lots. Conclusion: The filtration device offers a method for studying the kinetics of leukocyte filtration, thus providing a means for a better understanding of the filtration process. Monitoring of filtration times according to GMP regulations is made feasible by this device. Further adaptations in the detection principle will facilitate monitoring of soft -shell filters

\section{P 2.26}

\section{Sterility Testing of Blood Components}

\section{Müller-Kuller $T^{1}{ }^{1}$, Findhammer $S^{2}{ }^{2}$, Seifried $E .^{2}$, Sireis $W .{ }^{2}$}

${ }^{1}$ DRK Blutspendedienst Baden-Württemberg - Hessen, QM,

Frankfurt/Main, D,

${ }^{2}$ DRK-Blutspendedienst Baden-Württemberg - Hessen, Frankfurt/Main, D

Objectives: Bacterial contamination of blood components is one of the most common and dreaded causes of transfusion-transmitted disease. Here in particular the platelets are affected due to their storage conditions. In Germany the mortality rate related to bacterial contaminated platelets is about 1 per 400,000 platelet units disposed. We report on the data of sterility testing of homologous blood components within routine quality control. Moreover we report on our experiences with testing blood products after adverse transfusion reactions. Methods: $0.4 \times$ the square root of produced blood components per month are tested for bacterial contamination using original blood products. Testing of cellular blood components takes place at the expiry date + maximal 3 days; plasma is tested after production. Bacterial contamination of blood products is tested with BacT/ALERT automated microbial detection system. A $10 \mathrm{ml}$ sample is taken under the laminar flow hood and incubated at $37{ }^{\circ} \mathrm{C}$ for 7 days in aerobic and anaerobic media, respectively. Positive samples are tested twice again in the same media. If the positive result can be confirmed the sample is classified as positive. When the differentiated bacteria are identical in both approaches the sample is confirmed positive, otherwise the sample is classified as potentially positive. Results: In the years 2006 and 2007 10,552 homologous blood components were tested for bacterial contamination. In $2(0.02 \%)$ of 5515 erythrocyte concentrates, in $2(0.04 \%)$ of 2159 platelets and none of 2878 FFPs a bacterial contamination could be confirmed. The identified bacteria were skin commensals. However, in the same period a bacterial contamination in $1.11 \%$ of inquiries carried out after adverse transfusion reactions was determined. Conclusions: Our data show that bacterial contaminations are a very rare event. The contamination rate of platelets is 2 -fold higher than the contamination rate of erythrocyte concentrates. In agreement with our data, the contamination rate of platelet concentrates is cited to be between 0.02 and $1.2 \%$, depending on the production and method of bacterial testing. The 
germ spectrum e.g. E. coli detected in blood components after adverse transfusion reactions are pointing clearly to a secondary contamination that had taken place. These contaminations can result from incorrect locking, storage, packing and from the transport to the blood donor service. Causality with the adverse transfusion reaction is only conditionally given.

\section{P 2.27}

\section{Comparison of Haemolysis Rates in Red Blood Cells}

\section{Knels R. ${ }^{1}$, Müller-Kuller $T^{2}{ }^{2}$, Geusendam G. $^{3}$, Sireis $W{ }^{2}$}

${ }^{1}$ German Red Cross Blood Donation Service East, Institute Dresden, D, ${ }^{2}$ German Red Cross Blood Donation Service Baden-Württemberg-Hessen, Frankfurt/Main, D, ${ }^{3}$ German Red Cross Blood Donation Service North, Lütjensee, D

Purpose: Haemolysis of red blood cells (RBC) caused by mechanical damage during manufacturing and/ or poor storage conditions (temperature deviation, long storage time) could lead to serious hazards. To find out the status quo in our donation services we compared quality data of 7 institutes and analyzed the reasons for haemolysis in an institute with a very strict visual monitoring. Method: In Germany, $1 \%$ of the produced RBC must be tested for haemolysis at the end of shelf life. The limit for the haemolysis rate $(100-\mathrm{Hct} \mathrm{x}$ free $\mathrm{Hb} /$ total $\mathrm{Hb})$ is $0.8 \%$. We compared retrospectively and analyzed statistically (Student T-Test) the 31,276 quality data from 2005 to 2007 in our donation services. Further we analyzed the results of a 100\% visual control of the RBC supernatant $24 \mathrm{~h}$ after manufacturing in 1 institute. Results: The haemolysis rate in whole blood (wbf) was significantly lower than in red cell filtration ( $\mathrm{rcf} ; 0.36 \%$ vs. $0.27 \%$; $<<0.001$ ). The mean values in 2005-2007 were between $0.29 \%$ and $0.40 \%$ in the different institutes and correlate with the type on filtration. The exception was the Dresden institute with lower mean values of $0.12 \%$ (rcf) and $0.15 \%$ (wbf) and the lowes standard deviation. In this institute a $100 \%$ visual control after processing is implemented. Employees involved in the separation process and with higher rate of haemolytic $\mathrm{RBC}$ were trained with the result of a decrease of these units (160 down to 0-20 units of 15,000 collection/ month). In the las months the wasted number of units and the standard deviation is very stable on a low level. Conclusion: Instructing the staff about the correct handling of breakers and checking the quality data is an important detail in quality control, particularly when introducing new bags or separation devices. On first sight, breakers in blood bags are insignificant, but we found that this kind of mechanical damage is the most common reason for haemolysis found in transfusion services today. If breakers are not properly broken this could lead to a mechanical damage and in this way to serious hazards.

\section{P 2.28}

\section{Evaluation of Productivity and in vitro Quality of Platelet Concentrates in Plasma and Additive Solution (PAS) Using the Amicus Apheresis Platform}

Baumann-Baretti B. ${ }^{l}$, Brys B. ${ }^{2}$, Jaster $G .{ }^{2}$, Ulrich $E .^{2}$, Krause K. $-P$. $^{2}$

${ }^{1}$ Haema AG, Quality control, Berlin, D, ${ }^{2}$ Haema AG, Leipzig, D

Objective: High safety and efficacy of plateletapheresis with the Amicus, Fenwal (AM) has been previously described. An integrated procedure of the separator enables the delivery of standardized platelet products in additive solution (PAS) and plasma as well. Productivity, donor safety and in vitro quality parameters of platelet concentrates in PAS (PAS-PC) and platele concentrates in plasma (Plasma- PC) were compared. Design and Methods: 13 donors were included for plateletapheresis; the current donor suitability criteria had to be met. In 7 single needle and 6 double needle apheresis procedures 26 platelet concentrates, 12 Plasma- PC and 14 PAS-PC were obtained. Samples were analysed for various in vitro parameters at day 0 , day 5 and day 7 during 7 day storage. Results: The donors showed no significant differences in preprocedure physiognomic and haematimetric baseline parameters; mean product volume (224-247 ml), mean platelet yield per unit $(2.9-3.3 \times 10 \mathrm{e} 11 / \mathrm{TU})$ and residual white blood cells per unit $(0.02-0.6 \times$ $10 \mathrm{e} 6 / \mathrm{TU}$ ) showed similar values in Plasma- PC and PAS-PC. Regarding in vitro parameters like $\mathrm{pH}$ and base access both parameters did not vary throughout storage in PAS-PC whereas in Plasma-PC a slight decrease of $\mathrm{pH}$ and negative base access was observed. The baseline CD 62 expression showed significant lower values in Plasma-PC (d0: $17.3 \pm 10.4$; d5: 26.6 \pm 10.9 ; $\mathrm{d} 7: 30.5 \pm 12.7$ ) compared to PAS-PC (d0: $40.5 \pm 15.6$; d5: $43.7 \pm 13.5$; d7: $45.7 \pm 12.8$ ) during the whole storage time. After stimulation with ADP the increase of CD 62 expression in plasma-PC was higher than in PAS-PC (d0: $35.1 \pm 12.2 ; \mathrm{d} 5$ : $26.6 \pm 12 ; \mathrm{d} 7: 22 \pm 12.8$ versus d0: $11.2 \pm 7.6$; $\mathrm{d} 5: 8.7$ $\pm 6.2 ; \mathrm{d} 7: 8.3 \pm 5.6$ ). Hypotonic shock reaction (HSR) values decreased during storage in all units; all HSR scores throughout storage in PAS-PC were significant below Plasma-PC. Conclusion: Apheresis was performed safely and efficiently in all procedures. Satisfactory platelet content according to current standards was found in all products and residual white blood cells met the current quality control criteria. We observed significant differences in cellular and flowcytometric variables between PAS-PC and Plasma-PC. How far those effects are associated with the platelet storage environment and how far in vitro quality parameters reflect in vivo quality need to be investigated.

\section{P 3 Cellular Antigens and Immunohematology \\ P 3.01 \\ Kmod Phenotype Resulting from a Novel KEL*2(P704H) Mutation}

Mayer B. ${ }^{1}$, Ahrens $N^{2}{ }^{2}$, Auer $D .{ }^{3}$, Salama A. , Gassner $C .^{3}$

${ }^{1}$ Charité - Universitätsmedizin Berlin, Institut für Transfusionsmedizin, Berlin, D, ${ }^{2}$ Labor 28, Berlin, D, ${ }^{3}$ Central Inst. for Blood Transfusion and Immunological Dept., General Hospital and University Clinics, Innsbruck, A, ${ }^{4}$ Institute for Transfusion Medicine, Charité - University Medicine, Berlin,

Objective: Kmod describes an inherited rare phenotype, in which expression of Kell antigens is markedly reduced. So far several different point mutations of the KEL alleles contributing to this phenotype have been described, either existing in homozygosity or in compound heterozygosity with a KEL*2null allele. We report the case of a 70 year old male patient with a novel mutation in the KEL*2 allel. The patient became apparent because of a seemingly $\mathrm{K} 0$ phenotype, later corrected to Kmod phenotype. Design and Methods: Serological investigations were carried out in standard gelcard technique. Commercial reference antisera and donor samples containing Anti-Ku and Anti-KL were used for direct antigen investigation. Genetic analysis was performed after DNA-extraction using primers as previously described for PCR and sequencing. Results: The patient's red blood cells were found to be negative with commercial anti-K, and there were trace agglutinations with anti-k and with anti-Ku. The serum of the patient did not exhibit anti-K, antik, or other Kell-antibodies. The results of KEL genotyping showed one of the two parental KEL-alleles a KEL*2 (IVS3+1G>A) allel, which is the most frequent Knull allel observed worldwide so far. In the second parental KEL allel, a single-nucleotide mutation was detected by generic DNA sequencing in exon 19 of the KEL-gene: $2111 \mathrm{C}>\mathrm{A}$, predicting an amino-acid change from Proline 704 to Histidine resulting in KEL*2(P704H). Conclusions: Mutations involving Proline are known to cause drastic changes in steric characteristics of primary structures of peptides. It is therefore well conceivable to explain the appearance of a drastically diminished Cellanoexpression resulting in a Kmod phenotype by the described mutation in the presented case. The molecular basis of Kmod in this patient is a novel mutation, which has not been described previously.

\section{P 3.02 \\ Anti-S and Rh-Antibodies Are Associated with Red Blood Cell Alloantibodies}

Ahrens $N^{l}{ }^{1}$, Mayer B. ${ }^{2}$, Genth . $^{2}$, Herziger A. ${ }^{2}$, Salama $A .{ }^{2}$

${ }^{1}$ Labor 28, Berlin, D, ${ }^{2}$ Institut für Transfusionsmedizin der Charité Universitätsmedizin Berlin, D

Objective: Alloantibodies (ALLO) to red blood cells (RBC) are frequently associated with autoantibodies (AAB). The association between ALLO specificity and $\mathrm{AAB}$ has not yet been described. Design and Methods: All patients and healthy blood donors screened for RBC antibodies at the Charité between 2000 and 2006 were included. The odds ratio (OR) for ALLO in patients with $\mathrm{AAB}$ compared to those without $\mathrm{AAB}$ was correlated with the OR of general ALLO prevalence in patients with AAB (normalized OR). Results: ALLO were found in 4626 of 204,330 patients and healthy blood donors $(2.3 \%)$. The ALLO were associated with AAB in 413 cases $(8.9 \%)$. Among the specificities, anti-S with a normalized OR of 2.9 was overrepresented. This was most evident in pregnant women who showed a normalized OR of 15.1 for anti-S and AAB. The normalized OR revealed an additional association between $\mathrm{Rh}$ antibodies and AAB. No association was found between ALLO to the Kell glycoprotein, Duffy protein, Lewis, or Glycophorin $\mathrm{A}(\mathrm{M} / \mathrm{N})$ and $\mathrm{AAB}$. Conclusion: The majority of associated ALLO and $\mathrm{AAB}$ are directed against neighboring antigens of the $\mathrm{Rh}$ complex and Glycophorin B. 


\section{Shortage of Rhesus-D-Negative RBC: Frequency of Rhesus-D-Immunization}

Flommersfeld S. ${ }^{1}$, Forrest E.J. ${ }^{2}$, Oldenburg J. ${ }^{3}$, Hoch J. ${ }^{4}$

${ }^{1}$ Universitätsklinikum Halle (Saale), Einrichtung für Transfusionsmedizin, Halle (Saale), D, ${ }^{2}$ Blutspendedienst SRK, St. Gallen, $\mathrm{CH},{ }^{3}$ Institut für Experimentelle Hämatologie und Transfusionsmedizin, Bonn, D, ${ }^{4}$ Institut für Experimentelle Hämatologie und Transfusionsmedizin, Bonn, D

Background: Demographic change of age distribution in German population causes an increase of patients who need blood transfusions and a decrease of potential blood donors. Therefore the restricted transfusion policy switching the supply of D- patients to D+ RBC in case of emergency, which is based on historical data from D-immunization of healthy volunteers, should be revised. Methods: 32 D-negative patients (period 2002-2007, age 17 to 91 years) from surgical wards and intensive care units were retrospectively evaluated for the development of erythrocyte antibodies after transfusion of $\mathrm{D}+\mathrm{RBC}$ by a follow-up of antibody screening tests (enzyme-test, IAT, DAT; DiaMed-ID System, DiaMed Germany). Results: In total 688 D+ RBC units (mean: 21 [1-170] D+ RBC units) were transfused to the patients after receiving a total of $279 \mathrm{D}-\mathrm{RBC}$ units (mean: 12 [0-30] D- RBC units). $11(34 \%)$ patients died in the clinical course due to the underlying disease. In the eligible 21 patients follow up antibody screening tests were performed (mean: 206 days [34-1060] days). Anti-D was detected in 3/21 (14\%) patients on day 42/62/132 after initial D+ RBC transfusion (1/4/8 RBC units). All D-immunized patients acquired additionally antibodies such as antiC/anti-C,-Jk(b)/ anti-E,-Wr(a),-Lu(a). In further $2 / 21$ patients IAT revealed reactions without specifity particularly no anti-D. 1/21 patient developed temporarily HTLA-antibodies. $2 / 21$ patients exhibited positive DAT with anti-IgG, without detectable (IAT) antibody in plasma or eluate. Patient records revealed no signs of significant hemolysis. Conclusions: In accordance to latest published studies with surgical patients the frequency of antiD-formation was found to be $14 \%$. Anti-D-formation seems not to depend on the number of D+ RBC units transfused, and there might be an individual disposition for responder and nonresponder of alloimmunization, although the underlying pathomechanism is not yet understood. With consideration of the data, it is justified to change transfusion policy in a less restricted way in times of shortage. To optimize the early selection of D- patients for supply with $\mathrm{D}+\mathrm{RBC}$ a scoring system was developed, in respect to age, sex, risk profile and amount of requested RBC. This approach should save RBC resources for the provision of D-patients who have mandatory need of D$\mathrm{RBC}$.

\section{P 3.04 \\ Mixed Type Autoimmune Hemolytic Anemia: Differential Diagnosis and a Critical Review of Reported Cases}

Mayer B. ${ }^{l}$, Yürek S. ${ }^{2}$, Genth R. $^{2}$, Herziger $A .^{2}$, Kiesewetter $H_{.}{ }^{2}$, Salama A. ${ }^{2}$

${ }^{1}$ Charité - Universitätsmedizin Berlin, Institut für Transfusionsmedizin, Berlin, D, ${ }^{2}$ Institute for Transfusion Medicine, Charité - University Medicine, Berlin, D

Objectives: Autoimmune hemolytic anemia (AIHA) is usually classified as either warm or cold type. During the last few decades, mixed types have also been described in a number of cases (6-8\% of AIHA). However, serological data to support the diagnosis have often been incomplete. We demonstrate that the incidence of mixed type (Mx) AIHA is extremely rare. Design and Methods: Between August 1998 and August 2007, all in- and outpatients with detectable warm autoantibodies (WABs) were included in this study. Serologic testing was performed using standard techniques for the detection of antibodies to red blood cells (RBCs). Results: From a total of 2194 patients with detectable WABs, only two patients $(<0.1 \%)$ developed both, significant WABs and cold agglutinins (CAs) satisfying the criteria for Mx AIHA. However, only one of these patients showed cold and warm hemolysis. Insignificant CAs at temperatures $\leq 24{ }^{\circ} \mathrm{C}$ were found in 242 patients. Conclusions: There is evidence that the presence of CAs with high thermal amplitude, and WABs may lead to confusion and misdiagnosis in some patients with AIHA. This study demonstrates that Mx AIHA is less common than previously reported. 


\section{P 3.05}

Evaluation of Immunohematological Methods Using the Capture-Technology on the Galileo Immucor System

Pruß A. ${ }^{1}$, Pretzel K.J. ${ }^{2}$, Kempe K. ${ }^{2}$, Köcher $K^{2}{ }^{2}$, Korb M. $^{2}$

${ }^{1}$ Charité-Universitätsmedizin Berlin, Institute of Transfusion Medicine, Berlin, D, ${ }^{2}$ Berlin, D

Objectives: Immucor has developed a technology (Capture-R-Technology) for the detection of unexpected IgG antibodies (ABS) by solid phase red cell adherence methods, suitable for high throughput automation. The method is based on a modified solid phase antibody detection system. Blood grouping is performed on microtiter plates (MTP) with regular antiseras. Design and Methods: In a comparative study, EDTA blood samples from 403 blood donors and 574 patients were tested on Capture-R-Technology for antibody screening and from 523 blood donors and 574 patients for blood grouping (AB0 with direct and reverse typing, Rh factor) and Rh phenotyping (C, c, E, e), Kell, by two determinations. The observed data were directly compared with the results of the Charite blood bank methods: gel centrifugation technique on DiaMed gel cards for antibody screening and Olympus PK 7200 for $\mathrm{AB} 0 / \mathrm{Rh}$ blood grouping and Rh phenotyping. Results: 891 of 977 samples for antibody screening test Capture-R-Technology were correct negative. 75 of 84 known antibodies were correct positive in the two techniques. CaptureR-Technology showed 9 false negative results $(0.9 \%)$. These were confirmed as IgM antibodies, which are not detectable by this anti-IgG technology. 2 of 977 samples (Anti-Jk(a) and Anti-E) were found only by Galileo. These antibodies were later confirmed in complementary tests (DiaMed, Ortho, Biorad). 1 antibody (Anti-E) was found only by the gel card method. $\mathrm{AB} / \mathrm{Rh}$ grouping showed a complete concordance on common erythrocyte groups between observed results and expected ones. We observed discrepancies on 3 weak D samples, which were detected by the reference method but not by the Galileo system. All the results of the C, c, E, e, K tests were accurate in the first and the second determination and showed $100 \%$ of concordance between observed results and expected ones. Conclusions: The performed ABS comparative study reveals that Capture-R-Technology ABS test is as sensitive and reliable as the existing gel centrifugation techniques for the detection of clinically relevant IgG antibodies. Galileo provides a ful automation system (equipment and reagents) and is reliable and safe for $\mathrm{AB} 0 / \mathrm{Rh}$ grouping and $\mathrm{Rh}$ phenotyping, excluding the tests of weak $\mathrm{D}$ on MTP.

\section{P 3.06}

\section{The Performance of Three Different Tube IAT Methods and the Microplate Test System Solidscreen II in the Detection of Red Cell Alloantibodies}

Weisbach V. ${ }^{l}$, Teufel M. ${ }^{l}$, Bredehöft A. ${ }^{l}$, Strobel J. ${ }^{l}$, Eckstein R. ${ }^{2}$

'Department of Transfusion Medicine and Hemostaseology, University Clinic Erlangen, D, ${ }^{2}$ Department of Transfusion Medicine and

Haemostaseology, University Hospital Erlangen, D

Objectives: To evaluate whether there is a difference in sensitivity in the detection of red cell alloantibodies (ab) between three different tube IAT methods and the Solidscreen II. Previously, we and others had shown a lower sensitivity of the tube LISS-additive-IAT compared to microcolumn and microplate tests. Some critics argued that this difference in sensitivity would not have been observed if polyethylene glycol (PEG) or Liss-suspension would have been used in the tube IAT. Design and Methods: In a comparative study, we tested 379 sera which were previously demonstrated to contain red cell ab by means of the Scangel (Bio-Rad Laboratories GmbH, München, Germany) and the Immucor Capture-R Ready-Screen (4) (Immucor medizinische Diagnostik GmbH, Roedermark, Germany) in our routine laboratory. In the present study, the following tests were performed strictly in parallel: tube LISS-additive IAT, tube LISS-suspension IAT, tube PEG IAT (all three manually) and the Solidscreen II (automated using the Tango Optimo) (Biotest Medical Diagnostics GmbH, Dreieich, Germany). Tests were performed simultaneously by a single person on freshly thawed sera which had been cryopreservized at $-20{ }^{\circ} \mathrm{C}$. Results: The detection rate of ab which are assumed to be clinically significant (cs-ab, for example Rhesus, Kell, Duffy or Kidd ab) ( $\mathrm{n}=339)$ was: tube LISS-additive IAT: $230(67.8 \%)$, tube LISSsuspension IAT: 222 (65.5\%), tube PEG IAT: 241 (71.1\%), Solidscreen II: $290(85.5 \%)$.The detection rates of $40 \mathrm{ab}$ which are assumed to be of minor clinical significance (ms-ab, M, N, P1 or Lewis ab) was: tube LISS-additive IAT: 15 (37.5\%), tube LISS-suspension IAT: $16(40.0 \%)$, tube PEG IAT: 20 $(50.0 \%)$, Solidscreen II: $22(55.0 \%)$. Conclusions: The sensitivity of all three tube IAT test systems in the detection of cs-ab was markedly inferior to the sensitivity of the Solidscreen II. The sensitivity of the tube IAT is highest in the PEG IAT and lowest in the LISS-suspension IAT. Specificity can not be tested with the design of the present study. No single test system of the systems used in this study can detect all ab which can be detected by the combination of two different other test systems.

\section{P 3.07 \\ Typing of Neutrophil Antigens (HNA) to Establish a Screening Panel to Prevent Immune Transfusion-Related Acute Lung Injury (TRALI)}

\section{Grabowski C. ${ }^{\prime}$, Jorks S. ${ }^{l}$, Borowsky A. ${ }^{\prime}$, Reil A. ${ }^{2}$, Kroll H. ${ }^{1}$}

${ }^{1}$ Institute for Transfusion Medicine Dessau, Red Cross Blood Transfusion Service NSTOB, Dessau, D, ${ }^{2}$ Institute for Transfusion Medicine Hagen,

Red Cross Blood Transfusion Service West, Hagen, D

Purpose: Granulocyte-reactive antibodies are involved in several diseases. Transfusion-related acute lung injury (TRALI) is one of the most dangerous hazards of transfusion and can be induced by granulocyte-reactive alloantibodies. Prospective screening of plasma-containing blood products (platelet concentrates, fresh frozen plasma) for granulocyte antibodies is one of the effective measures to reduce the incidence of TRALI. We, therefore, established a screening panel of well characterized granulocyte donors. Methods: A total of 138 unrelated healthy blood donors were included into the study. 110 donors were typed for the HNA-1, HNA-4, and HNA-5 polymorphisms by molecular methods. In 105 donors serologic HNA-2 and HNA-3 typing was performed. DNA was extracted from EDTA-anticoagulated blood using chemagic Magnetic Separation Module I (Chemagen AG, Baesweiler, Germany) or GenoM6 workstation (GenoVision Vienna, Austria). Genotyping was performed by PCR-SSP (Bux et al. 1995/1997, Steffensen et al., 1999; Sachs et al., 2004/2005) with modified PCR conditions. Serologic typing was performed by granulocyte agglutination and immunofluorescence tests with well defined antisera. Results: The following antigen frequencies were found in 110 genotyped donors: HNA-1a: 65 (59.1\%), HNA-1b: 93 (84.6\%), HNA-1c: 7 (6.4\%), HNA-4a: 109 (99.1\%), HNA-4b: 26 (23.6\%), HNA-5a: $101(91.8 \%)$, and HNA-5b: $55(50.0 \%)$. The genotypes were: $1 \mathrm{a}+\mathrm{b}-\mathrm{c}-\mathrm{:}: 13$ $(11.8 \%), 1 \mathrm{a}+\mathrm{b}+\mathrm{c}-: 45(40.9 \%), 1 \mathrm{a}-\mathrm{b}+\mathrm{c}-: 45$ (40.9\%), 1a+b-c+: $4(3.6 \%)$, $1 \mathrm{a}+\mathrm{b}+\mathrm{c}+: 3(2.7 \%) ; 4 \mathrm{a}+\mathrm{b}-: 84(76.4 \%), 4 \mathrm{a}+\mathrm{b}+: 25(22.7 \%), 4 \mathrm{a}-\mathrm{b}+: 1(0.9 \%)$, $5 \mathrm{a}+\mathrm{b}-\mathrm{:} 55(50.0 \%), 5 \mathrm{a}+\mathrm{b}+: 46(41.8 \%), 5 \mathrm{a}-\mathrm{b}+: 9(8.2 \%)$. The gene frequencies were calculated: $1 \mathrm{a}: 0.373,1 \mathrm{~b}: 0.627,1 \mathrm{c}: 0.032,4 \mathrm{a}: 0.877,4 \mathrm{~b}: 0.123$, 5a: 0.709, 5b: 0.291. It was assumed that the HNA-1c allele was always located on the same chromosome as the HNA-1a. From 105 phenotyped donors $105(100 \%)$ carried the HNA-2a antigen and $102(97.14 \%)$ were HNA-3a positive. Conclusions: We typed our blood donors for HNAs allowing more accurate selection of panel cells for antibody detection. Typed panel cells can be employed for the screening of plasma-containing blood products for granulocyte antibodies to reduce the incidence of TRALI. The HNA gene frequencies of the investigated blood donors from SachsenAnhalt corresponded well to the gene frequencies described earlier in the German population.

\section{P 3.08}

\section{Cellular Sources for Elevated Tumor Necrosis Factor alpha Cytokine Levels in Carriers of TNFalpha Risk Allele}

\section{Wienzek S., Kissel K., Breithaupt K., Lang C., Nockher A.,} Hackstein H., Bein G.

Institute for Clinical Immunology and Transfusion Medicine Justus-LiebigUniversity, Giessen, D

Objectives: Carriage of the TNF rs1800629 A allele $(-308 \mathrm{~A} / \mathrm{G})$ has been recently identified to be associated with the development of sepsis syndrome, fatal outcome, and incremented TNF alpha plasma concentration in severely traumatized patients (Menges et al. 2008). Based on these results, the aim of our present study was to elucidate the cell type responsible for increased TNFalpha release in carriers of TNF -308 A allele. Design and Methods: Healthy blood donors between 18 and 45 years of age were randomly selected. Following isolation of distinct peripheral blood cells, we examined different ligands and costimuli to determine their potential to stimulate a TNFalpha relaease in vitro. In the next step, TNFalpha expression of distinct blood cells and monocyte-derived macrophages triggered with LPS and IFNgamma was measured in ELISA assay. Genotyping of TNFalpha promoter polymorphism rs 1800629 of the individuals was performed using TaqMan technique in an independend analysis. The possible association of TNFalpha promoter polymorphism rs1800629 (-308 A/G) and TNFalpha phenotype of the individuals was calculated in statistical analysis (two-tailed Mann-Whitney-U-test). Results: Using ELISA assay, TNFalpha cytokine production was detected in supernatants of different stimulated peripheral blood cells and monocyte-derived macrophages in variable amounts. CD14+CD16+ monocytes were identified as the major source of TNFalpha release in peripheral blood cells, while neutrophils released only very little amounts of TNFalpha. An association between carriage of the risk allele 
TNFalpha rs1800629 A and the phenotype high TNFalpha expression could not be verified neither in distinct human peripheral blood cells nor in monocyte-derived macrophages as representants of tissue resident cells. Conclusions: Our findings indicate that high TNFalpha levels detected in blood shortly after multiple traumas are not the result of a release from circulating blood leucocytes and macrophages. In contrast, tissue residuent cells like mast cells are good candidates for elevated TNFalpha cytokine shortly after trauma. Since TNFalpha rs1800629 A has been associated with high TNF levels, it is of high clinical importance to identify the cellular source of TNFalpha to improve anti-inflammatory therapy and to develop new intervention strategies for carriers of the risk allele.

\section{P 3.09}

\section{Tango Optimo versus Galileo - a Large-Scale}

\section{Comparison of the Routine Performance of Two Fully} Automated Systems in Blood Typing and the Detection of Red Cell Alloantibodies

\section{Weisbach V. ${ }^{l}$, Teufel M. ${ }^{l}$, Bredehöft $A .{ }^{l}$, Strobel J. ${ }^{l}$, Eckstein $R .{ }^{2}$}

${ }^{1}$ Department of Transfusion Medicine and Hemostaseology, University Clinic Erlangen, D

${ }^{2}$ Department of Transfusion Medicine and Haemostaseology, University Hospital Erlangen, D

Objectives: To compare the performance of two fully automated immunohematology systems under routine blood bank conditions. Design and Methods: We tested in parallel 3104 blood types (AB0,D,C,c,E,e and K) and 5206 red cell alloantibody $(\mathrm{ab})$ screening tests using the Tango Optimo (Biotest Medical Diagnostics GmbH, Dreieich, Germany) and the Galileo (Immucor medizinische Diagnostik GmbH, Roedermark, Germany). The ab detection system in the Tango was the Solidscreen II (Galileo: Capture-R Ready-Screen (4)). All tests were performed automatically. When necessary, the automated reading was corrected by the investigator. Discrepant results in ab screening were controlled in the Diamed Gel System (Diamed Deutschland $\mathrm{GmbH}$, Ottobrunn, Germany). Blinded replicate tests were performed using 60 aliquots of a negative and 60 samples of a weak positive plasma. Results: Both systems performed very good in the 3102 blood types, we observed no false results. In the Tango, in $73(2.4 \%)$ of the blood types single reactions had to be repeated manually in the tube test (Galileo:103 $(3.3 \%))$. Reasons for repeated tests were inconclusive results in serum testing (Tango $46(1.5 \%)$, Galileo $56(1.8 \%)$, pipetting errors (no serum or too much red cells) $(23(0.7 \%)$ versus $25(0.8 \%)$ and discrepant results in double testing of Rhesus or Kell antigens (4 $(0.1 \%)$ versus $22(0.7 \%)$. In red cell ab screening, both systems together detected 54 ab which are assumed to be clinically significant (cs-ab; for example Rhesus, Kell or Kidd ab), (Tango 40, Galileo 51). The Tango Optimo showed 9 'false' or unwanted positive results (inconclusive positive results, only HLA alloantibodies could be detected, IgG autoantibodies without hemolysis in the patient) in ab screening, the Galileo showed 35 of these 'false' or unwanted positive results. The Tango had $42(0.81 \%)$, the Galileo $65(1.25 \%)$ unwanted positive autocontrols (no sign of auto- or alloimmune hemolysis in the patient). Blinded replicate tests showed 3 false positive and 1 false negative result in the Galileo, in the Tango Optimo all replicates were diagnosed correctly. Conclusions: The performance of both systems in blood typing was excellent with a small advantage for the Tango Optimo. In screening for red cell ab, the Galileo showed a higher sensitivity, while the specificity was considerably better in the Tango Optimo.

\section{P 3.10}

\section{A Two-Steps Strategy for Testing Samples Weakly Reacting with Anti-D: Review of Results}

\section{Maccagno G., Jung A., Hitzler W.E.}

Klinikum der Johannes Gutenberg-Universität Mainz, Transfusionszentrale, Mainz, D,

Objectives: In our centre all new samples of patients and blood donors that are tested for the Rhesus D antigen and show weak reactions in the serology are immediately tested with a serological identification kit for partial Rhesus $\mathrm{D}$ to exclude some of the most frequent partial D phenotypes and on the following working day undergo a molecular testing. Aim of this study was to compare the findings of the serological and the molecular testing and to evaluate if the results obtained with the serological identification kit could reliably guide transfusion decisions. Design and Methods: From April 2000 to December 2007361 patients and 206 blood donors (total 567) were tested for the Rhesus D antigen according to German guidelines. The serological identification screening for partial Rhesus D was performed with the DScreen, Diagast, Loos, France and the molecular testing was carried out with the BAGene, BAG, Lich, Germany or with the Ready Gene, Inno-Train,
Kronberg, Germany. According to the results of the serological identification kit two groups of samples were defined: the one in which a partial D was detected (group A) and the one in which no specific result was shown (group B). The latter was assumed to identify weak D. The findings of each group were compared with the results of the molecular testing. Results: Of the 223 samples in group A $59(26.5 \%)$ were confirmed to be partial D, $125(56.1 \%)$ were shown to be weak D and $39(17.5 \%)$ were neither partial nor weak D. Of the 344 samples in group B $319(92.7 \%)$ were confirmed to be weak D, 5 $(1.5 \%)$ were shown to be partial D and $20(5.8 \%)$ were neither partial nor weak D. With the molecular testing clear results were obtained in 508 samples (444 weak D and 64 partial D), while no weak and no partial D could be identified in the remaining 59 samples. Conclusion: Only a quarter of the partial $\mathrm{D}$ found with the serological identification screening are confirmed with the molecular testing. Moreover $92 \%$ of samples in which no partial D was defined appear to be weak D. These findings can guide transfusion policy in case there is no time to wait until the results of the molecular testing are available. With the molecular testing $90 \%$ of the samples reacting weakly with anti-D could be safely defined in their specificity. The remaining $10 \%$ identify probably a normal $\mathrm{D}$, although a few samples could also be a rare variant, which is undetectable with the test in use.

\section{P 3.11 \\ Severe Autoimmune Hemolytic Anemia of an 18-Month- Old Boy with Auto-Anti-E}

\section{Strathmann $\mathrm{K}{ }^{1}$, Stenzel A. ${ }^{1}$, Bringmann $\mathrm{G} .{ }^{1}$, Kern I. ${ }^{2}$,} Doescher A. ${ }^{3}$, Zeiler T. ${ }^{l}$

${ }^{1}$ German Red Cross Blood Service West, Center of Transfusion Medicine Breitscheid, Ratingen, D,

${ }^{2}$ Pediatric Clinic, Elisabeth-Hospital Rheydt, Mönchengladbach, D, ${ }^{3}$ German Red Cross Blood Service NSTOB, Oldenburg, D

Purpose: The occurrence of autoimmune hemolytic anemia (AIHA) in children and adolescents is rare. The exact incidence is unknown, but the rate is estimated to be less than $1 / 100,000$ individuals below the age of 20 years. We report the rare case of a severe AIHA in an 18-month-old boy caused by auto-anti-E. Case report: An 18-month-old boy was admitted to the hospital with clinical signs of vomiting, fever, abdominal pain and icteric sclera. The initial blood tests showed severe anemia (Hb $21 \mathrm{~g} / 1$, Hct 7.6 1/1, reticulocytes $270.0 \%$ ), signs of hemolysis (LDH $528 \mathrm{U} / \mathrm{l}$, haptoglobin $<0.07 \mathrm{~g} / \mathrm{l}$ ) and leukocytosis $(21000 / \mu 1)$. Pretransfusional antibody screening and the crossmatching with A Rh positive (ccD.Ee) RBC (red blood cells) in the hospital laboratory were negative, the direct antiglobulin test (DAT with anti-IgG) was positive. The positive DAT in the initial test was not further investigated and the boy was transfused with A Rh positive (ccD.Ee) RBC. Four days after the first transfusion, antibody screening in the hospital laboratory became positive and specimens were sent to our regional immunohematologic reference laboratory. Child: A Rh positive (ccD.Ee) serology test, DAT positive (monospecific anti-IgG), auto-Anti-E (reactive in indirect antiglobulin test) in plasma and eluate. Autoimmunohemolytic anemia due to auto-anti-E was diagnosed. A variant of the E antigen was excluded by molecular diagnostic. Two compatible RBC concentrates (A Rh positive, ccD.ee) were transfused and the child was released from the ward in stable condition after additional treatment with immunoglobulin. Materials: Laboratory tests were performed with blood specimens (EDTA). ABO and Rhesus blood grouping were tested by tube technique. Antibody screening, identification tests, and DAT were performed by using the gel card method (DiaMed). RBC-bound antibodies were eluted by an acid elution kit (DiaCidel, DiaMed). A variant of the E antigen was excluded (NSTOB, Oldenburg) by multiplex PCR and sequencing (ABI-Prism 310, Applied biosystems). Conclusions: Due to the fact that positive DAT with anti-IgG in the initial test of the hospital laboratory was not further investigated, auto-anti-E initially was not detected and ccD.Ee red cells were transfused. This case shows that the further investigation of a positive DAT has to be done at any signs of hemolysis and anemia of unknown origin. The timely investigation before the first transfusion can avoid the transfusion of incompatible red cells, the boost of the antibody and the rapid decrease of the $\mathrm{Hb}$ after the first transfusion.

\section{P 3.12 Haplotype-Specific Extraction: A Simple and Efficient Method for Comprehensive Polymorphism Analysis}

\section{Hellbusch C. $^{l}$, Ibrahim $\mathrm{H}^{2}{ }^{2}$, Lennartz $\mathrm{K}^{2}{ }^{2}$} ${ }^{1}$ QIAGEN GmbH, R\&D, Hilden, D, ${ }^{2}$ QIAGEN GmbH, Hilden, D

Determination of allelic polymorphism combinations is required for many different genotyping applications. Several methods including sequencespecific priming (SSP) or sequencing-based typing (SBT) can be employed. 
Remaining ambiguous typing results, caused by different possible combinations of polymorphisms in an overlay of the two alleles or by new alleles, can be resolved by haplotype-specific extraction (HSE). The QIAGEN $^{\circledR}$ EZ1 HaploPrep Kit* utilizes this unique method for the physical separation of diploid genomic DNA into its haploid components. Data presented here show the usage of HSE for the comprehensive analysis of human leukocyte antigen (HLA) loci.

The extraction is performed fully automated on QIAGEN EZ1 workstations and consists of a probe-dependent hybridization and labeling process. The targeted DNA is subsequently coupled to magnetic beads for separation from nontargeted DNA. The HaploPrep probes show single-base specificity and provide high capture efficiency of genomic DNA. The extracted DNA fragments are up to $50 \mathrm{~kb}$ in length. Following HSE, analysis of the haplotypes of the targeted genes by SBT shows the successful reduction of complexity of the genetic information.

Therefore, HSE represents a fast and effective method for improving genetic analysis in complex genetic contexts, such as HLA. It has been shown to work in combination with various techniques including conventional PCR and sequencing approaches, Pyrosequencing ${ }^{\circledR}$, real-time PCR, and restriction fragment length polymorphism (RFLP) analysis. The number of other possible applications for HSE is growing with the rapidly increasing knowledge about polymorphism associated conditions and diseases. In the future, this method may also be applied to pharmacogenetics, oncology testing, or the emerging serology-replacing field of genotyping blood group subtypes.

* For Research Use Only. Not for use in diagnostics procedures. No claim or representation is intended to provide information for the diagnosis, prevention, or treatment of a disease.

\section{P 3.13}

Comparison of Iso-Haemolysin and -Agglutinin Testing of Platelet Donors in the Context of the Prevention of Haemolytic Transfusion Reactions

Schütz A. ${ }^{l}$, Kurta V. ${ }^{2}$, Hustinx $H^{3}{ }^{3}$, Mansouri Taleghani B. ${ }^{4}$, Niederhauser $C^{3}{ }^{3}$, Fontana $S^{3}{ }^{3}$

${ }^{1}$ Inselspital, University Hospital, Department of Haematology and Central Haematological Laboratory, Division of Transfusion Medicine, Bern, $\mathrm{CH}$, ${ }^{2}$ Department of Haematology and Central Haematological Laboratory, Division of Transfusion Medicine, Inselspital, University Hospital, Bern, $\mathrm{CH},{ }^{3}$ Regional Blood Donation Service of the Swiss Red Cross, Bern, $\mathrm{CH}$, ${ }^{4}$ Department of Hematology and Central Hematological Laboratory,

Division of Transfusion Medicine, Inselspital, University Hospital, Bern, $\mathrm{CH}$

Background: Testing for iso-haemolysins (IH) in platelet donors is mandatory in Switzerland. However, the few case reports of haemolytic reactions after minor incompatible platelet transfusion are related to high isoagglutinin (IA) titres ( $>1: 50$ or $>1: 100)$. Data about a correlation between IH and IA titres are lacking. Methods: Testing for IA titres and in parallel IH with 2 different methods ( $\mathrm{IH} 1, \mathrm{IH} 2)$ by tube technique were performed in consecutive platelet donors. IH1: serum dilution 1:4 with addition of $\mathrm{AB}$ plasma as complement source (single titre analysis); $\mathrm{IH} 2$ : classical titration without complement source. Specificity (Spec), sensitivity (Sens), positive (PPV) and negative (NPV) predictive values of IH1 (cut off $>1: 4$ ) and IH2 (cut off $>1: 2$ ) in detecting or excluding IA titres $>64$ and $>128$ are calculated. Results: Our results show $71 / 188$ donations $(37.8 \%)$ with IA titres $>64$ and $34 / 188(18.1 \%)$ with IA titres $>128$. The correlations with the specified cut offs of IH1 and IH2 are summarized in the table.

\begin{tabular}{|l|l|l|l|l|}
\hline$(\%)$ & $\mathrm{IH} 1 />64$ & $\mathrm{IH} 1 />128$ & $\mathrm{IH} 2 />64$ & $\mathrm{IH} 2 />128$ \\
\hline Sens & 45.1 & 55.9 & 29.6 & 41.2 \\
\hline Spec & 89.7 & 83.8 & 90.6 & 88.3 \\
\hline PPV & 72.7 & 43.2 & 65.6 & 43.7 \\
\hline NPV & 72.9 & 89.6 & 67.9 & 87.2 \\
\hline
\end{tabular}

Conclusions: Despite $1 / 3$ false positive results (low PPV), IH1 and IH2 detect only $1 / 2$ of the donations, using the accordingly defined cut off IA titres (low Sens). Our preliminary data suggest that IH testing may be of limited significance in the discrimination of high titre IA donations. But its value in platelet donation screening will be further assessed after completion of the data collection, including analyses for additional IH cut offs, different donor $\mathrm{ABO}$ blood groups and donor follow up.
P 3.14

Application of the Particle Gel Agglutination Assay in the Typing of Single Human Leukocyte Antigens

\section{Meyer O. ${ }^{1}$, Agaylan A. ${ }^{2}$, Constanze S. ${ }^{2}$, Kiesewetter $\mathrm{H}^{2}$,} Salama A. $^{2}$

${ }^{1}$ Charité - Universitätsmedizin Berlin, Institut für Transfusionsmedizin, Berlin, D, ${ }^{2}$ Charité - Universitätsmedizin Berlin, D

Purpose: The majority of laboratories utilize flow cytometry for typing of single human leukocyte antigens, for example HLA-B27. The microlymphocytotoxicity test (LCT) and polymerase chain reaction (PCR)-based techniques may also be used, but these techniques are laborious and cannot be implemented in most laboratories. Recently, we described a particle agglutination assay (PaGIA) for HLA-B27 typing. This test has been modified and extended to include the detection of HLA-A2 and HLA-B7. Design and Methods: Superparamagnetic streptavidin particles were coated with biotinylated monoclonal antibodies to HLA-A2, HLA-B7 and HLA-B27. Anticoagulated whole blood samples from healthy blood donors $(n=118)$ with known HLA patterns were incubated with monoclonal antibody coated particles, transferred into a standard ID-gel card, and subsequently centrifuged. Samples were evaluated macroscopically, with antigen-positive samples resulting in a visible agglutination reaction. Results: The results obtained were found to be in complete agreement with the known HLA pattern of the donors. A clear distinction could be made between all positive and negative samples tested. Fifty-seven samples were found to be positive for HLA-A2 (48\%), 26 samples for HLA-B7 (22\%), and five samples for HLA-B27 (4\%). Conclusion: The described PaGIA is suitable for rapid typing of single antigens. The advantages of this assay include its simplicity, and potential to be implemented in any routine laboratory.

P 3.15

\section{Prospective RHD Genotyping in Patients with Weak Agglutinations in Serologic RhD Typing}

Jorks S. ${ }^{l}$, Döscher A. ${ }^{2}$, Kroll $H$.

${ }^{1}$ Institute for Transfusion Medicine Dessau, Red Cross Blood Transfusion Service NSTOB, Dessau, D, ${ }^{2}$ Institute for Transfusion Medicine Oldenburg, Red Cross Blood Transfusion Service NSTOB, Oldenburg, D

Purpose: The Rh system is the most immunogenic and clinically important protein-based blood group system. Single point mutations in the transmembranous region lead to altered $\mathrm{RhD}$ protein expression (weak D). Other mutations or hybrid genes between RHD and RHCE are responsible for partial Ds. Since some patients with partial or weak D can form anti-D they should be well characterized. Here, we systematically analyzed the RHD genes in all patients with atypical reactions upon phenotyping. Methods: $\mathrm{RhD}$ phenotyping of patients of the immunohematologic laboratory in Dessau was performed by tube agglutination technique with two different monoclonal anti-D antibodies that did not react with D category VI. Over a period of 18 months, all samples that showed agglutinations of $2+$ or less or different reaction strengths between the two sera were further analyzed by genotyping. RHD genotyping was performed by polymerase chain reaction with sequence-specific primes (CDE SSP, weak D SSP, InnoTrain, Kronberg, Germany) and in selected cases by direct gene sequencing using dye terminators (Applied Biosystems, Weiterstadt, Germany). Results: A total of 117 patients with weak agglutinations in serologic $\mathrm{RhD}$ typing were analyzed. In 115 patients $(98.3 \%)$ a weak D $(n=111,94.9 \%)$ or partial $\operatorname{RHD}(\mathrm{n}=4$, $3.4 \%$ ) was detected. In detail, the following RHD genes were identified: weak D type 1: 65 (55.4\%), weak D type 2: 29 (24.7\%), weak D type 3: 12 (10.2\%), weak D type 41 : 1 , weak D type $42: 1$, D cat VII: 2 (1.7\%), DHMi: 1, wild type D sequence: $2(1.7 \%)$. Interestingly, three new weak D alleles: weak D type 61: 1, weak D type 63: 1, weak D type 64: 1 and one new hybrid allele (RHD-CE-D) were found. Conclusions: Weak reactions in RhD phenotyping were caused by weak or partial RHD alleles in $98.3 \%$ of the patients. Eight different weak D types and three different partial RHD alleles were found. However, no clear association between strength of agglutination with a certain weak or partial RHD allele was detected. We think that a $2+$ agglutination in the tube technique is a reasonable threshold to initiate RHD genotyping. In addition, our strategy allowed the identification of four new RHD alleles. 
P 3.16

\section{A Case of Severe Thrombocytopenia Associated with Pentamidine-Dependent Antibody Specific for Glycprotein IIB}

\section{Heidinger K. ${ }^{1}$, Giptner . $^{2}$, Eva O. ${ }^{2}$, Bein G. ${ }^{2}$, Sachs $U .{ }^{2}$}

${ }^{1}$ Institute of Clinical Immunology and Transfusion Medicine, Giessen, D, ${ }^{2}$ Giessen, D

Background: Pentamidine, an antiprotozoal agent, has been used in the treatment of Pneumocystis carinii pneumonia in USA. Parenterally administered pentamidine is associated with a variety of side effects, but severe thrombocytopenia has been observed infrequently. Case report: We report a case of a 75 -year old women with severe thrombocytopenia (nadir 1.000/ $\mu \mathrm{l}$ ) and severe bleeding after having been treated for pneumocystis jiroveci infection with Pentam ${ }^{\circledR}$ per inhalation and intravenously. Methods: We studied the serum from this patient using platelet immunofluorescence test (PIFT), enzyme immunoassay (EIA) with addition of the drug and glycoprotein specific immunoassay (MAIPA) in the presence or absence of pentamidine. Also FACS analysis and immunoprecipitation were performed. Results: The serum reacted strongly in the PIFT in the presence of pentamidine. The EIA showed a strong reaction with pentamidine $(0,1 \mathrm{mg} / \mathrm{ml}$ extinction 1,753$)$ and $(1,0 \mathrm{mg} / \mathrm{ml}$; extinction 1,316$)$. Flow cytometric analysis revealed a strong binding of FITC-IgG in the presence of pentamidine (Geo Mean 311.30 versus 6.67). The MAIPA assay showed strong pentamidine- dependent antibody when anti-GPIIb monoclonal antibodies (mAbs) (Gi16 and Sz22) were used to capture the antigen. The drug dependent antibody did not cross- block the binding of the anti-GP IIb/IIIa mAbs (Gi5 and P2). Finally, the pentamidine-dependent antibody could be demonstrated by immunoprecipitation. Conclusions: This is the first report about severe pentamidine induced thrombocytopenia with a pentaminine- dependent antibody specific for glycoprotein IIb.

\section{P 3.17}

\section{Discrimination of Null and Low Expression of HLA by Secretion Assays Using Soluble HLA-A*3014L}

Hinrichs J. ${ }^{1}$, Lukis S. ${ }^{2}$, Neumann $N^{2}{ }^{2}$, Hirv K. ${ }^{3}$, Blasczyk R. ${ }^{2}$, Eiz-Vesper B. ${ }^{2}$, Horn $P^{2}{ }^{2}$

${ }^{1}$ Hannover Medical School, Institute for Transfusion Medicine, Hannover, D, ${ }^{2}$ Hannover, D, ${ }^{3}$ Munich, D

The disruption of disulfide bridges can abolish or decrease expression of HLA class I molecules on the cell surface. Such disulfide bridges are formed by cysteine residues between aa positions 101/164 ( $\alpha_{2}$ domain) and 203/259 ( $\alpha_{3}$ domain). Ten HLA-A molecules have been described to be affected by sequence alterations in codon 101, 164, 203 or 259. All of these variant result in null alleles except for A*3014L and A*3211Q. HLA-A*3014L shows a transversion at nucleotide position 563, resulting in the substitution of cysteine to serine at position 164 of the mature polypeptide. By standard microlymphocytotoxity assay HLA-A30 was not detectable.

To verify low or non expression of the allele, we cloned soluble A*3014L and $A * 3001$ into a eukaryotic expression vector and transfected K562, C1R and HEK293 cells. In alone andand TNF- aaddition we investigated the effect of the cytokines IFN- $\gamma$ in combination on the expression pattern of the recombinant HLA. Soluble HLA was measured in the cell culture supernatant using a w6/32 and anti- $\beta_{2}$-microglobulin sandwich ELISA. The mRNA transcripts of both alleles were determined by real-time RT-PCR.

We were unable to detect $A * 3014 \mathrm{~L}$ in the supernatant of transfected cells. Addition of IFN- $\gamma$ and TNF- $\alpha$ slightly increased $A * 3014 \mathrm{~L}$ secretion to a detectable amount, whereas the expression of $A * 3001$ was increased up to 100 fold. In contrast, no difference was found in the increase of he mRNA levels of both the A*3014L and A*3001 as assessed by real-time RT-PCR Because the increase in the mRNA level of $A * 3014 \mathrm{~L}$ was comparable with A*3001, the protein expression defect is likely caused by an incorrect disulfide bond formation in the $\alpha 2$ domain. In conclusion, exposing the cells to cytokine stress showed to be helpful for discrimination of low- and nonexpressed alleles. This discrimination may be important in allotransplan settings, where a cytokine storm follows pretransplant myeloablative as well as posttransplant immunosuppressive treatment.

\section{P 4 Stem Cell Biology}

P 4.01

Precursor Cells in Peripheral Tissue Niches Are

Regulated by Suppressor of Cytokine Signaling-2

Hollemann $D .{ }^{1}$, Rüger $B .{ }^{2}$, Yanagida G. ${ }^{2}$, Fischer M.B. ${ }^{2}$

${ }^{1}$ Medical University of Vienna, Department of Transfusion Medicine, Vienna, A, ${ }^{2}$ Medical University of Vienna, A

Maintenance and survival of precursor cells in peripheral tissue niches is dependent on input from the surrounding microenvironment, and suppressors of cytokine signaling (SOCS) proteins are potent candidates in regulating signals by cytokines and growth factors, by inhibiting the JAK/STAT pathway. Of the eight SOCS (SOCS1, SOCS2, SOCS3, SOCS4, SOCS5, SOCS6, SOCS7, CIS) family members investigated, the predominant SOCS protein expressed by CD34+ precursor cells resident in synovial niches was SOCS2. The surrounding STRO-1+ mesenchymal precursor cells also expressed SOCS2, but only a few of the rare CD133+ precursor cells within the niches or in the sublining expressed SOCS2. In contrast, precursor cells showed only weak SOCS1, SOCS3 and CIS expression, and no SOCS5 and SOCS7. When equal amounts of total RNA were used for RT-PCR or RNAse protection assays, no difference between RA and OA could be observed in SOCS2 expression, but approximately 3-5 times more synovial tissue of patients with OA had to be processed compared to RA. In conclusion we can say that precursor cells in synovial niches can control their responses to cytokines and growth factors by SOCS2, and that SOCS2 was functional as SOCS2-dependent STAT4, STAT5a and STAT5b were downregulated.

\section{P 4.02}

\section{Impact of Sparsely lonizing and High Energetic Carbon Ion Irradiation on Hematopoietic Stem Cells}

\section{Becker D. ${ }^{l}$, Fournier $C^{2}{ }^{2}$, Seifried $E^{3}{ }^{3}$, Tonn $T^{3}{ }^{3}$}

${ }^{1}$ Institute for Transfusion Medicine and Immunohaematology, German Red Cross Blood Donation Service, JWG University Clinics, Frankfurt/Main, D, ${ }^{2}$ Gesellschaft für Schwerionenforschung, Darmstadt, D, ${ }^{3}$ Institute for Transfusion Medicine and Immunohaematology, German Red Cross Blood Donation Service, JWG University Clinics, Frankfurt/Main, D

Background: The increasing application of heavy ions in radiotherapy and the exposition of astronauts during manned space exploration is a strong motivation to expand the fundamental research with respect to long term side effects of heavy ions in different cell systems. The estimation of radiation induced chromosomal aberrations by cytogenetic analyses is usually conducted with differentiated lymphocyte populations only. Here many chromosomal aberrations may not be detected, due to apoptosis of damaged cells. In addition, the impact of heavy ion irradiation to hematopoietic stem cells is not well analysed and may be of relevance in the malignant formation of cancer stem cells. Methods: CD34+ hematopoietic progenitor cells were isolated from the peripheral blood of G-CSF mobilized healthy donors (purity $>90 \%$ ) and were irradiated with X-rays [16mA, $250 \mathrm{kV}$ ] or with Carbon ions $[100 \mathrm{MeV} / \mathrm{u}, 29 \mathrm{keV} / \mu \mathrm{m}]$ at the SIS facility at GSI. Energy for Carbon ion exposure was choosen to simulate the exposure of cells located near a tumor. The cultivated colony forming units (CFU-E, BFU-E, CFU-G, CFU-M, CFU-GM, CFU-GEMM) were classified and enumerated based on morphological recognition of mature cells by light microscopy. Results: A linear decrease in colony forming unit ability after exposure to X-rays was observed. First results showed a similar capacity to form colonies following Carbon ion exposure. After exposure to X-rays the amount of erythroid restricted progenitors increased with higher doses concomitantly with a decrease of cells from granulocytic and monocyte-macrophage lineages. The number of more committed progenitors (CFU-E) increased. Conclusion: Our data indicate that heavy ion irradiation has a pronounced impact on the proliferation potential of early hematopoietic progenitors (CFU-E, BFU-E, CFU-G, CFU-M, CFU-GM, CFU-GEMM). In contrast, numbers of more committed erythroid progenitors (CFU-E) increased upon irradiation. Further analysis will be performed to assess chromosomal aberrations in these populations and the potential for malignant transformation in NOD SCID mice models.

(Supported by grant to D. Becker) 


\section{P 4.03}

Progenitor Cells Characterized by Immunofluorescence and Aldehyde Dehydrogenase Expression

Gebauer W., Barklage I., Gnoth S., Leichter I.

DRK BSD NSTOB Oldenburg, D

Progenitor cells of benign and malignant origin are known to express increased activity of aldehyde dehydrogenase (ALDH) making them more resistant to toxic agents compared to other cells. Flow cytometric immunological characterization of blood progenitor cells (bpc) was combined with flow cytochemical determination of ALDH expression optimized by decreasing spectral overlap of detected signals.

An aminoacetaldehyde was converted to the corresponding aminoacetate by the cytosolic enzyme ALDH and was detected by flow cytometry. In control experiments this reaction was inhibited by 4-(diethylamino) benzaldehyde. By confocal microscopy ALDH expression was localized in the cytosol, qdot $605 \mathrm{~nm}$ marked secondary antibodies showed CD34 related to the cell surface. ALDH expressing cells in blood cell suspensions were analysed after staining cells with antibodies conjugated with different fluorochromes PE, PE Cy7 and APC.

ALDH expressing cells with low orthogonal light scatter can be characterized by gating strategies without physical enrichment procedures or depletion of cellular fractions. ALDH activity as nonimmunologic marker is significantly related to immunologically described bpc. Flow cytometric detection of ALDH expression in CD34PE treated bpc was accompanied by compensation difficulties between green and red fluorescence. These problems were solved by using antibodies PE Cy7 conjugated. Spectral overlap was even better resolved using CD34 APC.

\section{P 4.04}

\section{Long-Term Storage of Peripheral Blood Progenitor Cells} (PBPC) at $-80^{\circ} \mathrm{C}$ Leads to a Decrease of the Hematopoietic Potential Compared to Storage over Liquid Nitrogen

\section{Sputtek A. ${ }^{\prime}$, Rowe A.W. ${ }^{2}$}

${ }^{1}$ Univ-Klinikum Hamburg-Eppendorf, Inst. f. Transfusionsmedizin, Hamburg, D, ${ }^{2}$ New York University School of Medicine, New York, USA

Objective: Usually, autologous PBPC for therapeutic use are stored below $170^{\circ} \mathrm{C}$ directly in or over liquid nitrogen or at $-80{ }^{\circ} \mathrm{C}$ in mechanical refrigerators. The aim of this study was to investigate the above-mentioned storage temperatures with regard to leukocyte (WBC) recovery, membrane integrity (trypan blue exclusion) and colony forming potential (CFU) in semisolid culture assays after storage of 3 and 6 months. Material \& Methods: Fiftytwo frozen reference samples $(1.5 \mathrm{ml})$ of PBPC concentrates obtained from 13 patients. The samples contained $10 \%(\mathrm{v} / \mathrm{v})$ DMSO and had been cooled down to $-90{ }^{\circ} \mathrm{C}$ at $1.5^{\circ} \mathrm{C} / \mathrm{min}$ in a controlled rate liquid nitrogen operated freezer. After storage for 3 and 6 months at $-80{ }^{\circ} \mathrm{C}$ and below $-170{ }^{\circ} \mathrm{C}$, respectively, they were thawed within 3 min using a shaking water bath Terminology: group $1:<-170{ }^{\circ} \mathrm{C} / 3$ months, group $2:-80{ }^{\circ} \mathrm{C} / 3$ months, group 3: $<-170{ }^{\circ} \mathrm{C} / 6$ months, group $4:-80{ }^{\circ} \mathrm{C} / 6$ months. Paired samples with identical storage times (but different storage temperatures!) were thawed together and analyzed in parallel by the same person on the same day after 3 and 6 months storage, respectively. Results: Numerical WBC recovery of groups 2 and 4 were significantly lower (Student's t test, $\mathrm{p}<0.05$ ) compared to groups 1 and 3: $1.2+/-0.6 \times 10 \mathrm{E} 8 / \mathrm{kg}$ body weight (b.w.) (group 1) vs. 1.1 $+/-0.8 \times 10 \mathrm{E} 8 / \mathrm{kg}$ b.w. (group 2), and $1.9+/-1.2 \times 10 \mathrm{E} 8 / \mathrm{kg} \mathrm{b.w}$. (group 3) vs. $1.0+/-0.7 \times 10 \mathrm{E} 8 / \mathrm{kg}$ b.w. (group 4 ), respectively. Membrane integrities differed significantly as well: $70.2+/-10.9 \%$ (group 1 ) vs. $59.0+/-12.3 \%$ (group 2) and $80.9+/-12.6 \%$ (group 3) vs. $67.9+/-15.2 \%$ (group 4), respectively. Also there was a significant difference in the colony forming potential (CFU-GM + CFU-Mix + BFU-E): $21.2+/-13.5 \times 10 \mathrm{E} 5 \mathrm{CFU} / \mathrm{kg}$ b.w. (group 1) vs. $7.6+/-9.6 \times 10 \mathrm{E} 5 \mathrm{CFU} / \mathrm{kg} \mathrm{b.w.} \mathrm{(group} \mathrm{2)} \mathrm{and} 20.9+/-$ $23.7 \times 10 \mathrm{E} 5 \mathrm{CFU} / \mathrm{kg}$ b.w. (group 3) vs. $5.2+/-5.8 \times 10 \mathrm{E} 5 \mathrm{CFU} / \mathrm{kg}$ b.w. (group 4), respectively. Conclusions: Storage of PBPC in mechanical refrigerators at $-80^{\circ} \mathrm{C}$ leads to a highly significant loss of cell membrane integrity and clonogenic potential already after 3 months compared to storage for an equivalent time period in the vapor phase over liquid nitrogen $\left(<-170{ }^{\circ} \mathrm{C}\right)$ However, due to the well-known variability of the viability tests from day to day and from one institution to another, a comparison of the results is only possible between samples processed in parallel by the same individual on the same day. This may be the major reason why others, to date, have failed to detect differences in WBC recovery, membrane integrity and colony forming potential of PBPCs stored at $-80^{\circ} \mathrm{C}$ versus below $-170{ }^{\circ} \mathrm{C}$.

\section{P 4.05}

\section{Long Term Storage of Cryopreserved Hematopoietic Progenitor Cells}

Rosskopf K. ${ }^{1}$, Rohde E. ${ }^{2}$, Sipurzynski S. ${ }^{2}$, Stubenrauch M.-L. ${ }^{2}$, Lanzer $\mathrm{G}^{2}$

${ }^{1} \mathrm{LKH}-$ Univ.Klinikum Graz, blood group serology and transfusion medicine, Graz, A, ${ }^{2}$ LKH-Univ.Klinikum Graz, A

It is rather unclear how long cryopreserved hematopoietic progenitor cells (HPC) keep their functionality. Depending on cryopreservation solutions, methods of freezing and storage conditions five to ten years of storage could be achieved. We examined our freezing strategy of 10\% DMSO (Dimethyl Sulfoxide), computer controlled freezing $(1 \mathrm{~K} / \mathrm{min})$ and storage in liquid nitrogen containers by measuring cryopreserved HPC older than five years from patients after their death (study group). We compared these data with quality controls of autologous HPC which were thawed 6 to 50 days after cryopreservation (control group).

29 Cryopreserved HPC apheresates ( $n=17$, study group) or test tubes $(n=12$, control group) were thawed at $37^{\circ} \mathrm{C}$ and immediately diluted with phosphate buffered saline and ACD-A. Nucleated cell counts (NC) were analysed by an automatic cell counter. Percentage of viable (7-amino-actine negative) CD34+ and CD45+ cells was assessed by multicolour flow cytometry. Cell viability and morphology were determined additionally in a hemacytometer by trypan blue exclusion. Clonogeneic capacity ((CFU-GM+BFUE)/CD34+) was performed using a commercially available stem cell culture kit.

For results see table. In 15 out of 16 cases clonogeneic capacity was detectable. One additional culture was contaminated.

Long term storage of HPC apheresates with freezing strategy of $10 \% \mathrm{DMSO}$, computer controlled freezing $(1 \mathrm{~K} / \mathrm{min})$ and storage in liquid nitrogen leads to acceptable viability of CD34+ HPC compared to short term storage. Functional capacity is retained in $94 \%(15 / 16)$ of tested HPC after a storage time up to ten years in vitro.

\begin{tabular}{|l|l|l|}
\hline median (range) & Study Group & Control Group \\
\hline & $\mathrm{n}=17$ & $\mathrm{n}=12$ \\
\hline Storage before thawing & 7.5 years $(5.8-10.8)$ & 37 days $(6-50)$ \\
\hline Viability: & & \\
\hline CD45+/7-AAD- (\%) & $81(25-100)$ & $92(80-97) *$ \\
\hline CD34+/7-AAD- $(\%)$ & $97(0-100)$ & $98(74-100)$ \\
\hline NC trypan blue negative $(\%)$ & $72(12-96)$ & $90(74-95) *$ \\
\hline Functionality: & $\mathrm{n}=16$ & $\mathrm{n}=12$ \\
\hline Clonogeneic capacity $(\%)$ & $6(0-52)$ & $9(5-64)$ \\
\hline & & $* \mathrm{p}<0.05$ \\
\hline
\end{tabular}

\section{P 4.06}

\section{Mesenchymal Stem Cells from Different Tissue Sources}

\section{Yanagida G. ${ }^{l}$, Rüger B. ${ }^{2}$, Fischer M.B. ${ }^{2}$}

${ }^{1}$ Medical University of Vienna, Department of Transfusion Medicine, Vienna, A, ${ }^{2}$ Medical University of Vienna, A

Mesenchymal stem cells have an enormous plasticity to differentiate to chondroblasts, osteoblasts, adipocytes, and fibroblasts, but are also involved in new vessel formation by providing pericyte precursor cells required to potentially stabilize the newly formed vessels. We used bone marrow (BM) aspirate, fat tissue aspirate from long tubular bone and fatty tissue to isolate mesenchymal stem cells (MSCs) and investigated chemokine receptor CXCR4, involved in CXCL12-dependent retention of MSCs in the BM. Furthermore, the role of suppressor of cytokine signalling proteins, that negatively regulate cytokine and growth factor signals by inhibiting the JAK/STAT pathway, was studied in MSCs.

\section{P 5 Experimental Cellular Therapy}

\section{P 5.01}

\section{Dendritic Cell Vaccination Therapy of Glioblastoma}

Sorg R. ${ }^{l}$, Özcan Z. ${ }^{l}$, Rapp M. ${ }^{2}$, Rox J. ${ }^{1}$, Fischer J. ${ }^{1}$, Sabel M. ${ }^{2}$

${ }^{1}$ Heinrich Heine University Hospital, Institute for Transplantation Diagnostics and Cell Therapeutics, Düsseldorf, D, ${ }^{2}$ Heinrich Heine University Hospital, Department of Neurosurgery, Düsseldorf, D

Objectives: Dendritic cell (DC)-based immunotherapy is a promising approach in glioblastoma. Patients are vaccinated with tumor-antigen loaded 
DC. After vaccination, the DC have to migrate to lymph nodes and there to induce specific anti-tumoral T-cell responses. We have established such a protocol and report here on initial results. Methods: Autologous tumor material is obtained from surgery. After minimal mechanical dissection, necrosis is induced and lysates are prepared. Monocytes enriched from leukapheresis products are used as starting population for DC cultures. Successive generation of immature and mature DC for tumor lysate-loading and vaccination, respectively, are generated in a two-step culture system. Five vaccines are prepared and applied weekly by intradermal injection. Results: 24/24 tumor samples processed yielded a preparation of sterile, avital tumor cell lysates. For 14/24 of these preparations, diagnosis of GBM and a tumor cell content of at least $70 \%$ was confirmed neuropathologically. For 6 patients, vaccines were produced. From leukapheresis products containing $1.6 \pm 0.1 \times 10 \mathrm{E} 10$ leukocytes with a monocyte frequency of $24.2 \pm 1.5 \%$, monocytes were enriched to $97.6 \pm 0.7 \%$ CD14+ purity. Immature and mature DC obtained after 6 and 9 days of culture showed typical phenotypic and functional properties of bona fide DC, including induction of anti-tumora responses in vitro. Overall, for each patient 5 vaccines containing $3.8 \pm 0.7 \times 10 \mathrm{E} 7$ cells each were produced with a final purity of CD $83+$ mature DC of $87.6 \pm 2.4 \%$. Vaccination was well tolerated and severe adverse events have not been observed. In two patients there was clear evidence of antitumoral immunity induced by the vaccines. Two of the patients progressed and died early. One patient vaccinated after 3rd recurrence died $260 \mathrm{~d}$ after the last resection ( $668 \mathrm{~d}$ after $1 \mathrm{st}$ resection). One patient vaccinated between radiochemotherapy and temozolomide chemotherapy was progression free for $529 \mathrm{~d}$ but died $663 \mathrm{~d}$ after resection. Two patients are still alive. Conclusion: Vaccine production in glioblastoma patients is feasible and early results of vaccination, including induction of anti-tumoral immunity, are promising.

\section{P 5.02}

\section{Evaluation of a Tubing System with an Incorporated DMSO-Resistant Sterile Filter for Cryopreservation of Cellular Products outside of Cleanroom Facilities}

\section{Humpe A. ${ }^{\prime}$, Schubert S. ${ }^{2}$, Ketels A. ${ }^{\prime}$, Gramatzki M. ${ }^{\prime}$}

${ }^{1}$ Section of Stem Cell and Immunotherapy, Second Department of Medicine, University Hospital Schleswig-Holstein Campus Kiel, D, ${ }^{2}$ Institute of Infection Medicine, University Hospital Schleswig-Holstein Campus Kiel, D

Objectives: Processing of cellular therapeutics in an open system according to GMP guidelines requires a cleanroom grade A with surrounding grade B conditions. In a former study with a different system but the same sterile filter disfunction of the filter was detected in one lot of the system. In a validation project the DMSO-resistant sterile filter of a newly developed tubing system (Closed Cryo Prep Set, Cell•Max, Germany) for cryopreservation of cellular products was tested for function by performing challenge experiments with solutions of defined concentrations of bacteria. Design and Methods: In a first series, filter of 3 systems were challenged with spiked dimethyl sulfoxide (DMSO). $20 \mathrm{ml}$ of DMSO were spiked with a defined solution of Bacillus subtilis (strain ATCC 6051) leading to a concentration of $1 \times 10 \mathrm{E}+06$ colony forming units $/ \mathrm{ml}$. Prior filtration $100 \mu \mathrm{l}$ were used to titrate bacteria counts of the inoculum in $\log 10$ steps using BHI agar plates. $20 \mathrm{ml}$ of the bacterial suspension were applied to the system through the DMSO resistant filter. The filtrate was collected and finally titrated in log 10 steps on BHI agar plates. The influence of DMSO on the bacterial growth was examined by spiking DMSO and by analysis of bacterial growth afte different times. In a second series, filter of 3 systems were challenged in the same way but instead of DMSO $\mathrm{NaCl} 0.9 \%$ was used as medium. Results: In the DMSO series, after spiking but before filtration the number of detect able bacteria was already diminished by 4 to $5 \log$ leading to detectable concentrations of $1 \times 10 \mathrm{E}+01-10 \mathrm{E}+02 / \mathrm{ml}$. After filtration, bacterial growth was no longer detectable. Bacteria spiked in DMSO exhibited a time dependent decline of growth with a complete growth inhibition after 5 minutes of incubation. In the $\mathrm{NaCl}$ series, 35 to $50 \%$ of the spiked bacteria could be detected after spiking and before filtration. After passing the sterile filter, bacterial growth was no longer detectable. Conclusions: Although certainly most of the potential bacterial contaminants of hematopoetic progenitor cell (HPC) grafts are not viable after treatment in 99\% DMSO (similar results were obtained for $\mathrm{S}$. epidermides as published recently) the sterile filte offers a security measure to eliminate potential contaminants. Additiona validation experiments of the systems with media fill runs simulating all processing steps of HPC grafts are the next task.

\section{P 5.03}

Apoptosis of Lymphocytes and Monocytes during ShortTerm Storage of MNCs Obtained from LRS Chambers of the Trima Accel Cell Separator

\section{Strasser ${ }^{l}{ }^{l}$, Weidinger $T^{2}{ }^{2}$, Weiss $D .^{2}$, Ringwald J. ${ }^{2}$, Eckstein $R^{2}{ }^{2}$}

${ }^{1}$ Universitätsklinikum Erlangen, Transfusionsmedizinische und Hämostaseologische Abteilung, Erlangen, D, ${ }^{2}$ Universitätsklinikum Erlangen, D

Objectives: There is great interest to obtain small amounts of mononuclear cells (MNCs) for experimental purpose, to test T-cell or dendritic cell (DC) function, to optimize DC culture. Recently, this new source of peripheral mononuclear cells (PBMCs) obtained from the leukocyte reduction system chambers (LRSCs) of the Trima Accel apheresis machine was described. Design and Methods: The LRSCs of Trima Accel of nine $(n=9)$ plateletpheresis procedures were analysed for the apoptosis rate of lymphocytes and monocytes. The blood volume of each LRSC was transferred into a plastic bag (150 mL, PVC). The bags were stored for 72 hours (RT, in the dark, no agitation) and the apoptosis of lymphocytes and monocytes was analysed one hour after production, after 6, 24, 48 and 72 hours. A blood count was performed with the ADVIA TM 120 analyser (Siemens, Germany). The lymphocytes and CD14-positive monocytes were analysed by flow cytometry (FACS Calibur, BD, USA). Apoptosis was analysed by Annexin-V-staining (FACS Calibur). Irreversible cell death of cells was shown by the 7-AAD uptake of cells. Results: The mean leukocyte (WBC) concentration of LRS chambers was $93.0 \pm 32.2 \mathrm{WBC}$ per microliter. We found $64.2 \pm 9.6 \% \mathrm{lym}-$ phocytes (LYM) and $11.2 \pm 5.7 \%$ monocytes (MON) in the LRSCs. The Annexin-V-positive cells were found as follows: one hour after production (LYM: 24.7 $\pm 12.8 ;$ MON: 48.5 \pm 8.8 ), after 6h (LYM: 22.0 $\pm 9.5 ;$ MON: $34.0 \pm 10.5$ ), after $24 \mathrm{~h}$ (LYM: $23.1 \pm 10.1$; MON: $29.9 \pm 5.9$ ), after $48 \mathrm{~h}$ (LYM: 23.2 \pm 4.5 ; MON: $50.0 \pm 8.4$ ) and after 72 h (LYM: 22.3 \pm 4.7 ; MON: $69.5 \pm 5.8$ ). Only Annexin-V-positive monocytes differed significantly between the different periods of storage. Conclusions: Lymphocytes obtained from the LRSCs of the Trima Accel machine and stored in PVC-bags are stable within a period of at least 72 hours. The apoptosis, measured by Annexin-Vstaining, did not differ significantly between day of production and Day 3 of storage. However, CD14-positive monocytes showed significant differences during the storage period. The percentage of Annexin-V-positive cells was high after production, decreased until $24 \mathrm{~h}$ of storage and increased between Day 2 and Day 3 of storage. If monocytes obtained from LRSCs are used for research application, the cells should be stored for 6 to 12 hours at RT before usage.

\section{P 5.04 \\ Bacterial Contamination of Hematopoietic Progenitor Cell Grafts Leading to Detection of a Contaminated Port System in a Patient with NHL}

\section{Ketels A. ${ }^{l}$, Borries V. ${ }^{2}$, Kneba M. ${ }^{2}$, Gramatzki M. ${ }^{1}$, Humpe A. ${ }^{.}$}

${ }^{1}$ Section of Stem Cell and Immunotherapy, Second Department of Medicine, University Hospital Schleswig-Holstein Campus Kiel, D, ${ }^{2}$ Second Department of Medicine, University Hospital Schleswig-Holstein Campus Kiel, D

Purpose: Essential basis for harvest, production and release of hematopoietic progenitor cell (HPC) products of sufficient quality is a well established quality management system with a timely exchange of information between laboratory and clinic unit. We report a case of a patient with a Non-Hodgkin lymphoma (NHL) of the central nervous system with bacterial contaminated HPC products caused by a contaminated port system. Case Report: HPCs were collected by apheresis from a 46-year-old female patient with NHL and subsequently three products were cryopreserved. Sterility testing results showed that all products were contaminated with Staphylococcus epidermidis. Retesting reference tubes from all products confirmed the results, products were not released and an investigation for errors during processing was initiated. The positive microbial results were reported to the clinician of the patient leading to further examinations of the patient. Swaps and specimens for blood culture were taken from several sites of the patient. All samples taken from the thoracal port system were contaminated with Staphylococcus epidermidis at a low level. As consequence the patient was treated with Vancomycin and the port system was removed. After a second cycle of chemotherapy and G-CSF administration, a new apheresis was performed and a sufficient amount of HPCs for autologous transplantation was harvested and cryopreserved. Microbial testing of the products revealed that all products from this apheresis series were sterile and the products were released. Conclusions: The reported case demonstrates that trouble-shooting of contaminated HPC products should include all process steps ranging from the patient to the final processing of the product. In the reported case the 
patient benefited in different ways from the results of trouble-shouting. From the clinical point of view, the contaminated port system, representing a potential infectious risk during HPC transplantation, was detected before serious problems occurred. From the pharmaceutical point of view, the second apheresis series lead to sterile products which were released for autologous transplantation.

\section{P 5.05}

\section{Transplantation Lin-/CD117+ Bone Marrow Cells in Lethally Irradiated Mice}

\section{Filip S. ${ }^{1}$, Hodek M. ${ }^{2}$, Vavrova J. ${ }^{3}$, Blaha M. ${ }^{2}$}

${ }^{1}$ Charles University in Prague, Medical Faculty and Teaching Hospital in Hradec Králové, Oncology and Radiotherapy, Hradec Králové, CZ ${ }^{2}$ Charles University in Prague, Medical Faculty and Teaching Hospital in Hradec Králové, CZ, ${ }^{3}$ University of Defance, Medical Faculty, Hradec Králové, CZ

Experiments presented here were aimed at the description of hematopoiesis repair and in vivo homing of transplanted separated lin-/CD117+ bone marrow cells after whole-body lethal irradiation at LD 9Gy. ROSA 26 mice were used as donors of marrow cells for transplantation [B6; 129S/G (ROSA)26Sor] were tagged with lacZ gene and F2 hybrid mice [B6129SF2/J] were used as recipients of bone marrow transplanted cells Hematopoiesis repair was provided by transplantation both suspension of whole bone marrow cells and isolated lin-/CD117+ cells. Mice survived up to thirty day after irradiation. We demonstrated that transplantation of suspension of whole bone marrow cells led to faster recovery of CFU-GM in a bone marrow and in a spleen too. It is not clear what is the share of residential and transplanted cells in the repair process. Our results demonstrate that sufficient hematopoietic repair occurs after transplantation of lin-/CD117+ $(\mathrm{lacZ}+)$ in lethally irradiated mice, and the difference in CFU-GM numbers in the bone marrow and spleen found on day 8 posttransplant has no influence on survival of lethally irradiated mice (30 days follow-up).

This work has been supported by Research project MZO 00179906 and MSM 0021620820 from the Ministry of Education Youth and Sport of the Czech Republic.

\section{P 6/8 Hemotherapy and Clinical Disorders}

\section{P 6/8.01}

\section{Chemical Chaperones as a New Concept to Improve Factor VIII Secretion}

\section{Roth S. ${ }^{1}$, Schuettrumpf J. ${ }^{2}$, Bott D. ${ }^{2}$, Seifried E. ${ }^{2}$, Tonn T.}

${ }^{1}$ Red Cross Blood Donor Service Baden-Württemberg - Hessen, Institute for Transfusion Medicine and Immunohematology, Frankfurt/Main, D ${ }^{2}$ Red Cross Blood Donor Service Baden-Württemberg - Hessen,

Frankfurt/Main, D

Current substitution therapy for patients with hemophilia A is primarily based on administration of recombinant FVIII (rFVIII) concentrates, industrially produced in mammalian cells. In such cell factories, secretion of recombinant FVIII is still inefficient due to failure in intracellular FVIIItrafficking. An increasing number of studies showed that low-molecularweight compounds called 'chemical chaperones' (CC) can restore trafficking of misfolded proteins in storage diseases. $\mathrm{CC}$ may be an attractive tool to increase factor VIII production in heterologous systems and might also serve as a drug to increase FVIII levels in patients with bleeding disorders due to secretion defects.

As expression system we used $\mathrm{CHO}$ cells, the most common industrially used cell line, and the hepatoma cell line HepG2, representative for hepatocytes as a physiological source of FVIII. Cell lines were stably transduced with self-inactivating lentiviral vectors carrying a full-length or B-domain deleted FVIII (FL- or BDD-FVIII) or a mutant BDD-FVIII protein. Poin mutations in the $\mathrm{A} 1$ or $\mathrm{C} 2$-domain were chosen by the online database HAMSTeRS and introduced in lentiviral transfer vectors coding for BDD FVIII by site-directed mutagenesis. Experiments were performed in 96 well plates by supplementing cell media with Betaine or Ectoine at concentrations from 1 to $150 \mathrm{mM}$ or Thapsigargin and Curcumin in a $\mu$ molar range. After $72 \mathrm{~h}$ coincubation with CC the levels of FVIII-antigen and active FVIII were determined in the supernatants.

We could show that addition of all tested $\mathrm{CC}$ increased the secretion rate of both FL- and BDD-FVIII proteins in CHO cells. Addition of $50 \mathrm{mM}$ Betaine proofed to be most effective, increasing the yield of BDD-FVIII $(60 \%)$ and FL-FVIII (100\%). Rescued FVIII proteins appeared to be functionally active as confirmed by a chromogenic assay. Additionally first experiments confirmed that CC significantly improved secretion of FVIII mutants expressed in HepG2 cells. Secretion of FVIII mutant aa2307R $>$ Q increased from approximately 59 to $134 \mathrm{mIU}(127 \%)$ by $50 \mathrm{mM}$ Betaine supplementation.
$100 \mathrm{mM}$ Betaine further increased the FVIII secretion, but was accompanied by a marked cell growth inhibition. Interestingly, secretion of mutant FVIIIaa2313W $>$ A could be raised from non detectable to physiologically relevant FVIII levels upon treatment with combined Betaine and Ectoine.

In conclusion Betaine not only appears to be an attractive option to overcome current limitations in pharmaceutical FVIII-production systems. Due to its high safety aspects a systemic application of Betaine in patients suffering from haemophilia A due to a trafficking-defect is also promising.

\section{P $6 / 8.02$ \\ Prediction of CD34+ Yield of Autologous Stem Cell Harvest Using the Cobe Spectra and the AutoPBSC Setting}

\section{Maddox J. ${ }^{1}$, Teviotdale $C^{2}{ }^{2}$, Norris A. ${ }^{2}$, Douglas $K^{3}$}

${ }^{1}$ Ninewells Hospital, Department of Haematology, Dundee, UK, ${ }^{2}$ Scottish National Blood Transfusion Service, Dundee, UK, ${ }^{3}$ Scottish National Blood Transfusion Service, Glasgow, UK

Objectives: Harvesting of peripheral blood stem cells is a common procedure, often aiming to collect at least $2 \times 10^{\wedge} 6 \mathrm{CD} 34+$ cells per kilogram bodyweight for autologous re-infusion and often higher for allogeneic transplant. The Cobe Spectra is the most widely used cell separator machine internationally, with over $90 \%$ of the world market: it has two software settings (AutoPBSC and MNC) which can be used for PBSC collection. Using Cobe Spectra with the AutoPBSC collection setting, our aim was to derive a collection-efficiency-based formula for predicting yield. Design and Methods: Individual procedure collection efficiencies were calculated from 115 consecutive PBSC harvest procedures over an 88 month period at Ninewells Hospital, Dundee, Scotland. Median collection efficiency was 0.39. We then used this data to derive a formula for dose prediction. Results: Using the median collection efficiency of 0.39 , the following formula was derived: $0.39 \times$ peripheral blood CD34 $($ cells $/ \mu \mathrm{L}) \times($ predicted final inlet volume - anticoagulant volume $[\mathrm{ml}]) /$ patient weight $(\mathrm{kg}) \times 1000$. As we set the ratio of processed blood to anticoagulant to default to $12.5: 1$, the formula could be simplified to: CD34 yield (cells $\times 10^{6} / \mathrm{kg}$ ) = peripheral blood CD34+ $($ cells $/ \mu \mathrm{L}) \times$ predicted final inlet flow $(\mathrm{ml}) /$ patient weight $(\mathrm{kg}) \times 2800$. 'Predicted final inlet flow' is given by Cobe Spectra at the start of the procedure following initial data entry. We found that although predicted dose using this formula did correlate strongly with actual CD34+ dose obtained $(\mathrm{R} 2=0.83$, median variance $=0.1)$, this was no better than dose prediction based on peripheral $\mathrm{CD} 34+$ cell count $(\mathrm{R} 2=0.82$, median variance $=-2 \%)$. Conclusions: We have previously described a dose prediction formula for the MNC collection setting on Cobe Spectra, which does predict harvest dose more accurately than using peripheral CD34+ count alone (Journal of Clinical Apheresis 23(1):21-22). We had hoped that it would be possible to perform a similar exercise for the Auto-PBSC collection setting on Spectra. However, it appears that collection efficiency is significantly more variable for the Auto-PBSC than for the MNC setting. This is somewhat counterintuitive, as the Auto-PBSC is a highly automated procedure, while MNC requires continuous interface monitoring by the operator. However, collection efficiency during the Auto-PBSC procedure appears significantly dependent on initial data entry for a large number of variables (including patient mononuclear cell count, haematocrit, chase volume, harvest volume and number of collection cycles), while the MNC procedure is much less dependent on initial data entry and therefore has more predictable efficiency.

\section{P 6/8.03}

Comprehensive Antibody-Screening in Apheresis Donors with Suspected Risk for Induction of TRALI

Fürst D. ${ }^{l}$, Pabst K. ${ }^{2}$, Reinhardt $P^{2}{ }^{2}$, Mayr-Wohlfart $U{ }^{2}$, Kress $R^{2}{ }^{2}$, Koerner K. ${ }^{2}$, Wiesneth M. $^{2}$, Schrezenmeier $\mathrm{H}^{2}$, Mytilineos $\mathrm{J}^{2}$ ${ }^{1}$ IKT UIm, Transplantationsimmunologie, UIm, D, ${ }^{2} \mathrm{IKT}$, UIm, D

TRALI is a serious complication in transfusion therapy with a high mortality rate. Alloreactive HLA and HNA antibodies are implicated in an immunemediated pathway triggering non-cardiac pulmonary edema. Rapid, reliable and cost-effective antibody-screening for HLA and HNA-antibodies could help to reduce the risk for TRALI by exclusion of potentially sensitized donors.

Female apheresis donors with history of pregnancy or transfusion $(n=104)$ and male donors with transfusion history $(n=22)$ were screened for HLA Class I and Class II as well as HNA 1a, 1b, 1c, 2a and 4 antibodies with a commercial, Luminex based method. Consistency of HLA antibody evaluation was assessed by concurrent ELISA Class I and Class II testing with a commercial kit. 
72 donors $(57.7 \%$ ) were positive for any antibody (females $64.4 \%$, males $22.7 \%$ ). 50 donors $(39.7 \%$; female $48.1 \%$, male $0 \%$ ) were found to be HLA Class I positive, whereas HLA Class II antibodies were detected in 30 individuals $(23.8 \%$; female $27.9 \%$, male $4.5 \%)$. HNA antibodies were present in 20 donors (15.8\%; female $15.4 \%$, male $18.2 \%)$. Of these $11(8.7 \%)$ had HNA-antibodies (female $6.7 \%$, male $18.2 \%$ ) only, whereas $9(7.1 \%$ ) had both, HLA and HNA antibodies (female 8.7, male $0 \%$ ). Concurrent testing with ELISA revealed a concordant result for CLASS I antibodies in $79.4 \%$ $(\mathrm{n}=100)$ of the donors whereas a discordant result was found in 26 donors $(20.6 \%)$. All discordant results were positive in Luminex and negative in ELISA. Comparison between ELISA and Luminex CLASS II antibody testing revealed a concordant result in 110 donors $(87.3 \%)$. Of the 16 $(12.7 \%)$ discordant cases, $12(9.5 \%)$ were Luminex positive/ELISA negative, whereas 4 (3.2\%) were Luminex negative/ELISA positive.

In our study the prevalence of TRALI associated antibodies in females after pregnancy or transfusion was shown to be even higher than demonstrated in previous studies based on ELISA techniques, and affected almost $2 / 3$ of all tested women. Whereas the prevalence of HLA-antibodies was significantly higher in females after pregnancy/transfusion when compared with transfused men $(57.7 \%$ vs. $4.5 \%)$, this was not the case for HNA antibodies. Luminex is suitable as a high troughput method for screening of HLA and HNA antibodies, however, it will have to be clarified whether the increased sensitivity when compared to ELISA techniques has a significantly better diagnostic impact on the manifestation of clinical TRALI cases.

\section{P 6/8.04 \\ Platelet Function Testing by Impact-R in Transfused Patients Undergoing Chemotherapy}

\section{Horvath M. ${ }^{1}$, Eichelberger B. ${ }^{2}$, Koren D. $^{2}$, Binder S. ${ }^{2}$, Panzer S. ${ }^{2}$,} Jilma $P^{2}$

${ }^{1}$ Medical University of Vienna, Dept.of Blood Group Serology and Transfusion Medicine, Leitstelle 4i, Vienna, A, ${ }^{2}$ Vienna, A

Background: Platelet transfusion is a mainstream therapy for preventing or treating bleeding episodes in patients with low platelet counts. The efficacy is usually evaluated from the corrected count increment of platelets 1 hour or 24 hours after transfusion, which does not assess platelet function in the patient. We therefore evaluated the in vivo efficacy of platelet transfusions in thrombocytopenic patients before and after platelet transfusion. Methods: Platelet function was assessed in 20 chemotherapy-treated patients and in the platelet concentrate (PC) by the Impact-R. This device evaluates platelet adhesion and aggregation recorded as surface coverage (SC \%) and average size (AS $\mu \mathrm{m}^{2}$ ). Although the Impact-R is designed to use whole blood, it is also possible to evaluate the in vitro quality of a $\mathrm{PC}$ sample reconstituted with red blood cells and plasma. Patients without factors affecting platelet function (fever, splenomegaly, antibiotics, HLA or HPA-antibodies, anticoagulant medication) were included in this study. Results: Data are shown in the table. The storage time of the PCs was median $67 \mathrm{~h}$ (range 54-80h).

\begin{tabular}{|l|l|l|l|}
\hline & Platelets & $\mathrm{SC} \%$ & $\mathrm{AS}\left(\mu \mathrm{m}^{2}\right)$ \\
\hline Before transfusion & $9.5 \mathrm{G} / \mathrm{L}(4.6-14)$ & $0.3(0.2-1)$ & $30.2(25-35)$ \\
\hline After transfusion & $29.5 \mathrm{G} / \mathrm{L}(20.9-38)$ & $0.7(0.3-1)$ & $27.8(24-32)$ \\
\hline PC & $5 \times 10^{11}(4.1-6)$ & $3.6(2.0-5)$ & $18.3(17-19)$ \\
\hline
\end{tabular}

$\mathrm{SC}$ before transfusion correlated with $\mathrm{SC}$ after transfusion $(\mathrm{R}=0.51 \mathrm{p}=0.045)$, and $\mathrm{SC}$ after transfusion correlated with platelet increment $(\mathrm{R}=0.65$, $\mathrm{p}=0.007)$. Conclusions: The Impact- $\mathrm{R}$ is a valuable tool for evaluating in vivo efficacy of platelet transfusions, but the preparation of PCs for the Impact- $\mathrm{R}$ is rather time consuming.

\section{P 6/8.05}

\section{Belated Diagnosis in Two Patients with Sneddon's Syndrome and Associated Autoimmune Thrombocytopenia}

\section{Meyer O. ${ }^{1}$, Worm M. $^{2}$, Kiesewetter $\mathrm{H}^{2}{ }^{2}$, Salama A. $^{2}$}

${ }^{1}$ Charité - Universitätsmedizin Berlin, Institut für Transfusionsmedizin, Berlin, D, ${ }^{2}$ Charité - Universitätsmedizin Berlin, D

Purpose: Sneddon's Syndrome is characterized by ischemic cerebrovascular events and fixed livedo reticularis. Although thrombocytopenia and antiphospholipid syndrome are frequently present in affected patients, Sneddon's Syndrome is largely unknown in the fields of internal medicine and hematology. Design and Methods: Two patients with heterogeneous clinical pictures including cerebrovascular accidents, livedo reticularis and thrombocytopenia were referred for evaluation of possible autoimmune thrombocytopenia. Platelet serology was performed using standard tests. Results:
Platelet glycoprotein specific autoantibodies to platelets were detected in both patients, and remained detectable in patient no. 1 following treatment with low dose prednisolone. An increase in the platelet count from $30 \times$ $10^{3} / \mu 1$ to roughly $90 \times 10^{3} / \mu 1$ was observed. Patient No. 2 was previously treated with prednisolone and an increase in the platelet count from $13 \times$ $10^{3} / \mu 1$ to $>200 \times 10^{3} / \mu 1$ was observed. Autoantibodies to platelets became detectable, when the platelet count dropped to $50 \times 10^{3} / \mu 1$. Retrospectively, both patients were found to suffer from progressive Sneddon's Syndrome. Conclusion: Sneddon's Syndrome remains often unrecognized. Autoantibodies appear to be responsible for the thrombocytopenia observed in affected patients.

\section{P 6/8.06}

\section{Detection of an Early HIV-1 Infection by NAT}

Weber-Schehl M. ${ }^{1}$, Hedges D. ${ }^{\text {, }}$, Weinauer $F^{2}$

${ }^{1}$ Blutspendedienst des BRK gemeinnützige $\mathrm{GmbH}$, Wiesentheid, D ${ }^{2}$ Blutspendedienst des BRK gemeinnützige $\mathrm{GmbH}$, München, D

Objectives: Case study of a HIV-1 RNA positive donation without antibodies for HIV-1. Design and Methods: Screening for antibodies to human immundeficiency virus 1 and 2 (HIV) was performed by chemiluminescent immunoassay (ChLIA, Abott Prism ${ }^{\circledR}$ HIV-0 Plus and since 2008 Prism ${ }^{\circledR}$ HIV Ag/Ab Combo). Sensitive detection of viral genomes was done by inhouse real-time RT-PCR in minipools (up to 96 samples) with a sensitivity of $1,800 \mathrm{IU}$ per $\mathrm{ml}$ individual donor plasma (probit analysis $95 \%$ hit rate). Confirmation testing of anti-HIV-1/2 repeat reactive samples took place with microparticle enzymeimmunoassay (MEIA, Abott AxSym ${ }^{\circledR} \mathrm{HIV}-1 / 2 \mathrm{gO}$ and since $2008 \mathrm{AxSym}^{\circledR} \mathrm{HIV} \mathrm{Ag} / \mathrm{Ab}$ Combo) and westernblot (New Lav Blot I Ac-Ab-AK, Sanofi or Inno LIA ${ }^{\mathrm{TM}}$ HIV-I/II Score, Innogenetics). Results: Minipool-NAT screening of over 5 million blood donations (February 1999 until April 2008) identified one HIV-1 RNA positive donation without antibodies. The screening for antibodies in two different assays (Prism and AxSym) were non reactive for this specific donation. Additional testing with an antigen/antibody combo assay and westernblot analysis also delivered negative test results. 14 days later, in a follow-up drawn sample, seroconversion was confirmed by the detection of antibodies against HIV-1/2. Quantitative real-time PCR analysis concluded a virus load of approximately 10E03 $\mathrm{IU} / \mathrm{ml}$ in the window-period donation and more than $10 \mathrm{E} 05 \mathrm{IU} / \mathrm{ml}$ in the following up sample. Conclusion: In this observed case antigen/antibody screening was not sensitive enough to detect HIV infection. Therefore, sensitive NAT screening in minipools is an efficient method of detecting window-period donations of HIV-1.

\section{P 6/8.07 \\ Significance of HBsAg Testing in Addition to HBV-DNA and Anti-HBc Screening of Blood Donations}

Weber-Schehl M. ${ }^{I}$, Hedges D. ${ }^{l}$, Weinauer F. $^{2}$

${ }^{1}$ Blutspendedienst des BRK gemeinnützige $\mathrm{GmbH}$, Wiesentheid, D, ${ }^{2}$ Blutspendedienst des BRK gemeinnützige $\mathrm{GmbH}$, München, D

Objectives: To investigate significance of Hepatitis B surface antigen (HBsAg) screening of blood products, follow-up donations of only HBsAg positive donors were monitored for seroconversion. Design and Methods: All blood donations were screened for Hepatitis B surface antigen (HBsAg) and antibodies for hepatitis B Core antigen (anti-HBc) by chemiluminescent immunoassay (ChLIA, Abbott Prism ${ }^{\circledR}$ HBsAg and Abbott Prism ${ }^{\circledR}$ HBcore). In addition to german guidelines, all blood donations were tested for Hepatitis B DNA by in-house PCR in minipools with up to 96 samples. Neutralization assay (Abbott) or microparticle enzymeimmuno assay (MEIA, Abbott AxSym $^{\circledR}$ HBsAg) were used for confirmation of all repeat reactive HBsAg donations. HBsAg repeat reactive donations were also tested in a single sample in-house PCR with a sensitivity of $12 \mathrm{IU} / \mathrm{ml}$ (probit analysis $95 \%$ hit rate). Hepatitis B surface antigen antibodies (anti-HBs) were determined by microparticle enzymeimmuno assay (MEIA, Abbott AxSym ${ }^{\circledR}$ Ausab). Results: Screening of 2.8 million blood donations identified 24 HBsAg confirmed positive donations without detectable levels of anti-HBc. Two of these donations proved positive in routine PCR screening. Sensitive single PCR testing of the remaining 22 specimens detected no HBV-DNA. In 21 out of these 22 cases the positive HBsAg test result couldn't be confirmed in a second drawn sample. Due to HBV vaccination 18 out of 22 donors were HBsAg positive. Follow-up donation(s) of the three remaining donors were all negative for HBsAg, HBV-DNA and anti-HBc. Therefore, a hepatitis B infection couldn't be proved by seroconversion. In only one case, a followup-drawn sample, 15 days after donation, HBsAg and anti-HBs tests resulted positive again. Up to now, further follow-up samples from this donor were not available. Conclusion: Out of 2.8 million donations, tested from January 2003 until April 2008, no isolated HBsAg positive tested donor with low- 
level HBV-DNA or confirmed seroconversion could be identified. Most of the HBsAg positive test results could be explained by vaccination. Up to now, HBsAg testing in addition to screening for HBV-DNA and anti-HBc, didn't show any evidence of increased safety of our blood products.

\section{P 6/8.08}

\section{Evaluation of Safety and Efficacy of Recombinant Factor IX in Daily Clinical Practice: A Pharmacovigilance Evaluation of BeneFIX}

Westfeld M. ${ }^{l}$, Kosch M. ${ }^{2}$, Pollmann H. ${ }^{3}$, Huth-Kühne A. ${ }^{4}$ Eisert R. ${ }^{5}$, Laws H.J. ${ }^{6}$, Niekrens C. ${ }^{7}$, Girisch M. ${ }^{8}$, Severin K. ${ }^{9}$, Ries $\mathrm{M}^{10}$, Oldenburg J. ${ }^{11}$

${ }^{1}$ Wyeth Pharma GmbH, Medical, Münster, D, ${ }^{2}$ Wyeth Pharma $\mathrm{GmbH}$, Münster, D, ${ }^{3} \mathrm{ITH}$ - Institut für Thrombophilie und Hämostaseologie, Münster, D, ${ }^{4}$ Kurpfalzkrankenhaus, Heidelberg, D, ${ }^{5}$ Medizinische Hochschule, Hannover, D, ${ }^{6}$ Universitätsklinikum Düsseldorf, Klinik für Kinder-Onkologie, Hämatologie und klinische Immunologie, Düsseldorf, D, ${ }^{7}$ Klinikum Delmenhorst, D, ${ }^{8}$ Universitätskinderklinik Tübingen, D, ${ }^{9}$ Praxis Dr. Severin, Köln, D, ${ }^{10}$ Klinikum Memmingen, D, ${ }^{11}$ Universitätsklinikum Bonn, D

Objectives: Haemophilia B is a rare coagulation disorder with an incidence of about 1:25,000 in male newborns. Treatment of choice is prophylactic or on-demand replacement of coagulation factor IX (FIX) in a home-treatment setting. Today, two different types of factor concentrates are marketed in Germany: plasma-derived products and a recombinant product (nonacog alfa, BeneFIX). Nonacog alfa has proven its safety and efficacy in clinical studies including PTPs, PUPs and during surgery. A new formulation of nonacog alfa was introduced to the market in October 2007. Clinical studies have confirmed bioequivalence between the former and new formulation as well as safety and efficacy for the new formulation. Since haemophilia B is a very rare disease and only a limited number of patients can be included in clinical trials, a non-interventional post-authorization study with a special focus on safety parameters appears to be adequate. We here report on the study design and first results of a non-interventional pharmacovigilance evaluation (PE) of BeneFIX. Methods: To prospectively evaluate BeneFIX in the usual health care setting we started a non-interventional study including haemophilia B patients of any severity that are treated with reformulated BeneFIX. Primary objective of the study is the long-term evaluation of BeneFIX safety profile when used outside of clinical trials. The secondary objective is the evaluation of efficacy of treatment with BeneFIX. Inclusion criteria for patients are: diagnosis of haemophilia $\mathrm{B}$, treatment with reformulated BeneFIX and written informed consent prior to data collection. The aim is to include approx. $80-100$ patients within the first three years. Results: With regulatory and ethic committee's notification the PE started in Germany in February 2008. The study is set up and managed by the medical department of Wyeth in collaboration with a scientific advisory board. Datacollection and data-management as well as monitoring is supported by a clinical research organization. The data collection period will last for at leas 3 years and is very likely to be extended beyond this point. Until the end of April 20089 centers have been initiated, and 8 patients have been included Conclusions: Non-interventional trials in the usual health care setting are adequate means to assess the safety and efficacy of a treatment in the postauthorization phase. Especially in very rare diseases such as haemophilia B the conduct of this kind of study appears to be reasonable in order to monitor a larger cohort of patients over a longer period of time. First results will be presented in Sept. 2008

\section{P 6/8.09}

\section{No Detection of Herpes Simplex Virus DNA in Plasma of} Patients with Recurrent Herpes Labialis

\section{Juhl D. ${ }^{l}$, Lesiecki C. ${ }^{2}$, Hagenström H. $^{2}$, Dadgar S.M. ${ }^{2}$,} Kirchner $\mathrm{H}^{2}$, Hennig $\mathrm{H}^{2}$

${ }^{1}$ Universitätsklinikum Schleswig-Holstein, Institut für Transfusionsmedizin, Lübeck, D, ${ }^{2}$ Institut für Transfusionsmedizin, Lübeck, D

Objectives: Several studies revealed the possibility of a herpes simplex (HSV) viremia in primary and recurrent herpes genitalis, although herpes viruses are considered to be mainly neurotropic. The aim of our studies was to investigate whether a herpes labialis can be accompanied by viremia and to assess the risk of transmitting an HSV infection via blood transfusion. Methods: To obtain data about the spread of HSV-1 and -2 among blood donors, antibody states of 653 blood donors were investigated by ELISA and Western Blot. Blood specimens of 18 otherwise healthy subjects with herpes labialis were investigated concerning HSV DNA in their plasma and in peripheral blood mononuclear cells (PBMC's) by TaqMan PCR. Results: In 457/653 blood donors, only HSV-1 antibodies were detectable, in 46/653 blood donors, both HSV-1 and -2 antibodies were detectable and antibodies only against HSV-2 were detectable in 2 blood donors. The prevalence of HSV-1 antibodies in younger donors was lower than in older donors. The patients with herpes labialis showed the typical clinical picture of recurrent herpes infection. HSV infection was confirmed by detection of HSV-1 DNA in swabs of the labial lesions. HSV-1 DNA was detectable in neither in their PBMC's nor in their plasma, using TaqMan PCR. Conclusions: Since the prevalence of anti-HSV is lower in younger blood donors, they seem to be at higher risk for a primary HSV-1 infection. As we cannot exclude the possibility of viremia in primary HSV-1 infection, blood donors could be at risk to transmit HSV, if they suffer from an unexpected, subclinical primary HSV-1 (or HSV-2) infection at the time of blood donation. Donors with apparent primary HSV-1 (and -2) infection should be rejected from donation. Blood donors with recurrent herpes labialis are probably not at risk of transmitting HSV-1, as no viremia occurred in recurrent HSV-1 infection.

\section{P 6/8.10 \\ Hemovigilance Goes Active - Local Initiative to Improve Adverse Event Reporting in Transfusion Medicine}

Mueller M.M. ${ }^{1}$, Parisi-Wisniewska S. ${ }^{2}$, Wiesneth M. ${ }^{3}$, Gräßler J. ${ }^{2}$, Hoechsmann B. ${ }^{3}$, Seifried $E^{2}{ }^{2}$, Schrezenmeier $H^{3}{ }^{3}$, Henschler $R^{2}{ }^{2}$ ${ }^{1}$ Institute for Transfusion Medicine \& Immunohematology, Clinics of the JWG University \& GRC Blood Donor Service, Frankfurt/Main, D, ${ }^{2}$ Institute for Transfusion Medicine \& Immunohematology, Frankfurt/Main, ${ }^{3}$ Institute for Transfusion Medicine \& Immunohematology, Ulm/Donau, D

Background: Hemovigilance in Germany is a rather passive system, where manufacturers have to rely on full reporting of adverse events (AE) by hospitals, private practice and clinical colleagues. Compared to other European hemovigilance systems, which took a more proactive approach, the rate of adverse reporting after transfusion of blood products is rather low in Germany. Objectives: An investigator initiated trial (IIT) reporting acute transfusion reaction rate (ATR) and serious adverse transfusion events (SATE) was jointly established in three university hospital settings by the departments of hematology and the institutes of transfusion medicine. Design and Methods: A novel ATR and SATE reporting form was established and introduced on the hematology wards. Furthermore, all platelet concentrates (PC) distributed to the hematology departments are equipped with a transfusion reaction form attached to the blood bag. Following each PC transfusion, it has to be documented on these forms, whether or not a transfusion reaction was observed. These barcoded forms covering patient data, date and time of transfusion and name of the transfusing physician, will then be entered into an electronic database. All transfusion reactions observed have to be described in detail on the novel ATR and SATE reporting form. Results: In 2005, 2006 and 2007, 7.5, 6.1 and 7.5 AE per 10,000 transfused packed red cell concentrates (PRCC), 8.3, 11.9 and 6.8 AE per 10,000 transfused platelet concentrates (PC) as well as 4.6, 8.1 and 5.8 AE per 10,000 fresh frozen plasma (FFP) units were reported from one university hospital. This serves as a basis of comparison for our novel approach in order to establish an evidence-based desicion model in our clinics. Conclusions: Combining modern tools for hemovigilance in a jointly established system helps to improve reporting accuracy of adverse transfusion reactions.

\section{P 6/8.11}

\section{Implementation of Transfusion Guidelines for Red Blood Cells (RBC) in Elective Hip and Knee Replacement: A Prospective, Multicenter, Before-and-after Study in 10 Swiss Hospitals}

Fontana S. ${ }^{l}$, Müller U. ${ }^{2}$, Staub $L^{2}{ }^{2}$, Luginbühl M. ${ }^{3}$, Kwasna $M{ }^{2}{ }^{2}$, Schmid P. ${ }^{4}$, Krummen L. ${ }^{4}$, Lädrach A. ${ }^{4}$, de la Cuadra C. ${ }^{4}$, Mansouri Taleghani $B .^{4}$

${ }^{1}$ Regional Blood Donation Service of the Swiss Red Cross, Bern, $\mathrm{CH}$ ${ }^{2}$ Institute for Evaluative Research in Orthopaedic Surgery, University of Bern, $\mathrm{CH},{ }^{3}$ Department of Intensive Care Medicine, Emergency Medicine and Anaesthesiology, Inselspital, University Hospital and Universität, Bern, $\mathrm{CH},{ }^{4}$ Department of Hematology and Central Hematological Laboratory, Division of Transfusion Medicine, Inselspital, University Hospital, Bern, $\mathrm{CH}$

Background: Limited data and no general guidelines on transfusion practice in elective orthopedic surgery are available in Switzerland. Therefore we launched a Swiss study group and initiated a study, analyzing our preintervention transfusion practice in elective hip and knee replacement and the effects following the introduction of a straightforward guideline on RBC transfusion. We report the data of the first, observational phase. Methods: Prospective, multicenter before-and-after study comparing the use of RBC in adult elective hip or knee replacement before and after the implementation of a transfusion guideline in 10 Swiss hospitals. During the first 6 months 
(08.2007-02.2008) we monitored RBC use and patient outcomes. In a following transition period a RBC transfusion guideline, jointly developed by the participating hospitals, was introduced and implemented. Currently we continue monitoring the data of the post-intervention period (03.-10.2008) Results: Preliminary data of 1168 patients are available $(45.5 \%$ male, $43 \%$ knee and 57\% hip replacements, median ASA physical status 2). $19.9 \%$ of the patients received a total of $595 \mathrm{RBC}$ units (including 81 autologous), corresponding to a mean of $0.51 \mathrm{RBC}$ units per patient. These rates varied between the hospitals (4.4-42.4\%; 0.09-1.12 RBC units per patient). Transfused patients received a median of 2.53 units/patient. In-hospital mortality and cumulative complication rate (cardiovascular, bleeding, infections) afte a median hospitalization of 9 days were 0.4 and $9.3 \%$, respectively; and after follow up (639 patients, median 48 days) 0.5 and $12.4 \%$ respectively. Conclusions: This first Swiss multicenter study in elective hip and knee replacement revealed a considerable variation of transfusion practice between the participating hospitals. Although we observed a lesser degree than reported for other countries, there may be a further harmonization by the introduction of a straightforward practice guideline. Our preliminary data don't show any correlation between transfusion practice and patient outcome.

\section{P 6/8.12}

\section{Analysis of Factors Predicting Poor PBSC Yields and Evaluation of a Chemotherapy Scoring System in Patients with Haematological Malignancies}

\section{Mathur K. ${ }^{1}$, Frame $D^{2}{ }^{2}$, Douglas $K^{2}{ }^{2}$}

${ }^{1}$ Beatson West of Scotland Cancer Centre, SNBTS Clinical Apheresis Unit, Glasgow, UK, ${ }^{2}$ Scottish National Blood Transfusion Service, Glasgow, UK

Objectives: To identify factors associated with poor peripheral blood stem cell yields in haematological malignancies and evaluate a chemotherapy scoring system. Methods: Retrospective data analysis on 248 PBSC collection procedures from 173 patients with lymphoma $(\mathrm{LPH} ; \mathrm{n}=104)$, myeloma $(\mathrm{MM} ; \mathrm{n}=61$ ) and acute lymphoblastic leukaemia (ALL; $\mathrm{n}=8$ ) to identify predictive factors affecting adequacy of PBSC dose. A chemotherapy scoring system proposed by Janutnen et al. (modified from Drake et al.'s origina scoring system), with further modifications by ourselves, was also evaluated for predictive value. Results: Data were available for 95/104 LPH patients, $57 / 61$ MM patients and 8/8 ALL patients. Overall, $25 \%$ of patients (44/173) were 'poor mobilizers' with $<2 \times 10^{\wedge} 6 / \mathrm{kg} \mathrm{CD} 34+$ cells being collected in one treatment cycle. By far the strongest predictive factor for poor mobilization was prior chemotherapy exposure, as evaluated by our modification of Janutnen's scoring system. Prior chemotherapy scores were significantly higher on average for the LPH patients than for the MM patients $(\mathrm{p}<0.001)$ All ALL patients (8/8) had scores of 73 , reflecting heavy prior chemotherapy treatment as per UK MRC ALL XII trial. Taking all three patient groups together, patients with scores of 40 or less showed a 'poor mobilization' rate of just $15.7 \%$ (9/57); patients with scores of 41-60 showed a 'poor mobilization' rate of $39 \%(13 / 33)$; and patients with scores $>60$ showed a 'poor mobilization' rate of $62 \%(8 / 13)$. The five patients scoring $>60$ who did mobilise PBSC all had ALL rather than MM or LPH, i.e. all patients with myeloma or lymphoma with scores $>60$ were 'poor mobilizers'. Among other factors, prior exposure to fludarabine also showed significant independent association with poor mobilization (6/9 patients receiving fludarabine were 'poor mobilizers'; $\mathrm{p}<0.05$ ). There were nonsignificant trends towards poorer mobilization with increasing patient age, male gender, use of single-agent cyclophosphamide rather than combination regimes (DHAP IVE etc.) as mobilizing chemotherapy; and (for myeloma patients) IgA rather than IgG subtype. No effect was seen for prior radiotherapy treatment Conclusions: We confirm previous findings that the cumulative amount of prior chemotherapy treatment is by far the strongest predictor of poor PBSC mobilization, and we have validated our modification of Janutnen's scoring system (derived originally from Drake et al.) for the assessment of prior chemotherapy. We suggest that patients scoring highly for prior chemotherapy should possibly be considered in the future for alternative approaches to PBSC mobilization, such as Plerixafor (Mozobil).

\section{P 6/8.13}

Red Blood Cell (RBC) Use in Elective Cardiac and Vascular Surgery: A Prospective Assessment Prior to the Implementation of Transfusion Guidelines in a Swiss University Hospital

\section{Fontana S. ${ }^{1}$, Müller U. ${ }^{2}$, Staub L. ${ }^{2}$, Eberle B. ${ }^{3}$, Regli $B .{ }^{3}$,} Carrel T. $-P^{4}{ }^{4}$, Schmidli J. ${ }^{4}$, Kwasna M. ${ }^{2}$, Schmid $P^{5}{ }^{5}$, Mansouri Taleghani B. ${ }^{5}$

${ }^{1}$ Regional Blood Donation Service of the Swiss Red Cross, Bern, $\mathrm{CH}$, ${ }^{2}$ Institute for Evaluative Research in Orthopaedic Surgery, University of Bern, $\mathrm{CH},{ }^{3}$ Department of Intensive Care Medicine, Emergency Medicine and Anaesthesiology, Inselspital, University Hospital and Universität, Bern, $\mathrm{CH},{ }^{4}$ Department of Cardiovascular Surgery, Inselspital, University Hospital and University of Bern, $\mathrm{CH},{ }^{5}$ Department of Hematology and Central Hematological Laboratory, Division of Transfusion Medicine, Inselspital, University Hospital, Bern, $\mathrm{CH}$

Background: Limited data and no general guidelines on transfusion practice in elective cardiac and vascular surgery are available in Switzerland. We started a single center study, analyzing our pre-intervention transfusion practice in elective cardiac and vascular surgery and the effects following the introduction of a straightforward guideline on RBC transfusion. We report the data of the first, observational phase. Methods: Prospective, before-andafter study comparing the use of RBC in major adult cardiac and vascular surgery (valve replacement, coronary bypass $[\mathrm{CABG}]$, open abdominal aortic aneurysm procedures) before and after the implementation of a transfusion guideline. During the first 6 months (08.2007-02.2008) we monitored $\mathrm{RBC}$ use and patient outcomes. In a following transition period an institutional RBC transfusion guideline, jointly developed by the participating services, was introduced and implemented. Currently we continue monitoring the data of the post-intervention period (03.-10.2008). Results: Preliminary data of 351 patients are available (median age 68 y, $74.6 \%$ male, median ASA physical status 3, 409 cardiac procedures [176 valvular, 233 $\mathrm{CABG}]$ and 23 abdominal aortic procedures including several combined interventions). 214 of 351 patients $(61.0 \%)$ received a total of $683 \mathrm{RBC}$ units. This corresponds to a mean of 1.95 RBC units per patient and 3.19 units per transfused patient. Median length of hospital stay was 8 days. Inhospital mortality and cumulative complication rate (cardiovascular, bleeding, infections) during hospitalization were 0.8 and $21.6 \%$, respectively. Conclusions: We report the first data on perioperative transfusion practice for cardiac and vascular surgery in a Swiss university hospital. The preliminary observed pre-interventional transfusion practice seems to be more liberal than reported in the literature. It is expected to be positively influenced by the introduced guidelines.

\section{P 6/8.14}

\section{Thromboembolic Risk Assessment after Orthotopic Liver} Transplantation Due to Coumarin Induced Liver Failure

\section{Strobel J. ${ }^{1}$, Ringwald J. ${ }^{2}$, Eckstein R. ${ }^{2}$}

${ }^{1}$ Universitätsklinikum Erlangen, Transfusionsmedizinische und Hämostaseologische Abteilung, Erlangen, D, ${ }^{2}$ Universitätsklinikum Erlangen, D

Objectives: To report the peculiar and instructive history of a patient being cured of one of his major risk factors for thromboembolism by liver transplantation and therefore being able to stop prophylactic anticoagulation; organ failure was due to treatment with phenprocoumon. Design and Methods: Case Report. Results: We present a patient who had been treated with phenprocoumon as secondary prophylaxis after the first episode of pulmonary embolism. Nicotine abuse and a heterozygous factor $\mathrm{V}$ Leiden mutation with pathological resistance to activated protein C (APC) had been discovered as risk factors for venous thromboembolism. Anticoagulation therapy with phenprocoumon was recommended for one year. After six months of treatment the patient developed the clinical picture of acute liver failure. As all other probable reasons for acute liver failure such as viral, autoimmune or toxic pathogenesis had been ruled out by laboratory testing and the patient's medical history, coumarin therapy was considered to be the cause. Liver failure is a well known but rare complication of therapy with coumarin type oral anticoagulants. After transplantation, the patient was referred to our hemostaseology outpatient clinic for reassessment of his thromboembolic risk and further anticoagulation therapy. In contrast to the preoperative result, APC-resistance testing which was done repeatedly in order to exclude laboratory bias now showed normal results. The patient had stopped smoking, too. We therefore decided to discontinue anticoagulation. Conclusions: Checking APC-resistance routinely after liver transplantation, as has been suggested before, may be of importance, especially if a formerly known 
pathologic value in a patient with known thromboembolism may have impact on further decisions concerning anticoagulation therapy.

P 6/8.15

Temporal Changes in Antibody Reactivities in 64 Patients with Anti-PF4/Heparin-IgG, -A, and -M Antibodies

Juhl D. ${ }^{l}$, Eichler P. ${ }^{2}$, Lubenow $N^{2}$, Strobel U. ${ }^{2}$, Wessel A. ${ }^{2}$, Greinacher A. $^{2}$

${ }^{1}$ Universitätsklinikum Schleswig-Holstein, Institut für Transfusionsmedizin, Lübeck, D,

${ }^{2}$ Institut für Immunologie und Transfusionsmedizin, Greifswald, D

Objectives: IgG-antibodies against complexes of heparin and platelet facto 4 (PF4) can cause heparin-induced thrombocytopenia (HIT) by platelet activation via Fc $\gamma$ RIIa-receptor. Anti-PF4/heparin IgM and -A antibodies, and non-platelet activating PF4/heparin-IgG-antibodies are of minor clinical relevance, justifying the continuation of heparin. However, the frequency of a seroconversion toward a more pathological serological profile is unknown. Methods: from patients tested positive in a monovalent ( $\operatorname{IgG}, \operatorname{IgA}, \operatorname{IgM}$ ) PF4/heparin enzyme-immunoassay (EIA) a second blood sample was obtained about 10 days later to assess changes in the immunoglobuline class distribution and the platelet activating capacity. All samples were investigated by heparin induced platelet activation (HIPA) test. Results: 62/64 intial samples contained anti-PF4/heparin IgG antibodies with or without IgM and/or IgA antibodies. In 2/64 initial samples only IgM and IgA antibodies were detectable. 12/64 samples became EIA-negative in the second sample. Of 30 sera being HIPA positive in the first sample, 11 became HIPA negative in the second sample, however, also 7/32 initially HIPA negative sera became HIPA positive about 10 days later. None of the isolated anti$\mathrm{PF} 4 /$ heparin IgM and -A positive sera became anti-PF4/heparin IgG positive subsequently. Conclusion: the rapid disappereance of HIT antibodies indicates their adsorbtion from the circulation even after cessation of heparin compatible with a transient autoimmune disorder. Therefore, patients with acute isolated HIT may benefit from prolonged anticoagulation. Continuation of heparin in patients with non-platelet activating IgG antibodies needs a carefully follow-up, as about $20 \%$ of HIT-antibodies change their reactivity pattern and cause a positive HIPA test.

\section{P $6 / 8.16$}

\section{Transfusion Reactions 2002 to 2007 at the University Hospitals in Jena: The Savety Experience with the Solvent Detergent Plasma Octaplas}

\section{Lorenzen T., Kummer C., Barz D.}

Universitätsklinikum Jena, Institut für Transfusionsmedizin, Jena, D

Objectives: A haemovigilance system is a prerequisite for the safety of transfusion and is required by the German transfusion law (TFG). Each transfusion reaction is to be reported to Transfusion Medicine. We looked at data collected in Jena with special regard to the transfusion of fresh frozen plasma. Jena uses the solvent detergent plasma OCTAPLAS only, excluding the risk of viral infection hereby. Furthermore D. Barz et al. showed already in 1994, that no antigen bearing cells or cell fragments can be found in Octaplas and U.J. Sachs et al. found no HLA class I or II and no granulocyte specific antibodies 2005. This reduces the risk of immunological caused adverse effects like TRALI. Methods: 310 Reports of transfusion reactions at the University Hospital Jena over a period of six years were analyzed with special regard to the side effects of OCTAPLAS. Results:

\begin{tabular}{|l|l|l|l|l|l|l|}
\hline $\begin{array}{l}\text { Erythrocyte } \\
\text { concen- } \\
\text { trates (EC) } \\
\text { transfused }\end{array}$ & $\begin{array}{l}\text { Thrombapheresis } \\
\text { concentrates } \\
\text { (TAC) transfused }\end{array}$ & $\begin{array}{l}\text { Octaplas } \\
\text { transfused }\end{array}$ & $\begin{array}{l}\text { Transfusion } \\
\text { reactions } \\
\text { reported }\end{array}$ & $\begin{array}{l}\text { Severe } \\
\text { reac- } \\
\text { tions } \\
\text { reported }\end{array}$ & $\begin{array}{l}\text { Transfusion } \\
\text { reactions } \\
\text { with Octa- } \\
\text { plas in- } \\
\text { volved }\end{array}$ \\
\hline 2002 & 20408 & 6287 & 10167 & 32 & 5 & 2 \\
\hline 2003 & 22136 & 7650 & 9966 & 52 & 6 & 2 \\
\hline 2004 & 23054 & 8323 & 11577 & 54 & 1 & 2 \\
\hline 2005 & 21270 & 8789 & 11018 & 46 & 3 & 1 \\
\hline 2006 & 22843 & 9137 & 10489 & 43 & 0 & 0 \\
\hline 2007 & 26379 & 7864 & 13408 & 52 & 3 & 0 \\
\hline total & 136090 & 48050 & 66625 & 279 & 18 & 7 \\
\hline
\end{tabular}

Compared to cellular blood components, the transfusion of OCTAPLAS is fairly safe. The reports involving OCTAPLAS shows 4 cases of allergic reactions and 2 of fever. All but one report included other cellular blood components. Therefore the OCTAPLAS cannot be determined as the defini- tive causative agent. Only one case was considered 'severe', with shock and MI, but the underlying disease was oesophageal bleeding and also EC were given. No TRALI or anaphylactic shock related to OCTAPLAS $(\mathrm{n}=66625)$ was reported. The adverse reactions in Jena added up to $236 \mathrm{EC}(0.17 \%$ of all used EC), 148 TAC ( $0.3 \%$ of all TAC) and 21 SD-Plasma $(0.032 \%$ of all OCTAPLAS). Only one report regarding 2 units of OCTAPLAS $(0,003 \%$ of all used OCTAPLAS) did not involve parallel transfusion of other blood components. Our experience in Jena proves that the use of Octaplas fulfils the intention of $\S 1$ of the TFG, to supply the patient with a save blood component.

\section{P 6/8.17}

Inherited Macrothrombocytopenia and von Willebrand Disease as a Combined Defect in a Patient with Alport Related Symptoms - Perioperative Cochlear Implantation Management

\section{Schenk J.F., Stephan B., Pindur G., Eichler H.}

Institute of Clinical Hemostaseology and Transfusion Medicine, Saarland University Hospital, Homburg/Saar, D

Introduction: We first report about a rare case of combined congenital platelet function defect. Macrothrombocytopenia and heterogeneously inherited Alport related symptoms (especially high frequency sensorineural deafness) besides typical leukocyte inclusions led to the suspicion of Fechtner syndrome (FS) which was proved by electron microscopy. The aim of an adequate hemostaseological management of cochlear implantation was to achieve an improvement in quality of life. Methods: Platelet counts and volume distribution were objected by hematologic analyzer. Platelet aggregation was induced by ADP $(10 \mu \mathrm{mol} / \mathrm{ml})$, Collagen $(2 \mu \mathrm{g} / \mathrm{ml})$, and Ristocetin $(1.25 \mathrm{mg} / \mathrm{ml})$. Global coagulation parameters including factor VIII:C activity, vWB factor activity, and inflammation markers were measured. Free as well as bound platelet antibodies were excluded. Results: Two AB0identical apheresis platelet concentrates were transfused leading to platelet counts of 109/nl. vWB factor activity and CRP value were in normal range and no additional administration of desmopressin was necessary. Platelet function was found to be normal before surgery cut. The patient was hospitalized for at least three days and satisfied for its clinical outcome. She was omitted with platelet counts of about $60 / \mathrm{nl}$ without the occurrence of any bleeding signs/symptoms. Conclusion: A rare case of inherited FS macrothrombocytopenia associated with $\mathrm{vWB}$ disease was reported. Platelet transfusions were successfully performed before cochlea implantation. Since platelet counts using hematoloty analyzers may be hard to interprete in macrothrombocytopenia, testing of platelet function cannot be avoided. We suggest also be aware of congential/acquired platelet function defects.

P 6/8.18

Adverse Events of Platelet and Blood Component Transfusions - Plasma Constituent Incompatibility in a Young Patient Three Years of Age

\section{Schenk J.F. ${ }^{1}$, Stephan B. ${ }^{2}$, Pindur G. ${ }^{2}$, Eichler $\mathrm{H}^{2}$}

${ }^{1}$ University of Saarland, Institute of Clinical Hemostaseology and Transfusion Medicine, Homburg/Saar, D, ${ }^{2}$ University of Saarland, Homburg/Saar, D

Introduction: Diagnosis of neuroblastoma in a three years old male patient led to multiple chemotherapy, surgery and autologous stem cell transplantation. Initially blood component therapy was well tolerated. Few weeks later transfusions of apheresis platetels concentrates (APC) were associated with anaphylactic side effects and acute lung edema so that TRALI was primarily suspected. IgA-deficiency could be excluded, as well as no product contamination and/or any sign of infection by human blood culture became obvious. Methods: Platelet antibodies using ELISA, MAIPA (monoclonal antibody immobilization of platelet antigens) could not be detected. Lymphocytotoxicity testing resulted in weak IgM autoantibodies. Due to further chemotherapy, platelet counts decreased before stem cell-retransplantation. Further reasons for thrombocytopenia were also found to be explained by the comedication (antibiotics, fluconazol) and hematopoietic insufficiency. Washing of APC and red blood cells (RBC) was initialized because of suspicion of serum protein incompatability. Platelet function was objected by aggregometry acc. to Born, and $\mathrm{pH}$ was measured. Results: There was a big variation of platelet count response either corresponding with the use of PPCs (pooled platelet concentrates) or APCs. Platelet function was pathologic in any product, as well as ph-values were not different (about 5.1). No side effects could be found after transfusion of washed PCs. Conclusions: Based on our results improvements of additive solutions for washing platelets may be 
mandatory. This phenomenon might be attributed with $\mathrm{pH}$. Any delay of transfusion after washing platelets should be avoided.

\section{P 6/8.19 \\ Allergic Transfusion Reactions in a Patient with Multiple Food Allergies}

Strobel E. ${ }^{I}$, Schöniger M. ${ }^{2}$, Münz M. ${ }^{3}$, Hiefinger-Schindlbeck $R .^{4}$

${ }^{1}$ Städtisches Klinikum München $\mathrm{GmbH}$, Department Medizinische

Mikrobiologie und Krankenhaushygiene, Medizet, München, D,

${ }^{2}$ Kinderklinik, Klinikum Schwabing, Städtisches Klinikum München $\mathrm{GmbH}$,

München, D, ${ }^{3}$ Blutspendedienst, Städtisches Klinikum München $\mathrm{GmbH}$,

München, D, ${ }^{4}$ Department Klinische Chemie, Medizet, Städtisches

Klinikum München $\mathrm{GmbH}$, München, D

Objectives: Mild allergic transfusion reactions are very frequent, but their cause remains usually unkown. Case report: A 13 years old girl with an osteosarcoma of the right tibia was operated and became pre- and postoperative chemotherapy. At the first transfusion of an apheresis platelet concentrat (PC) she showed a mild allergic reaction. The next 5 PCs were given after premedication with an antihistamine and were well tolerated. At the transfusion of the 7th PC she showed again an allergic reaction in spite of premedication with clemastine iv. At the 8th PC the allergic reaction was still stronger although clemastine and decortine were given before transfusion. Therefore the next PC was washed and given after premedication with clemastine and a higher dose of decortine. Now it was well tolerated. The last (10th) PC was given $2 \frac{1}{2}$ months later. Premedication was only clemastin, but now no adverse reaction occured. No adverse reactions were seen after transfusion of red blood cell concentrates or virus-inactivated frozen poo plasma. Design and Methods: After the adverse reactions on the 7th and the 8th PC an intensive evaluation was done in the laboratory. As the patien declared to be allergic against some foods, also in-vitro-tests for allergenspecific IgE were performed. Results: There was no hemolysis or red blood cell minor incompatibility. Sterility testing of the PCs showed no growth. No HLA or HPA antibodies were detected in the patient's serum. Also the patient had no IgA deficiency. However the patient showed positive results for IgE against celery, carrot, peanut, and hazelnut and less stronger agains barley, rye, wheat, almond, walnut, potato, tomato, strawberry and pear. When the donor of the 7th PC was questioned at a later point of time, he remembered that he had eaten carrots and chocolate with hazelnuts the evening before platelet donation. Conclusions: In this case we assume that the allergy of the patient against a lot of vegetable foods was the cause for several allergic transfusion reactions. Therefore we recommend to ask patients for allergies before transfusion of PCs (and FFPs) and to be alert for allergic reactions in such patient who have a positive history especially of food allergies.

\section{P 7 Therapeutic Apheresis and Immunomodulation}

\section{P 7.01}

\section{Extracorporal Elimination of Lipoproteins (26 Years of Treatment in Czech Republic)}

Blaha M. ${ }^{\text {, }}$ Zadak Z. ${ }^{2}$, Blaha V. ${ }^{3}$, Vyroubal $P^{2}{ }^{2}$, Havel E. ${ }^{2}$, Maly J. ${ }^{3}$, Blazek M. ${ }^{3}$, Jebavy L.

${ }^{1}$ Medical Faculty and Faculty Hospital, Charles University, IInd Dpt. of Medicine, Haematology, Hradec Kralove, CZ, ${ }^{2}$ Medical Faculty, Charles University, Hradec Kralove, ${ }^{3}$ Faculty Hospital and Medical Faculty, Charles University, Hradec Kralove, CZ

Introduction: We began to treat familial hyperlipoproteinemia $(\mathrm{FH})$ using continual plasmapheresis 26 years ago and it stays rescue method in critical situations. In 1994 we started immunadsorption treatment. The developmen headed back to present removing of several pathogenic substances and influencing rheologic function of microcirculation, because blood abides not only Newtons principles. Methods: We have been using plasmapheresis for treatment of hyperlipoproteinemic crises; we remove plasma volume using separators Cobe-Spectra (replace solutions: albumin and crystalloids). We have performed 1500 immunapheretic sessions using adsorption column Lipopak with sheep antibodies. We execute these long-term $(8.2 \pm 2.96$ years $)$ treatment in severe cases of FH resistant to standard therapy. Since 2003, we performed 400 hemorheophereses using filters Evaflux, Kuraray. In 2006, we began therapy using adsorbers Lipocollect 300. In present time, we treat long-term 12 patients with FH as only center in Czech Republic. 25 patient were treated using series of hemorheophereses. Results: LDL-apheresis removed xantoms in all $\mathrm{FH}$ patients in 9 months and reduced subjective symptoms. Intima-media thickness of carotid arteries showed reduction or stagnation in $50 \%$ of patients. We use our own software to optimize adsorbe performance so immunapheretic sessions can significantly reduce LDL- cholesterol, ApoB and Lp(a) - our target level of LDL after session is 0.5 $\mathrm{mmol} / \mathrm{L}$. Using repeated session (after $17.6+1.6$ days) we can keep median levels of LDL-cholesterol within normal limits mostly. Hemorheopheresis has further rheologic effects- increase of microcirculation blood flow. According to our knowledge, this is important in critical limb ischemia, ARD or acute hearing loss. We have noticed $5.6 \%$ of non-significant side effects. Conclusion: Our experience with EE can be therefore summarized: Immunapheresis is successful in FH, lifesaving in homozygous FH. It is well tolerated. Hemorheopheresis improves microcirculation blood flow and ameliorates the course of other diseases mentioned above.

Supported by grant: IGA MH CZ NR/9103-4.

\section{P 7.02}

Complications of Therapeutic Plasma Exchange: A Single Center Experience

Altuntas $F^{1}{ }^{1}$, Kocyigit $I^{2}{ }^{2}$, Kurnaz $F^{2}{ }^{2}$, Kaynar L. ${ }^{2}$, Korkmaz $U^{3}{ }^{3}$, Oztekin M. ${ }^{3}$, Solmaz M. ${ }^{3}$, Eser B. ${ }^{2}$, Cetin M. ${ }^{2}$, Unal A. ${ }^{2}$

${ }^{1}$ Erciyes Universisty Mediacl School, Hematology, Kayseri, TR, ${ }^{2}$ Erciyes Universisty Mediacal School, Kayseri, TR, ${ }^{3}$ Kayseri, TR

Therapeutic plasma exchange (TPE) is used successfully as a therapeutic option in a variety of diseases. However, it can cause some complications The aim of this study was to analyze the complications associated with TPE. The type and the number of the complications were retrospectively reviewed in 1375 TPE procedures in 189 patients at the University Hospital from November 2005 to February 2008. The main TPE indications were thrombotic thrombocytopenic purpura, hemolytic uremic syndrome, Good Pasture syndrome, Guillian-Barre syndrome, myasthenia gravis, severe hyperthyroidism and HELLP syndrome. Albumin-saline (30\%) and fresh-frozen plasma (FFP) $(70 \%)$ were used as replacement solutions. All patients received an intravenous infusion of $10 \%$ calcium gluconate during the procedure. Central venous catheter was introduced in $151(80 \%)$ patients. Catheter related complications were observed in 16 patients $(10 \%) ; 8(5 \%)$ catheter dysfunctions, $5(3 \%)$ hematom and 3 catheter related infection $(2 \%)$. There were $282(21 \%)$ procedure-related complications. Most complications were minor; there were no deaths. Eight procedures $(0.5 \%)$ were discontinued due to severe complications i.e., hypotension. The most common complications were hypocalcemia (4\%), palpitation $(4 \%)$, fever $(2 \%)$ and urticaria $(1 \%)$. Hypocalcemic symptoms resolved after intravenous administration of calcium. Complications were more with FFP compared to albumin ( $16 \%$ vs. $5 \%$ ). While the most common complications with FFP were urticaria, fever, chills and pruritis, hypocalcemia and hypotension were more common with albumin-saline. In conclusion, therapeutic plasma exchange is a relatively safe procedure. Patients should closely follow-up in terms of complications associated with the procedure, i.e., catheter, replacement solution, and citrate during and after the procedure.

\section{P 7.03}

Therapeutic Plasma Exchange in Patients with Severe Hyperthroidism: A Single Cener Experience

Altuntas $F^{1}{ }^{1}$, Kocyigit $I^{2}{ }^{2}$, Kurnaz $F^{2}{ }^{2}$, Dogruel $F^{3}{ }^{3}$, Kaynar L. ${ }^{2}$, Oztekin $M{ }^{4}$, Eser $B{ }^{2}$, Unluhizarci $K^{5}$, Cetin $M{ }^{2}$, Unal $A^{2}{ }^{2}$, Kelestimur $F$.

${ }^{1}$ Erciyes University Medical School, Hematology, Kayseri, TR, ${ }^{2}$ Erciyes Universisty Mediacal School, Kayseri, TR, ${ }^{3}$ Erciyes University Medical School, Kayseri, ${ }^{4}$ Kayseri, TR, ${ }^{5}$ Erciyes University Medical School/ Endocrinology, Kayseri, TR, ${ }^{6}$ Erciyes University Medical School/Endocrinology, Kayseri, TR

The thyrotoxic crisis is a medical emergency caused by exacerbation of the hyperthyroid state characterized by decompensation of one or more organ systems. We report our experience with therapeutic plasma exchange (TPE) performed for severe hyperthyroidism. Eight patients presented with hepatotoxity or agranulocytosis due to use of propylthiouracil therapy. On admission to apheresis unit, all patients were using beta-blockers before TPE. Median four TPE sessions were performed (range; 3-7). Human albumin or fresh-frozen plasma was used as replacement solutions. We observed an improvement in thyroid hormone levels, and clinical findings in six patients. No improvement was seen in two patients. In six patients, serum free T3 (normal; $2.20-4.70 \mathrm{pg} / \mathrm{mL}$ ) and free T4 (normal; $8-20 \mathrm{pg} / \mathrm{mL}$ ) concentrations decreased to normal levels after plasma exchange (Table 1). After TPE radioactive iodine (RAI) was given in five patients and near-total thyroidectomy was performed in one patient. There was no severe complication due to plasma exchange procedure. Coagulation tests were within normal limits before and after plasma exchange. TPE can be used as an alternative therapeutic option in the management of severe hyperthyroid patients before RAI or surgery in patients with adverse reactions to anti-thyroid drugs. 
Table 1. Serum thyroid hormone levels before and after TPE (median 4 sessions)

\begin{tabular}{|llll|lll|}
\hline \multicolumn{3}{|l|}{ Before TPE } & \multicolumn{3}{l|}{ After TPE } \\
\hline & $\begin{array}{l}\text { FT3 } \\
(\mathrm{pg} / \mathrm{ml})\end{array}$ & $\begin{array}{l}\text { FT4 } \\
(\mathrm{pg} / \mathrm{ml})\end{array}$ & $\begin{array}{l}\text { TSH } \\
(\mathrm{IU} / \mathrm{ml})\end{array}$ & $\begin{array}{l}\text { FT3 } \\
(\mathrm{pg} / \mathrm{ml})\end{array}$ & $\begin{array}{l}\text { FT4 } \\
(\mathrm{pg} / \mathrm{ml})\end{array}$ & $\begin{array}{l}\text { TSH } \\
(\mathrm{IU} / \mathrm{ml})\end{array}$ \\
\hline 1.patient & 22.9 & 49.8 & 0.01 & 3.1 & 13.4 & 0.04 \\
2.patient & 32.6 & 73.2 & 0.03 & 2.8 & 17.1 & 0.01 \\
3.patient & 26.8 & 52.9 & 0.04 & 4.8 & 16.7 & 0.05 \\
4.patient & 10.9 & 41.1 & 0.04 & 2.1 & 17.1 & 0.02 \\
5.patient & 23.4 & 111.1 & 0.01 & 3.1 & 17.8 & 0.21 \\
6.patient & 14.7 & 44.1 & 0.01 & 4.2 & 23.1 & 0.01 \\
7.patient & 6.4 & 37.5 & 0.04 & 6.1 & 51.2 & 0.02 \\
8.patient & 14.5 & 58.4 & 0.01 & 14.2 & 47.2 & 0.01 \\
\hline
\end{tabular}

P 7.04

\section{Efficacy of Different Lipoprotein (a) Elimination \\ Procedures}

\section{Borberg $\mathrm{H}$.}

Deutsches Hämpherese Zentrum, Köln, D

Lipoprotein (a), (abbreviated $(\mathrm{Lp}(\mathrm{a})$ ), is a particle similar to LDLCholesterol however differs in density, particle size, molecular weight and protein, as it contains Apolipoprotein (a) in addition to Apoprotein B 100. In combination with an elevated LDL-cholesterol it is considered to be an independent genetic risk factor for premature atherosclerosis. Approximately $60 \%$ of our patients with familial hypercholesterolaemia are characterised from such additional elevation of Lp (a). However, also a selective elevation of Lp (a) without an additional increase of LDL-cholesterol may occur. It is under debate, whether such selective increase of $\mathrm{Lp}$ (a) may need therapeutical intervention. Patients with a selectively elevated Lp (a) without angiological alterations and clinical symptoms should be examined at regular intervals without treatment, however, if progression occurs or if clinical symptoms are present treatment must be initiated. Diet or drugs have been shown to be ineffective and without clinical value. Alternatively, several apheresis procedures such as heparin precipitation, liposorption, differrentia filtration and LDL-immune apheresis all lower elevated Lp (a) levels to a certain extent mainly in relation to the initial elevation. According to our experience with patients suffering from advanced coronary heart disease and a selective Lp (a) elevation Lp (a) apheresis is most effective lowering even excessively high $\mathrm{Lp}$ (a) values about $80-85 \%$ of the initial value to target values of not more than $30 \mathrm{mg} / \mathrm{dl}$ by the end of the treatment. Thus, further progression of the coronary heart disease can be prevented under long term Lp (a) apheresis.

\section{P 7.05}

\section{Significance of Non-Invasive Cardiovascular Examinations for the Evaluation of Extracorporeal LDL- Cholesterol Elimination Efficacy}

Blaha M. ${ }^{1}$, Strasova A. ${ }^{2}$, Ungerman $L^{2}{ }^{2}$, Blazek . $^{2}$, Blaha ${ }^{2}{ }^{2}$, Maly J. ${ }^{2}$, Masin $\mathrm{V}^{2}$

${ }^{1}$ Faculty Hospital and Medical Faculty, Charles University, IInd Dpt.of Medicine, Haematology, Hradec Kralove, CZ, ${ }^{2}$ Faculty Hospital and Medical Faculty, Charles University, Hradec Kralove, CZ

Introduction: Extracorporeal LDL-cholesterol elimination (EE) is a very successful therapeutic method in the treatment of severe familial hypercholesterolemia $(\mathrm{FH})$ after other therapeutic approaches have failed. The procedures must be effective but causing minimum discomfort to patients. However, it is very difficult to evaluate the actual activity of atherosclerosis. We report the significance of non-invasive cardiovascular examinations in longterm follow up of patients. Patients and methods: A group of 12 patients ( 7 males, 5 females) in the age of $47 \pm 16.6$ were treated during $7.2 \pm 2.96$ years Two methods of EE were used: LDL-apheresis and hemorheopheresis. Both invasive and non-invasive examinations were used in affected body parts EKG, ultrasound examination of heart, arteries and cathetrisation. Results: A rapid alleviation of symptoms was observed shortly after initiating EE therapy. Severe arteriosclerotic complications (myocardial infarctions and strokes) did not recur later. Invasive cardiovascular examinations were only necessary at the beginning of EE therapy. Non-invasive investigations (once in 6 months) were sufficient in the following period. The follow-up of the carotids (the media-intima) showed a regression of its thickness in 4 patients, an unchanged state in 3 and worsening was observed in 5 patients. Conclusion: Non-invasive cardio-angiologic examination of patients was sufficient as a follow-up in patients with FH treated by EE. It is of advantage to complement with selected haematological, biochemical and immunological indicators. EE of LDL-cholesterol is an effective method of treatment in severe forms of $\mathrm{FH}$.

Supported by the grants IGA MH CZ NR/9103-4.

\section{P 7.06 \\ Lymphocyto-Plasma Exchange in Ulcerative Colitis - a Case Report}

Handschel $D$.

$\mathrm{DHZ}$ gGmbH, Köln, D

Introduction: The very positive initial evidence of other published Lymphocyto-plasmapheresis (LCPA) procedures for the treatment of chronic inflammatory bowel disease (IBD) had sparked our interest to consider the innovative treatment. Furthermore, the very low risks and very minimal side effects associated with apheresis are in stark contrast to the risks and immense long-term side effects associated with conventional drug therapy for IBD. Beside genetic and environmental factors, a dysfunction of the immune system is discussed to be pathogenetic for IBD. In particular, cytokines, and lymphocytes are thought to play an important role. Alternative selective adsorber systems are able to bind granulocytes and monocytes. LCPA was more appealing to us in the technologically advanced ability to simultaneously reduce inflammation markers (e.g. cytokines) through performing a plasma exchange while depleting the wider range of activated leucocytes at the same time. Case report: 12 year old steroid-dependant female with a Clinical Activity Index (CAI) of 12 received 5 weekly +2 bi-weekly treatments as maintenance therapy ( 7 treatments in total). Each treatment consisted of a simultanous centrifugal plasma exchange therapy (55-60\% of the patient's plasma volume that was exchanged with a $5 \%$ albumin solution) and a centrifugal leukocyte depletion. Thin bloody stools had completely ceased - Frequency of bowel movement reduced from 3 to $1 \mathrm{x} /$ day - Normal texture of bowel - All joints are symtom free (competetive sports were possible again) - No medication necessary - Inflammation marker: Normal (ESR $1 \mathrm{~mm} / \mathrm{h}, \mathrm{CRP}<3)$ - CAI: 0 points - Normalization of bowel movement and joint problems were seen after the first treatment! Discussion: Through the use of centrifugal apheresis, we were able to achieve fantastic clinical results at lower costs. Although published long-term ( $>24$ months) clinical and histological remissions look promising, we would like to follow this young patient and additional patients long-term. Furthermore, additional well-designed clinical studies will be necessary to show statistical significance and allow for cost effective public health-care reimbursement.

\section{P 9 Hemostasis and Thrombosis}

\section{P 9.01}

\section{A New Molecular-Epidemiological Approach to Assess the Variability of Bleeding among Patients with von Willebrand Disease (vWD) Type 1 and Type 2}

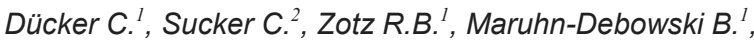
Scharf R.E.

${ }^{1}$ Heinrich Heine University Medical Center, Dept. of Hemostasis, Hemotherapy and Transfusion Medicine, Düsseldorf, D, ${ }^{2}$ Berlin, D

Background: At present, it is still difficult to explain the significant variation in bleeding risks and/or events among individual patients with vWD and similar pattern of their laboratory profile, including bleeding time in vivo and in vitro, aPTTT, FVIII:C, activity ( $\mathrm{RiCoF})$ and concentration $(\mathrm{Ag})$ of plasma von Willbrand factor (vWF), and its $\mathrm{RiCoF} / \mathrm{Ag}$ ratio. We hypothesize that genetically determined polymorphisms of platelet adhesion and aggregation receptors which are known to modulate platelet function, e.g., to increase their thrombogenicity, may delay or mitigate the severity of hemorrhage. In addition, expositional (non-genetic) determinants of hemostasis may augment or attenuate the likelihood of bleeding symptoms in patients with vWD of various types. Patients and Methods: To test this hypothesis, we have initiated a study, so far comprising 107 patients (37 males, 70 females, patients' mean age 41+17 yrs.) with prediagnosed vWD. Among the patients, 96 were classified vWD of type 1,7 of type $2 \mathrm{~A}, 2$ of type $2 \mathrm{~B}$, and 2 of other subtypes 2 . The patients were reexamined and assigned a bleeding severity score. For comparison, unrelated healthy individuals of a control group $(n=759)$ were matched for age and gender. The following laboratory parameters were determined: (i) genotyping of polymorphisms including $\alpha 2 \mathrm{C} 807 \mathrm{~T}$ and HPA- 5 of platelet $\alpha 2 \beta 1$, HPA- 1 and HPA-3 of $\alpha \operatorname{IIb} \beta 3$, HPA-2, GPIb $\alpha$ Kozak, GPIba VNTR of GPIb-IX-V, G1691A of factor V, G20210A of prothrombin; (ii) activity/antigen of fibrinogen, factors II, V, VII, VIII:C, IX, $\mathrm{X}, \mathrm{XI}, \mathrm{XII}, \mathrm{XIII}$, and vWF; (iii) in vitro bleeding time (PFA-100 closure times in response to collagen/epinephrine and collagen/ADP), and (iv) platelet aggregation in response to ristocetin, ADP, collagen, and epinephrine. Results: An interim analysis of complete data sets from 87 patients 
documented, as expected, no difference in the prevalence of platelet receptor polymorphisms between vWD patients and healthy individuals $(\mathrm{C})$, using a case-control design. For example, the frequency (\%) of HPA-1 alleles (vWD vs. C) was 69.0 vs. $72.3(1 \mathrm{a} / 1 \mathrm{a}), 29.9$ vs. $25.3(1 \mathrm{a} / 1 \mathrm{~b})$, and 1.1 vs. $2.4(\mathrm{lb} / 1 \mathrm{~b})$ ( $\mathrm{p}$ each $>0.05$ ). By contrast, in a case-only design, a trend was observed that prothrombotic platelet receptor variants such as HPA- $1 \mathrm{~b}$ and $\alpha 2807 \mathrm{TT}$ are more frequently present in $\mathrm{VWD}$ patients with minor bleedings than in those with intermediate or severe hemorrhagic episodes. This association requires confirmation in follow-up studies. Conclusion: The results of this pilot study are indeed supporting our hypothesis that the clinical feature of bleeding diathesis or complications (frequency, severity, site) in patients with prediagnosed VWD is modulated by genetically determined prothrombotic platelet variants and may be also modified by acquired alterations of hemostatic components.

\section{P 9.02}

\section{Correlation between Two ADAMTS-13 Activity Assays Based on Different Principles}

Wagner L. ${ }^{1}$, Geiter S. ${ }^{2}$, Vetr $\mathrm{H}^{2}{ }^{2}$, Graf M. $^{2}$, Dockal M. ${ }^{3}$, Scheiflinger $F^{3}$, Binder $B{ }^{4}$

${ }^{1}$ Technoclone Deutschland GmbH, Heidelberg, D, ${ }^{2}$ Technoclone GmbH, Wien, A ${ }^{3}$ Baxter Bioscience, Wien, A, ${ }^{4}$ Medizinische Universität, Wien, A

Aims: Defects in ADAMTS-13, the von Willebrand Factor (vWF) cleaving protease, are thought to be the main cause for the microvascular thrombotic disorder TTP (thrombotic thrombocytopenic purpura) that is in more than $90 \%$ of cases fatal if not treated early and appropriately. Usually this disease is clinically diagnosed, but in recent years the need for rapid and reliable diagnostic tests for ADAMTS-13 levels has increased. We present here the comparison of two commercially available assays for quantification of ADAMTS-13 activity both suitable for routine analysis but based on different principles. Methods: The two assays differ in their test principle and the readout system as follows: Assay 1 is a fluorogenic assay using a FRETSvWF73 substrate and a kinetic measurement (TECHNOZYM ${ }^{\circledR}$ ADAMTS-13 ELISA); with this assay ADAMTS13 Antigen can also be determined in a second step. Assay 2 is a chromogenic assay and detects the cleaved vWF73 substrate by a specific monoclonal antibody (TECHNOZYM ${ }^{\circledR}$ ADAMTS-13 Activity ELISA). Results: Citrated plasma of normal donors $(\mathrm{n}=7)$, of pooled normal plasma $(n=15)$ and of TTP patients $(n=14)$ were tested in both assays. Results are reported in both assays as percentage of normal activity. The standard for both assays is prepared from a pool of 100 normal donors and defined as $100 \%$. The samples comprised a range from $0.2 \%$ up to $107 \%$ activity. The overall correlation coefficient between the two different activity assays was 0.96 . Five samples were found to have less than $5 \%$ activity in both assays. Conclusions: These results show that data obtained by the new TECHNOZYM $^{\circledast}$ ADAMTS-13 Activity ELISA correlate very well with the fluorogenic assay (TECHNOZYM ${ }^{\circledR}$ ADAMTS-13 ELISA) in spite of the fact that these assays are based on very different principles.

\section{P 9.03}

\section{Expression of PAR1, Thrombin, Plasmin, and Activated Protein $\mathbf{C}$ in the Developing Murine Fetal Liver}

Jochheim-Richter A. ${ }^{l}$, Schüttrumpf J. ${ }^{2}$, Seifried E. ${ }^{2}$, Richter $R^{2}$ ${ }^{1}$ Institute of Transfusion Medicine and Immune Hematology, DRK Blutspendedienst Baden-Württemberg - Hessen gGmbH, Production, Frankfurt/Main, D, ${ }^{2}$ Institute of Transfusion Medicine and Immune Hematology, DRK Blutspendedienst Baden-Württemberg-Hessen gGmbH, Frankfurt/Main, D

Little is known about the coagulation system in the fetus during intrauterine life. The coagulation system and PAR signalling, however, are known to play important roles in angiogenesis of the fetus. Griffin and collegues showed that PAR1-deficient embryos die between embryonic days 9.5 and 10.5 due to a defect in hemostatic mechanisms or vascular integrity (Science, 2001, 293, 1666). To further elucidate the time-dependent development of the coagulation system and the PAR receptors in the fetus we performed micro array analysis in the fetal liver at days $9.5,11.5,13.5$ post coitum and in adult mice. Fetal liver tissues $(\mathrm{n}=2)$ as well as livers from adult BALB/C mice were prepared and total RNA was isolated using the RNeasy kit (Qiagen, Hilden). Hybridization of the samples was performed using the Murine Genome U74A Set Version 2 (Affymetrix, USA) probe arrays representing 12488 genes/EST sequences. All preparations and hybridizations were performed in duplicate. This resulted in a list of genes that were regulated over the analysed time schedule. On day 11.5 p.c., when the liver becomes the site of extramedullary hematopoiesis, data showed a distinct peak in PAR1 and PAR4 expression whereas PAR2 expression slowly decreases from day 9.5 to 13.5 p.c. Expression of thrombin as well as all other analysed coagulation factors (Factor V, VII, IX, X, XII, XIII) showed a common expression profile that is characterized by a moderate increase of expression between day 9.5 and 13.5 p.c. and a $\sim 10$-fold increased expression level obtained in the adult mice Levels of plasmin and activated protein $\mathrm{C}$ transcripts, also known to be involved in the activation of PAR receptor, steadily increased between day 9.5 to 13.5 p.c. from 1 to $10 \%$ respectively, and are higehest expressed in the mature liver. Interestingly we found plasminogen activator as well as plasmin activator inhibitor to be maximally expressed on day 9.5 and 11.5 p.c., and decreased to nearly undetectable levels in the adult mice indicating that the plasmin pathway is important at a particular timepoint in the fetal liver. Our results show that PAR1, PAR2 and PAR4 receptors are predominantly expressed at early stages of fetal murine liver development. Expression of PAR1 activators like thrombin, plasminogen and protein $\mathrm{C}$ are increasingly expressed during development of the fetal liver but are highest expressed in the adult liver. Increased expression of plasminogen activator as well as plasmin activator inhibitor in the fetal liver suggest that the activity of plasmin is differentially regulated during liver development

\section{P 9.04 \\ Exclusion of Heparin-Induced Thrombocytopenia by the Particle Gel Immunoassay?}

Schallmoser $K{ }^{1}$, Drexler $C^{2}{ }^{2}$, Rohde $E^{3}{ }^{3}$, Strunk $D .^{4}$, Groselj-Strele A. ${ }^{2}$, Lanzer G. ${ }^{5}$, Kroll H. ${ }^{6}$, Panzer S. ${ }^{7}$

${ }^{1}$ Medical University of Graz, University Clinic for Blood Group Serology and Transfusion Medicine, Graz, A, ${ }^{2}$ Medical University of Graz, A, ${ }^{3}$ Stem Cell Research Unit Graz, Medical University of Graz, A, ${ }^{4}$ Stem Cell Research Unit Graz, Medicine,Medical University of Graz, A, ${ }^{5}$ Dep. of Blood Group Serology and Transfusion Medicine, Medical University of Graz, A, ${ }^{6}$ Red Cross Blood Transfusion Service Dessau, D, ${ }^{7}$ Medical University of Vienna, A

Heparin-induced thrombocytopenia (HIT) is a prothrombotic condition, characterized by a platelet drop $>50 \%$ and/or thrombosis with a temporal relationship of 1-2 weeks after initiation of heparin. These surrogate markers are useful for the clinical assessment but are hardly applicable in multimorbid patients with clinical conditions that mimic HIT. Platelet activation assays (heparin-induced platelet aggregation assay, HIPA, and serotonin release assay, SRA) and platelet factor-4/polyanion enzyme immunoassays (PF4-ELISA) confirm HIT. HIPA and SRA are highly specific but laborious requiring selected donor platelets and extended experience. High titer $\operatorname{IgG}$ antibodies correlate with clinical HIT, but ELISA is also time-consuming. The alternative Heparin/PF4-antigen particle gel immunoassay (ID-PaGIA $\mathrm{H} / \mathrm{PF}^{\circledR}{ }^{\circledR}$, DiaMed, Cressier s/Morat, Switzerland) is easy, provides results within one hour and detects mainly $\mathrm{IgG}$, but also IgA/M antibodies. We evaluated specificity and sensitivity of the PaGIA in relation to HIPA and ELISA (PF4-ENHANCED ${ }^{\circledR}$; GTI, Waukesha, WI) in 285 patients (median $71 \mathrm{yrs}$, range $1-97,45 \%$ cardiovascular surgery; $\mathrm{f} / \mathrm{m} \mathrm{56/73}$; and $55 \%$ medi$\mathrm{cal}, \mathrm{f} / \mathrm{m}$ 78/78) with undetermined likelihood for HIT and 89 healthy controls (median 42yrs, range $26-64, \mathrm{f} / \mathrm{m} \mathrm{49/40)}$ to validate it as a rapid assay to exclude HIT. HIPA was positive in $12 \%$ of patients. Based on ROC curves (ELISAs vs. HIPA), OD-cutoff values for the IgG/A/M- and IgG-ELISA were 0.761 and 0.564 , respectively. In controls the OD of IgG-ELISA was $0.066(0.028-0.500)$ and lower than from patients' samples negative by PaGIA and IgG/A/M-ELISA ( $\mathrm{n}=158 ; 0.074 ; 0.009-0.339 ; \mathrm{p}=0.017)$. PaGIA was positive in 70 patients $(25 \%)$. In both patient groups both ELISA ODs were higher if PaGIA and IgG/A/M-ELISA were positive compared to negative PaGIA but positive IgG/A/M-ELISA $(\mathrm{p}<0.001)$. (Data as median; range.) Analyzed by ROC curves (ELISAs vs. HIPA), IgG/A/M-ELISA (OD-cutoff 0.761 ) and IgG-ELISA (OD-cutoff 0.564 ) had sensitivities of $81 \%$ and $86 \%$, and specificities of 75 and $81 \%$. Positive and negative predictive values were 31 and 97\% (IgG/A/M-ELISA) and 39 and 98\% (IgGELISA), respectively. PaGIA, IgG/A/M- and IgG-ELISA were significant predictors for the results of HIPA $(\mathrm{p}<0.001)$ and the IgG-ELISA had the highest explained variance (41\%). Based on our results the PaGIA can serve as a rapid test to exclude HIT since a negative PaGIA is rarely associated with high titer IgG PF4-antibodies or a positive HIPA. In cases of positive PaGIA results and in patients highly suspicious for HIT but with negative PaGIA, alternative anticoagulation should be considered until results from functional testing are available. 
P 9.05

Platelets Express Enhanced CD40L/CD154 in Human

Sepsis - Influence of Pre-Analytic Variation on Membrane-Bound and Soluble CD40L

Wolf Z. ${ }^{1}$, Wittmann S. ${ }^{2}$, Arlt M. ${ }^{2}$, Luchner A. ${ }^{3}$, Mueller T. ${ }^{3}$, Wrede C. ${ }^{4}$, Spanuth E. ${ }^{5}$, Schmitz G. ${ }^{6}$

${ }^{1}$ University of Regensburg, Institute for Clinical Chemistry and Laboratory Medicine, Current address: Dep. of Hemostasis, Hemotherapy and Transfusion Med., Düsseldorf, D, 'Department of Anaesthesiology, University of Regensburg, D, ${ }^{3}$ Department of Internal Medicine II, University of Regensburg, D, ${ }^{4}$ Department of Internal Medicine I, University of Regensburg, Regensburg, D, ${ }^{5}$ Dianeering GmbH, Diagnostic Engineering, Research and Know-How Services, University technology Park, Heidelberg, D, ${ }^{6}$ Institute for Clinical Chemistry and Laboratory Medicine, University of Regensburg, D

Background: Soluble CD40 ligand (sCD40L) has been proposed as a biomarker of cardiovascular events. However, pre-analytical problems on surface expression or shedding of CD40L/CD154 are not completely explored. Therefore, we investigated the effect of pre-analytic variation on CD40L/CD154 measurements. Methods: sCD40L levels were measured by ELISA using 4 different blood samples from healthy donors $(n=20)$, and patients with coronary artery disease $(C A D)(n=40)$ or sepsis $(n=40)$ processed as follows: CTAD platelet poor plasma (PPP) and CTAD at $0{ }^{\circ} \mathrm{C}$, citrate and serum at room temperature (RT). CD40L/CD154 and Pselectin/CD62P expression was assessed ex vivo and after in vitro stimulation by flow cytometry. Results: Serum samples presented significantly higher sCD40L levels than plasma samples $(\mathrm{p}<0.05)$. Elevated sCD40L concentrations in CAD patients were only detectable in sera. Septic patients displayed decreased sCD40L levels $(\mathrm{p}<0.001)$ and increased CD40L/CD154 and $\mathrm{P}$-selectin/CD62P surface expression $(\mathrm{p}<0.05)$, but not CAD patients. Consistent with enhanced platelet activation, a positive correlation between surface expression of CD40L/CD154 and P-selectin/CD62P $(\rho \geq 0.6$, $\mathrm{p}<0.001)$ and an inverse correlation of these receptors and platelet counts was observed $(\rho \geq-0.45, \quad \mathrm{p}<0.001)$. Moreover, altered release of CD40L/CD154 was detected upon in vitro platelet activation in sepsis. Conclusions: Our data demonstrate the influence of sample processing on sCD40L determination and suggest that in vitro platelet activation is reflected in elevated sCD40L concentrations. Furthermore, the results indicate a complex contribution of CD40L/CD154 to inflammatory processes in sepsis.

\section{P 9.06}

Platelet-Free Hemotherapy in Patients with Bernard

Soulier Syndrome: Successful Bleeding Prophylaxis with Recombinant Factor VIla for Dental Extraction

\section{Bomke B. ${ }^{l}$, Swamy K. ${ }^{2}$, Scharf R.E. ${ }^{2}$}

${ }^{1}$ Heinrich Heine University Medical Center, Dept. of Hemostasis, Hemotherapy and Transfusion Medicine, Düsseldorf, D, ${ }^{2}$ Heinrich Heine University Medical Center, Düsseldorf, D

Background: Bernard Soulier syndrome (BSS) is a hereditary platelet function disorder resulting from partial to complete deficiency or dysfunction of the GPIb-IX-V complex. This non-integrin receptor is essential for platelet adhesion onto von Willebrand factor, specifically under high-shear rate conditions. Patients with BSS present with mucocutaneous bleeding and prololonged bleeding time. Laboratory features also include giant platelets and thrombocytopenia of varying degree. Standard hemotherapy of bleeding episodes or prophylaxis for prevention of hemorrhages during surgical procedures comprises platelet transfusions. However, this treatment can be complicated by antibody formation to the GPIb-IX-V complex and/or alloimmunization by HLA, thus, limiting the responsiveness to future platelet transfusions. We have therefore evaluated the efficacy and safety of recombinant factor VIIa (rFVIIa, NovoSeven) as first-line therapy in patients with BSS. Patients, Therapy Protocol and Outcome: Six patients (2 males, 4 females, age ranging from 14 to 34 yrs) with prediagnosed BSS were included. Two of them have had platelet transfusions. The patients were now refered for hemotherapy prior to dental surgery. All of them presented without manifest mucutaneous bleedings but had abnormal closure times $(>300$ $\mathrm{sec}$ ), as determined by the platelet function analyzer (PFA-100) in response to collagen/epinephrine and collagen/ADP, corresponding to their congenital platelet defect. The therapy protocol included a bolus of rFVIIa $(110 \mu \mathrm{g} / \mathrm{kg})$ administered $15 \mathrm{~min}$ prior to surgery, followed by two doses of $90 \mu \mathrm{g} / \mathrm{kg}$ at $120 \mathrm{~min}$ intervals postoperatively. During the first 3 days after surgery, rFVIIa $(90 \mu \mathrm{g} / \mathrm{kg})$ was administered every $8 \mathrm{hrs}(2$ patients $)$ or every $12 \mathrm{hrs}$ (4 patients). Tranexamic acid (Cyklokapron $3 \times 1 \mathrm{~g}$ per day) was started postoperatively and continued for 10 days in all 6 patients. None of them experienced any intra- or postoperative bleeding episodes. By contrast, hemostasis and wound healing were near-normal. No platelet transfusions were required in any of the six patients. Conclusion: Perioperative administration of high-dose rFVIIa in combination with antifibrinolytics such as tranexamic acids can be indeed an effective and safe therapeutic alternative for prophylaxis of bleeding episodes in patients with BSS undergoing dental surgery. Although, this is an off-label use at present, administration of rFIIa should be considered instead of platelet transfusions, specifically in young patients with congenital platelet disorders in order to prevent alloimmunisation and the risk of refractoriness to future platelet transfusions whenever required.

\section{P 9.07}

Combined Analysis in Combined FV and FVIII Deficiency: Novel and Recurrent Mutations and the Ethnical Background of 8 Patients

Sittinger $K^{\prime}{ }^{1}$, Klarmann $D_{.}{ }^{2}$, Eisert $R^{3}{ }^{3}$, Zieger $B .{ }^{4}$, Kappert G. ${ }^{5}$, Klamroth R. ${ }^{6}$, Kadar J.G. , Laws H.J. ${ }^{8}$, Seifried E. ${ }^{2}$, Oldenburg J. ${ }^{9}$, Geisen C. $^{2}$

${ }^{1}$ DRK Blood Donor Service, Institute of Transfusion Medicine and Immunohaematology, Frankfurt/Main, D, ${ }^{2}$ Frankfurt/Main, D, ${ }^{3}$ Hannover, D, ${ }^{4}$ Freiburg, D, ${ }^{5}$ Duisburg, D, ${ }^{6}$ Berlin, D, ${ }^{7}$ Köln, D, ${ }^{8}$ Düsseldorf, D, ${ }^{9}$ Bonn, D

Objectives: Combined factor $\mathrm{V}$ and factor VIII deficiency (F5F8D) is caused by mutations in LMAN1 or MCFD2. To date, a total of 42 different mutations in either of the two genes in about 26 different countries are known. Here we describe the first patient from Azerbaijan with a novel frame shift mutation and seven additional families. Methods: F5F8D patients were analysed by direct sequencing of the corresponding genes on an automated sequencing system (ABI Prism 3100). In four Turkish patients sequencing of Exon 3 of the MCFD2 gene was done initially since in Turkish F5F8D families only MCFD2 mutations in Exon 3 and its donor splice site are known. From the two known mutations just the exonic frame shift mutation 249delT was exclusively found in Turkish ethnicity and could also be proven in Patient A-D with factor V and factor VIII levels about $10 \%$. As Patient E (FV 27\%, FVIII 38\%) appeared normal the remaining coding regions and splice sites were analysed. Then genetic testing revealed the stop mutation Lys302X in Exon 8 of the LMAN1 gene previously described in one family with French and five patients with Pakistani origin. The variety of Iranian mutations includes rare variations but also a common mutation of Middle Eastern Jews in Exon 1 of the LMAN1 gene (89-90insG). However the most frequent mutation in Iranian ethnicity is a splice site mutation in the LMAN1 gene at the last nucleotide of Exon 7 (IVS7 DS-1G $>$ A) that could also be detected in the Iranian female Patient F (FV 9\%, FVIII 12) by analysis of Exon 7 of the LMAN1 gene. In Poland only the frame shift mutation 841 delA in Exon 8 of the LMAN1 gene was recently identified in one family. Thus, screening of Exon 8 of the LMAN1 gene in the Polish Patient G (FV 23\%, FVIII 57\%) showed the same mutation. Since Patient H (FV 10\%, FVIII 17\%) represents the first Azerbaijanian F5F8D patient we started screening for mutations originating from Turkey, Iran and Armenia because of the close vicinity to Azerbaijan. Neither the Armenian mutation 1524delA in Exon 13 of the LMAN1 gene nor another known mutation was found. Finally complete sequencing revealed the novel frame shift mutation Cys230fs in Exon 6 of the LMAN1 gene. Conclusions: The data suggest apparent correlation between determined mutations and the patients' descent. Founder mutations in the LMAN1 and MCFD2 gene may lead to repeated occurrence of F5F8D in different countries. Thus, molecular diagnosis in F5F8D is facilitated by a screening strategy based on patients' ethnicity may simplify molecular diagnosis of F5F8D.

\section{P 9.08 \\ Correlation of Platelet RNA Profiles and Platelet Aggregation Response to Arachidonic Acid in Patients with Aspirin-Like Defect}

\section{Bugert P. ${ }^{l}$, Schedel A. ${ }^{1}$, Rolf N. ${ }^{2}$, Knöfler R. ${ }^{2}$, Suttorp M. ${ }^{2}$, Klüter $H^{l}{ }^{l}$}

${ }^{1}$ Institute of Transfusion Medicine and Immunology, Mannheim, D, ${ }^{2}$ University Children's Hospital, Dresden, D

Objective: The Aspirin-like defect (ALD) is an autosomal dominant inherited platelet disorder associated with mild bleeding symptoms and deminished platelet aggregation response (PAR) to arachidonic acid (AA) very similar to Aspirin effects. The AA pathway was supposed to be involved in ALD pathogenesis. Here, we investigated platelet RNA profiles in ALD patients and controls. RNA signals were correlated with the degree of PAR to AA. Methods: Platelets were isolated from citrated blood of 21 
ALD patients and 16 healthy relatives from 11 families. Platelet RNA was processed to Cy3- or Cy5-labelled cRNA, and hybridized to whole genome microarrays (Agilent Technologies). PAR to AA was determined by light transmission using APACT-4-A aggregometer. Pearson correlation analysis was performed with the use of the SPSS software package. Results: Expression analysis of more than 34,000 human genes in 21 ALD patients and 16 controls revealed 6,753 positive genes $(19.8 \%)$. ALD patients showed significantly lower PAR to AA (mean \pm SD: $16.7 \pm 12.8 \%$; range: $0-39 \%$ ) than controls $(69.4 \pm 5.9 \% ; 60-80 \%)$. Correlation analysis of RNA signals with PAR values in all individuals showed only moderate positive correlation for 248 genes and moderate negative correlation for 158 genes. Further correlation analysis was performed in 11 ALD patients (PAR $<10 \%$; AA nonresponders) and 11 controls (PAR $>65 \%$; AA responders). Thereby, strong positive correlation $(r>0.6)$ was identified for 5 genes, including thromboxane A2 receptor (TBXA2R) and arachidonate 5-lipoxygenase (ALOX5) Conclusions: Patients with ALD revealed significantly lower PAR to AA compared to healthy controls. AA non-responders showed significantly lower RNA signals of TBXA2R and ALOX5 both involved in AA metabolism. Further investigations at the protein level are performed to characterize the role of TBXA2R and ALOX5 in the pathomechanisms of ALD.

\section{P 9.09}

\section{Modification of the Factor IX Gla-Domain as a Strategy to Improve Hemophilia B Therapy}

\section{Schüttrumpf J. ${ }^{1}$, Milanov $P .{ }^{2}$, Seifried $E .{ }^{2}$, Tonn $T .{ }^{2}$}

${ }^{1}$ DRK-Blutspendedienst Baden-Württemberg - Hessen gGmbH, Institut für Transfusionsmedizin und Immunhämatologie, Frankfurt/Main, D, ${ }^{2} \mathrm{DRK}-$ Blutspendedienst Baden-Württemberg - Hessen gGmbH, Frankfurt/Main, D

Introduction: Engineering of coagulation factors could be an attractive strategy to improve therapeutic proteins, such as factor IX (FIX) in hemophilia B. The Gla-domain mediates membrane binding of FIX and of other vitamin $\mathrm{K}$ dependent coagulation proteases and therefore provides an interesting target for protein modification. Substitution of several amino acids in the Gla-domains of protein C or of factor VII have been reported to result in proteins with 20 - to $>150$-fold higher activity, respectively. In previous work, we introduced the mutations $\mathrm{K} 5 \mathrm{~A}$ and $\mathrm{V} 10 \mathrm{~K}$ into the Gla-domain of FIX to abolish collagen IV binding. The proteins resulted fully functional and led to an improved secretion following intramuscular gene transfer. Methods: In order to generate FIX with higher specific activity, we exchanged residues in the Gla-domain of FIX with corresponding amino acids from other vitamin $\mathrm{K}$ dependent coagulation proteases with reported higher affinity to phospholipid membranes than FIX. Mutations were introduced into a FIX expression cassette using site directed mutagenesis. Then, HEK293 cells were transfected with the expression plasmid and protein antigen levels and activity were measured in the supernatant of transfected cells. All experiments were performed in triplicates and at least repeated ones. Supernatants of non-transduced cells, or of wild-type FIX and of a FIX without protein activity (S365R) were used as controls. Results: In our study, we included 7 different amino acid substitutions (Y1A, G4Y, V10K, F25Y, N34D, N35D, and R37T). Most of the substitutions resulted in FIX variants with decreased protein activity and none of the single substitutions resulted in a variant with significantly increased activity in our assay system. Since above-mentioned higher activities of protein $\mathrm{C}$ and factor VII were only observed after combining the effect of several amino acid substitutions, we also combined amino acid substitutions in FIX with preference to substitutions which did not detrimentally decrease protein activity. Only one of this combination (Y1A G4Y) could at least retain a similar activity (102 $\pm 13 \%)$ compared to wild type FIX $(100 \pm 20 \%)$. Conclusion: In the present study, we could not generate a FIX protein with increased specific activity by modification of the Gla-domain. However, the Gla-domain migh still provide an interesting target for strategies to improve protein secretion and release on the cellular or on the supra-cellular level as desired for protein production or following gene transfer.

\section{P 9.10 \\ Comparison of Vitamin K1 and K2 Kinetics of Vitamin K epoxide reductase $\mathrm{C} 1$}

Marinova M. ${ }^{1}$, Westhofen $P^{2}{ }^{2}$, Watzka M. ${ }^{2}$, Hass $M .{ }^{2}$, Müller-Reible C. ${ }^{3}$, Lütjohann $D .^{4}$, Oldenburg J. ${ }^{2}$

${ }^{1}$ Uniklinik Bonn, Inst. f. Exp. Hämatologie und Transfusionsmedizin, Bonn, D, ${ }^{2}$ Inst. f. Exp. Hämatologie und Transfusionsmedizin, Bonn, D, ${ }^{3}$ Institute of Human Genetics, Würzburg, D, ${ }^{4}$ Inst. f. klinische Chemie u. Pharmakologie, Bonn, D

Objectives: Vitamin $\mathrm{K}$ is a co-factor of $\gamma$-carboxylase, an enzyme responsible for functional active blood coagulation factors. Carboxylation requires hydroquinone and results in its conversion to vitamin $\mathrm{K}$ epoxide. The vitamin $\mathrm{K}$ epoxide is recycled to vitamin $\mathrm{K}$ before it can be reutilised. This reaction is catalyzed by the enzyme vitamin $\mathrm{K}$ epoxide reductase (VKORC1). Here we present comparative data for VKORC1 kinetics using both substrates - vitamin K1 and vitamin K2 epoxide. Design and Methods: Gas-liquid chromatography - mass spectrometry analysis was done to confirm the identity of vitamin K1, vitamin K2 and their epoxides. Gas-liquid chromatography - flame ionization detection was used for quantification of vitamin $\mathrm{K} 1$ and $\mathrm{K} 2$ epoxides. The enzymatic activity of VKORC1 was measured by estimation of vitamin $\mathrm{K} 1$ and vitamin $\mathrm{K} 2$ quinone production from HEK transfected cells. Substrates and products were separated on HPLC-RPC18 and detected by DAD at $254 \mathrm{~nm}$. The apparent kinetic constants $\mathrm{Km}$ and Vmax were calculated. Results: VKORC1 velocity followed the Michaelis-Menten equation. Differences were observed comparing $\mathrm{Km}$ and Vmax for the both substrates. Km-values of 4.1601 and $1.7695 \mu \mathrm{M}$ were received for vitamin K1 and vitamin K2, respectively. Vitamin K2 has a 2.4fold lower $\mathrm{Km}$ so that the binding affinity of vitamin $\mathrm{K} 2$ epoxide to VKORC1 appears to be higher. Vitamin K1 epoxide seems to bind in a weaker manner to the enzyme. Differences were also identified when comparing the Vmax - values: $2.0825 \mathrm{nmol} \mathrm{x} \mathrm{mg-1 \times h-1} \mathrm{for} \mathrm{vitamin} \mathrm{K} 1$ and $2.5549 \mathrm{nmol} \times \mathrm{mg}-1 \times \mathrm{h}-1$ for vitamin $\mathrm{K} 2$. A slightly (1.2-fold) faster generation of $\mathrm{K} 2$ was observed compared with the formation of vitamin $\mathrm{K} 1$. Conclusions: The apparent VKORC1 kinetic constants for the reduction of vitamin $\mathrm{K}$ epoxide indicated a 2.4 -fold higher binding affinity to $\mathrm{K} 2$ epoxide and a 1.2-fold faster formation of $\mathrm{K} 2$.

\section{P 9.11 \\ Evaluation of Prospective Criteria for the Clinical Assessment of Efficacy and Safety of DDAVP (MINIRIN parenteral)}

Miesbach $W .{ }^{I}$, Dück $0 .{ }^{2}$, Schüttrumpf J. ${ }^{2}$, Alesci S. ${ }^{2}$, Großmann $R^{2}{ }^{2}$

${ }^{1}$ University Hospital Frankfurt, Medical Clinic III/Institute of Transfusion Medicine, Frankfurt/Main, D, ${ }^{2}$ Frankfurt/Main, D

Introduction: Although the prescribing description for DDAVP (Minirin parenteral) lists all known side effects, the extent and incidence of side effects that occur during administration of DDAVP in patients with coagulation disorders seem to be not that comprehensively defined. The ultimate goal of this prospective study therefore is to explore - prior to and after the administration of a DDAVP infusion - suitable prospective markers, which should help to identify patients with a high probability for experiencing side effects. We currently plan to enrol up to 100 patients into this study. Material and Methods: Prior to and three days after a standardised infusion of DDAVP $(0.3 \mu \mathrm{g} / \mathrm{kg} /$ body weight in $100 \mathrm{ml}$ physiological saline $)$, beside the patient history and the examination, the following laboratory investigations will be performed: general coagulation parameters (PT, aPTT, INR), blood count, multiple serum analysis, von Willebrand analysis (ristocetin cofactor, vWF-Antigen, FVIII-activity) and osmalality of urine. The results will be analysed dependent on the dosage of DDAVP, the amount of fluid intake and the respective underlying disease of the patient. Results: Up to now we were able to include 19 patients into this study (female: $68 \%$, male: $32 \%$, median age: 32.5 years, range: $19-54$ years). Patients presenting with potential contraindications for DDAVP were not enrolled into this study. Only 4 patients $(21 \%)$ reported no side effects, the resulting patients suffered from headaches presenting with a 'pressure-like sensation' $(47 \%)$ or regular headaches $(40 \%)$, fatigue $(33 \%)$, low blood pressure with vertigo $(27 \%)$, erythema (20\%), 'body heat' $(13 \%)$, nausea $(13 \%)$, increase of weight $(13 \%)$ and numbness of the extremities (13\%). One patient each complained about an intermittent pre-syncopal status and systremma. Three patients $(20 \%)$ did experience these symptoms for the period of up to three days after the DDAVP infusion. We did not find a correlation to changes of laboratory parameters nor were we able to identify a specific laboratory reaction towards the DDAVP infusion. Quite too often patients with side effects reported on stress, either due to a problematic state in their private- or business 
life. Seventeen percent (17\%) of the patients declined further DDAVPadministrations due to side effects. Summary: Seventy-nine (79\%) percent of the patients presented with side effects after administration of DDVAP. A correlation towards potential clinical- or laboratory parameters was not identified.

\section{P 9.12 \\ Molecular Genetic Analysis in Patients with Inherited Factor V Deficiency}

Delev D. ${ }^{1}$, Pavlova A. ${ }^{2}$, Junen $\mathrm{J}^{2}$, Schmitt . $^{2}$, Seifried $\mathrm{E}^{3}$, Oldenburg J.

${ }^{1}$ Institut für Experimentelle Hämatologie und Transfusionsmedizin, Universitätsklinik Bonn, Haemostaseologie, Bonn, D, ${ }^{2}$ Institut für Experimentelle Hämatologie und Transfusionsmedizin, Universitätsklinik Bonn, D, ${ }^{3}$ Institute of Transfusion Medicine and Immunohaematology, DRK Blood Donor Service Baden-Württemberg-Hessen, Frankfurt/Main, D

Background: Coagulation factor V (FV) plays an important role in maintaining the hemostatic balance. The gene for F5 is located on chromosome 1q24.2 and consists of 25 exons encoding a 28 amino acids leader peptide and a 2196 amino acids mature protein. FV deficiency represents a rare autosomal recessive bleeding disorder with variable phenotypic expression. Little is known about the molecular basis underlying this disease. In our study we report 35 patients with FV deficiency, due to different types of genetic alterations. Methods and Materials: Automated direct DNA sequence analyses were performed on the 25 exons and intron/exon boundaries for mutation identification. Results and Discussion: In our study we investigated 35 patients with FV deficiency. In 32 cases we identified 35 genetic alterations. In the remaining 3 patients no mutation was found. Nine of the mutations were previously reported in the F5 database and 20 were novel Six led to premature termination codons, because of nonsense or frameschif mutations. Fourteen patients exhibited missense mutations. This mutation profile corresponds well with data published in the F5 database. The FV activity values, matched with the genetic alterations found in these patients. In three patients with no detected mutation, large deletions or mutations in MCFD/LMAN1 could be considered as possible explanation. Conclusion: Our data substantially contributes to the knowledge the FV mutational spectrum. Identifying the molecular basis of mutations underlying this rare coagulation disorder will help to obtain more insight into the mechanisms involved in the variable clinical phenotype of patients with FV deficiency.

\section{P 9.13}

\section{Role of Microparticles in Thrombin Generation in Patients at Risk for Atherothrombosis}

Wagner L. ${ }^{1}$, Kaufmann V. ${ }^{2}$, Mager J. ${ }^{2}$, Graf M. ${ }^{2}$, Geiter S. ${ }^{2}$, Vetr $\mathrm{H}^{2}$, Lämmle B. ${ }^{3}$, Redondo M. ${ }^{4}$, Binder . $^{5}$

${ }^{1}$ Technoclone Deutschland $\mathrm{GmbH}$, Heidelberg, D, ${ }^{2} T e c h n o c l o n e ~ G m b H$, Wien, A, ${ }^{3}$ Inselspital Bern, $\mathrm{CH},{ }^{4}$ Kantonsspital Luzern, $\mathrm{CH},{ }^{5}$ Medizinische Universität, Wien, A

We have shown recently (Hron et al. JAMA 2006) that measuring thrombin generation can identify patients at low risk for recurrent venous thromboembolism and that peak thrombin is a suitable parameter to differentiate low risk from high risk patients. In this study we used the same assay (Technothrombin $^{\circledR}$ TGA) to analyze patients at high risk of atherothrombosis (a swiss study of patients with a history of myocardial infarction). Moreover, we investigated the influence of microparticles on thrombin generation in these patients. Thrombin generation was measured using Technothrom bin ${ }^{\circledR}$ TGA. The reagent used contained low levels of phospholipid and $5 \mathrm{pM}$ tissue factor. Platelet poor plasma from 178 patients $(n=178$, age $=55 \pm 8$ ys, male/female $=157 / 21$ ) who had a previous myocardial infarction and 79 normal age and sex matched controls. $(n=79$, age $=55 \pm 8$ ys, male/female $=$ 70/9) was analyzed. Microparticle-free plasma was generated from PPP plasma by filtration through a membrane $(0.2 \mu \mathrm{m}$ pore size $)$ using a standardized filtration device (Ceveron ${ }^{\circledR}$ MFU 500, Technoclone). In the contro group the mean value for peak thrombin in platelet poor plasma was $252 \pm 7.7$ $\mathrm{nM}(\operatorname{mean} \pm \mathrm{SD})$. A significantly higher $(\mathrm{p}<0.05)$ peak thrombin was found in the group of patients $(355 \pm 49 \mathrm{nM})$ when patients without medication were analyzed. In patients on aspirin $(n=109)$ the peak thrombin was not significantly different from untreated patients $(297 \pm 10 \mathrm{nM})$ while in patients on oral anticoagulation $(n=34)$ peak thrombin was significantly lower $(225 \pm 27$ $\mathrm{nM}$ ). In the group of patients on oral anticoagulation also the lag period was significantly longer as compared to controls or patients without medication (21.9 \pm 2 minutes versus $14.8 \pm 0.2$ minutes) whereas aspirin treatment did not affect the lag period significantly. After removing microparticles from the samples, the peak thrombin values between patient and control group were no longer significantly different. The difference between microparticle free plasma and platelet poor plasma was significantly higher $(\mathrm{p}<0.05)$ in the patient groups without therapy $(304 \pm 39 \mathrm{nM})$ and in patients on Aspirin therapy $(257 \pm 23 \mathrm{nM})$ as compared to the normal controls $(182.6 \pm 10.4 \mathrm{nM})$. These data indicate that thrombin generation is significantly increased in patients with previous myocardial infarction and that this increased thrombin generation is likely due to microparticles contained in these samples.

\section{P 9.14}

\section{Incidence and Laboratory Detection of Resistance to Antiplatelet Drugs in a Selected Population of Patients with Arterial Disease}

\author{
Swamy K., Kirchhoff E.M., Hoffmann T., Scharf R.E. \\ Heinrich Heine University Medical Center, Dept. of Hemostasis, \\ Hemotherapy and Transfusion Medicine, Düsseldorf, D
}

Background: Evidence of 'resistance to antiplatelet drugs', defined by failure of the agent to hit its pharmacological target, requires specific laboratory testing. True resistance to acetylsalicylic acid (ASA), documented by absent inhibition of cyclooxygenase (COX-1) and determined by serum thromboxane B2 (TXB2) levels, appears to be rare (1-2\%). In contrast to ASA, studies to measure pharmacological effects of clopidogrel reveal a broad variability of results, with a significant proportion of subjects (15$30 \%$ ), who are 'poor responders'. Design and Methods: To evaluate the rate of subjects who have (i) a true resistance to ASA and clopidogrel or (ii) a 'high residual platelet reactivity' while on treatment with ASA, clopidogrel, or both, we have performed a retrospective analysis of 135 orders from 99 consecutive patients whose blood samples were sent between January 2007 through March 2008 to our laboratory for testing under the clinical question 'resistance to antiplatelet drugs'. Pharmacological effects on platelet function were determined by aggregometry in response to epinephrine $(5 \mu \mathrm{M})$, ADP $(5 \mu \mathrm{M})$, collagen $(0.6$ and $2 \mu \mathrm{g} / \mathrm{ml})$, arachidonic acid $(1 \mathrm{mM})$, by TXB2 levels, and flow cytometric analysis of phosphorylation of the vasodilatorstimulated phosphoprotein (VASP). The results were classified according to the presence or absence of pharmacological effects, i.e. (i) 'resistance', (ii) 'poor response' including 'high residual platelet reactivity', and (iii) 'response', i.e. pharmacological inhibition. Results: The blood samples analyzed originated from 66 males and 33 females (patients' mean age $62+15$ yrs) treated with ASA $(n=12)$, clopidogrel $(n=15)$, or both $(n=72)$ for secondary prophylaxis of coronary artery or cerebrovascular disease. Of the 12 patients only on ASA, all were responders, as confirmed by complete inhibition of COX-1. Of the 15 patients only on clopidogrel, 7 showed pharmacological inhibition, whereas 8 were poor responders. Of the 72 patients on combined treatment, 19 were responders $(26 \%), 50$ poor responders $(69 \%)$ and 3 nonresponders $(4.2 \%)$ with true resistance to both agents. Among the 50 poor responders to both, ASA and clopidogrel, 21 had 'high residual platelet reactivity' $(42 \%)$. Conclusion: This retrospective study confirms that 'true resistance' to antiplatelet drugs is rather rare. The number of subjects on combined therapy with ASA and clopidogrel was overrepresented in this highly selected patient population, indicative of a subgroup at risk, obviously requiring a more intense antiplatelet treatment. Interestingly, among those, the number of poor responders was unusually high with a significant proportion of patients revealing 'high residual platelet reactivity'. To explore the nature of this phenomenon will be a challenge for future studies.

\section{P 9.15}

\section{Plasmaexchange in Thrombotic Microangiopathy}

Yürek S., Kiesewetter $H$.

Charité-Universitätsmedizin Berlin, Institut für Transfusionsmedizin, Campus Virchow Klinikum, Berlin, D

Introduction: The most prominent diseases associated with thrombotic microangiopathy are the thrombotic thrombocytopenic purpura (TTP) and the haemolytic uremic synrome (HUS). These diseases are characterized by thrombocytopenia and haemolytic anemia in the presence of thrombi in the microcirculation. The most effective treatment for TTP is plasma exchange (PE) with either fresh-frozen plasma (FFP) or SD-plasma. In our university hospital FFP and SD-plasma were used for PE in patients with TTP and HUS. In this retrospective study we compared the outcome regarding to the used exchange fluid. Results: A total of 89 patients with TTP $(n=57)$ or HUS $(n=32)$ were treated at the university hospital Charité-University Medicine Berlin between Jan 2005 and May 2007. During this time, PE was carried out on 27 patients ( 26 adults, one child). The mean age of these 27 patients was 47 years (6-80). Response was defined by a platelet count of more than $150 \times 109 / 1$ for at least 2 days. For the daily PE-treatment $40 \mathrm{ml} / \mathrm{kg}$ of body weight were used. 8 patients each received either FFP or SD-plasma, 11 patients received both. The overall mortality was $15 \%(4 / 27)$. In the 
surviving patients the average platelet count increased from $56.6( \pm 50.3)$ to $232.7( \pm 110) .8 / 27$ patients, who were refractory to PE or in relapse were treated additionally with vincristine or (in one case) with rituximab. Patients who exclusively received SD-plasma $(0 / 8)$ showed no allergic reactions, whereas a higher number of allergic reactions (4/8) occurred after using FFP for PE. Furthermore, the number of patients under complete remission was higher in the SD-plasma group (5/8) than in the FFP group (1/8). In contrast, the number of refractory patients was lower in the SD-plasma group (1/8) compared to the FFP group (6/8). Conclusion: Patients with TTP and HUS were successfully treated with PE. The use of SD-plasma seemed to be more tolerable than FFP due to the reduced number of allergic reactions. The number of patients under complete remission was also observed to be higher in the SD-plasma group. However, due to the small number of patients, further studies are required to confirm these results.

\section{P 9.16}

\section{Antioxidant Properties of VKORC1L1}

\section{Westhofen ${ }^{2}{ }^{1}$, Watzka M. ${ }^{2}$, Marinova M. ${ }^{2}$, Hass $M{ }^{2}$} Oldenburg $\mathrm{J}^{2}$

${ }^{1}$ Uniklinik Bonn, Inst. f. Exp. Hämatologie und Transfusionsmedizin, Bonn, D, ${ }^{2}$ Inst. f. Exp. Hämatologie und Transfusionsmedizin, Bonn, D

Objectives: Combined vitamin-K-dependent clotting factors deficiency (VKCFD2) is caused by allelic mutations in VKORC1. The biological function of VKORC1L1, the isozyme of VKORC1, is unknown. It cannot substitute defect VKORC1 in VKCFD2 despite its ability to reduce vitamin $\mathrm{K}$ epoxide to vitamin $\mathrm{K}$ quinone. VKORCL1 is not able to provide gCarboxylase with vitamin $\mathrm{K}$ hydroquinone, necessary for g-carboxylation of vitamin $\mathrm{K}$ dependent coagulation factors. Starting from the neuroprotective properties of vitamin $\mathrm{K}$, we investigated a possible role of VKORC1L1 in antioxidation. Design and Methods: VKORC1L1 was over expressed by plasmid transfection and silenced by siRNA in HEK cells. Antioxidan activity of VKORC1L1 was determined by CellTiter96 ${ }^{\circledR}$ Non-Radioactive Cell Proliferation Assay (Promega), based on the conversion of a tetrazolium salt into formazan. The photometric detection of the coloured product at 490 $\mathrm{nm}$ showed a linear relationship between the number of viable cells and colour formation. Viability of HEK cells was measured after treatment with hydrogen peroxid $(0-50 \mu \mathrm{M})$ for 18 hours. Results: Examination of the cell viability under various stress conditions with oxidative agents showed in creased resistance of the VKORC1L1 transfected HEK cells. The number of viable cells was 15 to $20 \%$ higher compared to non-transfected cells. Silencing the VKORC1L1 gene by siRNA transfection results in higher sensitivity towards oxidative stress and a reduced viability. Conclusion: Overexpression of VKORC1L1 in vitro shows a significant cytoprotective effect upon exposure to oxidative stress conditions, whereas VKORC1L1 knock down results increased sensitivity.

\section{P 9.17}

\section{Muscular Compartment Syndrome in Hemophilia A Inhibitor Patients}

Goldmann G. ${ }^{1}$, Horneff S. ${ }^{1}$, Berdel P. ${ }^{2}$, Wirtz $D .{ }^{2}$, Oldenburg J. ${ }^{2}$ ${ }^{1}$ Universitätsklinikum Bonn, Institut für experimentelle Hämatologie und Transfusionsmedizin, Bonn, D, ${ }^{2}$ Bonn, D

Objectives: Inhibitor development (against factor VIII or IX) is a severe complication of haemophilia treatment leading to life threatening bleedings. Compartment syndrome is a complication of musculoskeletal bleeding. Especially in the forearm, bleeds can cause large increases in tissue pressure in closed compartments leading to alteration of microcirculation and neuromuscular function, thus necessitating acute surgical treatment. Results: We report on 3 inhibitor haemophilia A patients with compartment syndrome of the forearm. Patient 1 , age $81 \mathrm{y}$, spontaneously developed a painful swelling of the left forearm and a compartment syndrome despite of FEIBA substitution. Before referring the patient to our institution, an incision was done, but persistent bleeding resulted in a decrease of haemoglobin from 16.2 to 10.2 $\mathrm{g} / \mathrm{dl}$ and a deterioration of neurological symptoms. A second incision was done in our orthopaedic department while 4000 IE FEIBA were substituted every 6 hours. There was no postoperative bleeding and the intramuscular haematoma resolved. Patient 2, age $6 \mathrm{y}$, had a fracture of the forearm. He was operated with a FEIBA substitution regimen. Postoperatively, he developed severe compartment syndrome of the left forearm with necrosis and was referred to our centre. Repeated operation was done with factor VIIa 240 KIE every two hours initially, because of persistent bleeding factor 8 was added. Thereafter bleeding was controlled and haematoma resolved. Patien 3 , age $22 \mathrm{y}$, had a diffuse muscle bleeding and developed a compartment syndrome of the left forearm. He still had an altered recovery of factor VIII and was therefore treated with high dosage of factor VIII. Incision was done at our orthopaedic centre without complications. All three patients had secondary wound heeling with a temporary artificial skin substitute. Conclusion: Compartment syndrome represents a severe complication of forearm bleeding in inhibitor patients. Interdisciplinary management in specialized centers experienced in controlling bleeds with FEIBA and $\mathrm{rF}$.

\section{P 9.18 \\ Evaluation of a Method for Removal and Determination of Thrombogenic Microparticles}

Wagner L. ${ }^{1}$, Vetr ${ }^{2}{ }^{2}$, Geiter S. ${ }^{2}$, Graf M. ${ }^{2}$, Kaufmann V. $^{2}$, Mager J. ${ }^{2}$, Oberreither M. ${ }^{2}$, Perkmann $T^{3}{ }^{3}$, Binder $C{ }^{3}$, Binder $B .{ }^{4}$

${ }^{1}$ Technoclone Deutschland $\mathrm{GmbH}$, Heidelberg, D, ${ }^{2}$ Technoclone $\mathrm{GmbH}$, Wien, $\mathrm{A},{ }^{3}$ CeMM, Wien, $\mathrm{A},{ }^{4}$ Medizinische Universität, Wien, A

Aims: Circulating cell-derived microparticles play a major role in thrombotic diseases. Currently available methods to analyse microparticles are not easy to standardize, need specialized technical equipment or detect only a subpopulation of microparticles. Here a new method for quantification of circulating thrombogenic microparticles is evaluated (Technothrombin ${ }^{\circledR} \mathrm{MP}$ Microparticle and Ceveron ${ }^{\circledR}$ MFU-500). Methods: The principle of this method is based on the differences in thrombin generation between plateletpoor-plasma (PPP) and microparticle-free-plasma (MPFP) obtained by filtration through a $200 \mathrm{~nm}$ filter using a filtration device (Ceveron ${ }^{\circledR}$ MFU500, Technoclone). PPP was prepared by centrifugation for $15 \mathrm{~min}$ at 2,500 xg. MPFP was generated by filtration (Ceveron ${ }^{B}$ MFU-500; $0.2 \mu \mathrm{m}$ low protein binding membrane) or by high speed centrifugation $(15,000 \mathrm{xg}$ for 30min). PPP and MPFP samples were analysed for thrombin generation using the Technothrombin ${ }^{\circledR}$ TGA method. For calibration, dilutions of purified MP from red blood cells were prepared in MPFP and thrombin generation was measured. Recovery of MP from the filter membrane was performed by rinsing the membrane with an equal volume of standard MPFP. In addition, filtered and non-filtered samples were analyzed in standard coagulation assays (PT, aPTT, Fibrinogen, FVIII-activity, Lupus-assay). Results: Peak thrombin from centrifuged $(57 \mathrm{nM} \pm 8)$ or filtered samples $(79 \mathrm{nM} \pm 11)$ was not significantly different $(p=0.14)$ but was significantly lower $(p<0.05)$ than that from PPP $(171 \mathrm{nM} \pm 21)$ indicating that MP have a significant effect on thrombin generation and that centrifugation and filtration are equally effective in removing microparticles. The analysis of purified MP diluted in MP free plasma showed that the difference in peak thrombin before and after filtration correlated to the number of microparticles and thus a calibration curve could be established. Significant differences between PPP and MPFP were found for aPTT tests only in one of three reagents tested (PPP $36.0 \mathrm{sec}$ \pm 3.5 , MPFP $38.2 \mathrm{sec} \pm 3.4, \mathrm{p}<0.05)$. The Lupus LCA Index for MPFP $(34.8 \pm 6)$ was significantly lower than in PPP $(47.4 \pm 7 ; \mathrm{p}<0.05)$. For the other coagulation parameters tested no significant difference was found. Conclusions: All these results show that circulating microparticles are a major determinant for thrombin generation and that thrombogenic microparticles can easily and quantitatively be analyzed from the difference in thrombin generation between PPP and MPFP obtained by filtration through Ceveron ${ }^{\circledR}$ MFU-500. It is shown that microparticles have a significant effect on thrombin generation and on some standard clotting assays.

\section{P 10 Vascular Biology \\ P 10.01 \\ Platelet Interaction with Immobilized Fibrinogen under Arterial and Venous Flow Conditions Is not Different between Men and Women}

Stoldt V.R.

Heinrich Heine University Medical Center, Dept. of Hemostasis, Hemotherapy and Transfusion Medicine and Biological Medical Research Center, Düsseldorf, D

Background: Gender-related differences in the incidence of arterial thrombosis have been a focus for many years. In this study, we have evaluated platelet adhesion onto immobilized fibrinogen under various flow conditions in men and women, using an in vitro system that simulates normal and abnormal shear rates present in venes and arterioles. Design and Methods: Platelets in whole blood anticoagulated with PPACK were labeled with the fluorescent dye mepacrine and perfused through a rectangular flow chamber over cover slips coated with fibrinogen. Shear rates of 50, 500, and $1500 \mathrm{sec}-$ 1 were applied. Visualization and quantification of adherent platelets at 15 sec, 1 and 5 min (after start of perfusion) was achieved by laser-scanning microscopy and imaging software (ImageJ). Blood from 28 age- and sexmatched healthy individuals ( 14 men, 14 women, mean age $44+/-12 \mathrm{yrs}$ ) was examined. Results: During perfusion, platelet adhesion linearly increased with regard to exposition time and shear rate. After 5 min of perfu- 
sion, the platelet adhesion rate showed no significant geneder-related difference, neither at $50 \mathrm{sec}-1$ nor at 500 or $1500 \mathrm{sec}-1$ ( $\mathrm{p}>0.05)$, respectively. The same was true for relative adhesion, defined by the ratio of absolute adhesion after $1 \mathrm{~min}$ and at $15 \mathrm{sec}$ after start of perfusion. At low shear $(50 \mathrm{sec}-1)$ relative adhesion was $4.72+/-2.05$ in men and $3.02+/-2.15$ in women, at high shear (1500 sec-1) corresponding data were 5.39+/-2.40 and 4.56+/-1.44 (p each $>0.05)$. Among the female volunteers, no significant difference was observed either with regard to the menopausal status $(\mathrm{p}>0.05)$. Conclusion: This study demonstrates that hormonal differences between men and women have no significant impact on the interaction of platelets with immobilized fibrinogen, neither under venous nor under arterial flow conditions. However, this conclusion is limited to the observations made by an in vitro system. Therefore, it remains to be shown if the same is true in vivo.

\section{P 11 Diagnostic Tool, New Technologies}

\section{P 11.01}

\section{The Role of PDI and the L-Type Lectin LMAN2L in the Secretion of Full-Length and B-Domain-Deleted Factor FVIII}

\section{Roth S. ${ }^{1}$, Seifried E. ${ }^{2}$, Tonn $T^{2}$}

${ }^{1}$ Red Cross Blood Donor Service Baden-Württemberg - Hessen, Institute for Transfusion Medicine and Immunohematology, Frankfurt/Main, D, ${ }^{2}$ Red Cross Blood Donor Service Baden-Württemberg - Hessen, Frankfurt/Main, D

The transport of coagulation FVIII from ER to Golgi is mediated by the cargo receptors LMAN1 and MCFD2, which in case of mutations are known to induce FV/FVIII deficiency in patients. But there are still rare hemophilia A cases where no cause is found in the FVIII gene itself or the LMAN1/MCFD2 cargo receptor complex. Therefore we aimed to analyze if the related lectin LMAN2-like protein plays a role for the secretion of B domain-deleted and full-length FVIII in human hepatic cell lines. Furthermore we investigated the impact of phosphodisulfide isomerase (PDI) on secretion of recombinant FVIII and especially secretion-defective FVIII mutants.

SK Hep-1 and HepG2 cells, representing liver sinusoidal endothelial cells and hepatocytes, were stably transduced with lentiviral vectors carrying a full length (FL) - or B-domain-deleted (BDD) - FVIII transgene or a mutan BDD-FVIII. Point mutations in FVIII domains were chosen by the online database HAMSTeRS and introduced in lentiviral transfer vectors coding for BDD-FVIII by site-directed mutagenesis. Specific knockdown of PDI and LMAN2-like (LMAN2L) protein was induced by siRNA transfection. 24 to $96 \mathrm{~h}$ after RNAi-application the amount of active FVIII in comparison to total FVIII:Ag was determined in cell supernatants.

We could show that downregulation of LMAN2L protein led to an increase of FVIII:Ag in SK Hep-1 and HepG2 cells expressing FL- or BDD-FVIII. Problematically secreted FVIII in SK Hep-1 cells was mainly inactive, probably due to marked cell toxicity $48 \mathrm{~h}$ after anti-LMAN2L siRNA application. In contrast HepG2 cells showed less cell toxicity effects and $72 \mathrm{~h}$ after LMAN2L-knockdown the yield of active and total FL-/BDD-FVIII in the cell supernatant of these cells was increased by more than $100 \%$. We could also show that anti-LMAN2L siRNA improved secretion of BDD-FVIII mutants in HepG2 cells. Knockdown of PDI had contrary effects on FL- and BDD-FVIII secretion. Whereas PDI downregulation led to strong impairment of BDD-secretion, secretion of active FL-FVIII was slightly increased in both cell lines. An indirect FVIII-ELISA could reveal that up to 2fold more FL-FVIII-antigen was secreted, suggesting that PDI knockdown led to release of inactive FVIII proteins.

In conclusion, disulfide bonding by PDI is not only necessary for FVIII functionality it also seems to be the bottleneck in secretion of FL-FVIII. LMAN2-like protein could play a chaperone-like role either in ER-retention of FVIII or in degradation of the glycoprotein.

\section{P 11.02}

\section{Evaluating Human Parvovirus B19 Sequence Variability in Blood Donors with High Resolution Melt Analysis (HRM)}

\section{Pichl L. ${ }^{l}$, Raith S. ${ }^{2}$, Laue $T^{2}{ }^{2}$, Schottstedt V. ${ }^{l}$}

\section{${ }^{1}$ DRK-Blutspendedienst West, Zentrallabor Hagen, D, ${ }^{2}$ Qiagen Hamburg, D}

Purpose: Human parvovirus B19 (B19) actually forms three genotypes 1-3, where 1 is by far the most prevalent in Europe. Growing information on genetic diversity has raised the question on detectability of different genotypes by current NAT assays for B19. Aim of the ongoing study is to evaluate whether HRM is capable to identify single nucleotide polymorphism (SNP) and might be a tool to easily detect new or different sequence variants/ genotypes and if so to screen for sequence heterogeneity of human parvovirus B19 on the DNA level found in volunteer blood donations.
Methods: Currently available HRM dyes were evaluated in an optimized $\mathrm{B} 19$-specific real time PCR. Blood donations from volunteer donors are screened for B19 DNA with the artus Parvo B19 LC PCR kit in plasma minipools. Fresh frozen plasma units from donations with viral burden $\geq 10$ EE5 IU/ml have been identified by resolution analysis of minipools. Viral DNA has been isolated from plasma aliquots with the Qiagen virus kit and amplified by real time PCR (Qiagen HotStart kit) with specific oligos followed by HRM program on the RG6000 cycler. In parallel amplified targets have been sequenced by standard methods. Alignment and phylogenetic analysis is done with the DNA STAR software. Results: Plasma from 20 different blood donors of variant regional origin are under investigation. So far we were able to identifiy a variety of different melting curve profiles. Currently the profiles are compared to the sequence based phylogenetic analysis. We will report on the results of SNP detection by HRM and the comparison to sequence alignment. Conclusion: We will show the usability of current HRM methods to identify new genetic variants of B19. We may come up with distinguishable HRM profiles in relevant sequence sites that allow for accurate genotyping in combination with real time PCR detection. As a consequence HRM seems to be a simple and cost effective option to identify, characterize and monitor the presence of different genotypes/ relevant mutants of B19.

\section{P 12 Tissue Engineering and Regenerative Medicine}

\section{P 12.01 \\ High Efficiency Retro- and Lentiviral Transduction of Blood-Derived Endothelial Progenitor Cells (EPC)}

\section{Shardakova O. ${ }^{I}$, Stockschläder M. ${ }^{2}$, Scharf R.E.}

${ }^{1}$ Heinrich Heine University Medical Center, Düsseldorf, Germany., Dept. of Hemostasis, Hemotherapy and Transfusion Medicine and Biological

Medical Research Center, Düsseldorf, D,

${ }^{2}$ Heinrich Heine University Medical Center, Düsseldorf, D

EPC may play an important role in postnatal vasculogenesis. Enhanced thromboresistance of EPC through overexpression of antithrombotic genes might open new avenues for the treatment of prosthetic and vascular thromboembolic disease. To modify EPC genetically, we have used two culture conditions for isolation and generation of EPC from peripheral blood. Mononuclear cells harvested from healthy volunteers were cultured in Endocult or EBM2-MV medium. Emerging colonies were counted at day 5 or between days 14 and 25. Colony cells were analyzed on day 7, 14, 21, 28 or between days 30 and 60 for leukocyte markers CD45 and CD14, endothelial markers CD31 (PECAM), CD34, CD105 (endoglin), CD141 (thrombomodulin), CD144 (VE-cadherin), CD146 (P1H12), and von Willebrand factor antigen (vWF Ag). The proliferative potential was evaluated by growth kinetics, replating efficiency, and CFSE dilution analysis. Using nonadherent cultured cells, colonies appeared on day 4-5, consisting of central round cells with elongated spindle-shaped cells sprouting at the periphery. The colonies and the spindle-shaped cells slowly disappeared after day 8-10. FACS analysis on day 5, 12, and 21 showed strong expression of CD45 and CD14, weak expression of CD31, but no expression of CD 105 , CD34, and vWF Ag. Using cells adherent to collagen, we observed cells in $50 \%$ of the wells between at a median of $20 \pm 5$ days. These cells rapidly replicated to form colonies with a cobblestone-like appearance which later formed a confluent monolayer. After a lag phase of 20 days, cell expanded exponentially. By FACS analysis, these cells showed strong expression of CD31, CD105, and CD146, intermediate expression of CD141, weak expression of CD34, and no expression of CD45 or CD14. The cells stained positive for VE-cadherin and vWF Ag. An enhanced green fluorescent protein encoding retroviral SFFV vector (cell free supernatant from PG13; titer $1.5 \times 10^{6}$ virus particles $/ \mathrm{ml}$ ) and a novel lentiviral LeGO vector expressing the red chomophore tandem dimer (td)Tomato (cell-free supernatant from PhoenixGP or $293 \mathrm{~T}$ using 3rd generation packaging plasmids pMDLg/pRRE and pRSV-Rev; GALV Env; $16 \times 10^{6}$ virus particles $/ \mathrm{ml}$ ) were used for transduction. BEOC were transduced with high efficiency, $62-80 \%$ and $91-99 \%$, using murine retroviral and human lentiviral vectors containing the eGFP and dtTomato. Our results suggest that nonadherent cultured cells have a low proliferative potential and display an angiogenic macrophage-like phenotype. In contrast, adherent cultured cells have a high proliferative potential, display an endothelial phenotype without coexpression of leukocyte antigens, and are very efficiently transduced by lentiviral vectors. 


\section{P 12.02}

\section{Short Term Clinical Scale MSC Propagation in Animal Serum-Free Medium: Minimum Requirements for Sufficient Transplants}

\section{Schallmoser K. ${ }^{1}$, Rohde $E^{2}{ }^{2}$, Reinisch A. $^{2}$, Obenauf A.C. ${ }^{3}$,} Bartmann $C^{2}{ }^{2}$, Lanzer G. ${ }^{4}$, Linkesch $W^{5}{ }^{5}$, Strunk $D .{ }^{6}$

${ }^{1}$ Medical University of Graz, Stem Cell Research Unit Graz, Dep. for Blood Group Serology and Transfusion Medicine, Graz, A, ${ }^{2}$ Stem Cell Research Unit Graz, Medical University of Graz, A, ${ }^{3}$ Institute of Human

Genetics,Medical University of Graz, A, ${ }^{4}$ Dep. of Blood Group Serology and Transfusion Medicine,Medical University of Graz, A, ${ }^{5}$ Department of Internal Medicine, Division of Hematology,Medical University of Graz, A, ${ }^{6}$ Stem Cell Research Unit Graz, Medicine,Medical University of Graz, A

Ex vivo propagation of human multipotent mesenchymal stromal cells (MSC) is currently considered as a prerequisite for MSC therapy. This study was performed to define the minimum requirements for producing sufficient MSC numbers for therapeutic application in a completely animal serum-free standard system from small bone marrow aspiration volumes within clinically acceptable short time.

In compliance to good manufacturing practice we established a time and resource saving efficient procedure for MSC propagation. Bone marrow was seeded without manipulation directly in pooled human platelet lysate (pHPL) and L-glutamine supplemented minimum essential medium without antibiotics. Clinical scale expanded MSCs were harvested already after primary culture. MSC quality, identity, purity and function were assessed according to a defined panel of release criteria. Complete genomic hybridization was used to determine genetic stability of the expanded cells.

Starting from 790 to 1130 million nucleated cells in aspiration volumes of 14 to $17 \mathrm{~mL}$ (3 male donors; age: 30, 36, and 47 years; 1 female donor; age 13 years), four clinical scale expansions resulted in 906, 963, 256 and 982 million MSCs, respectively. This yield was achieved within a single culture period of 11 to 16 days. MSC quantity represents one to four application doses of $>200$ million MSCs each. MSC viability was $95-97.7 \%$ and flow cytometry revealed a CD73+/CD90+/CD105+ phenotype with less than $2 \%$ hematopoietic cell contamination. Bacterial, fungal and mycoplasma contamination was excluded by repeated negative testing. Endotoxin levels remained below $0.05 \mathrm{EU} / \mathrm{mL}$. Initial plating density inversely correlated with the fibroblast colony-forming unit (CFU-F) frequency. The differentiation potential of MSC into adipo-, chondro- and osteogenic lineages was verified. Complete genomic hybridization showed balanced profiles for all four MSC samples after expansion

The opportunity to achieve up to four application doses of MSCs without animal serum in a standardized single culture phase procedure within 2 weeks with a minimum of manipulation and without antibiotics supports therapeutic approaches that depend on the fast and safe availability of sufficient MSC doses in the clinical setting.

P 12.03

\section{Generation of Erythrocytic Cells from Embryonic Stem Cells in Small Scale and Mass Cultures}

Fatima A. ${ }^{1}$, Hintze C. ${ }^{2}$, Ströbele C. ${ }^{2}$, Seifried E. ${ }^{3}$, Hescheler J. ${ }^{4}$, Sarić $T^{4}$, Henschler $R^{3}$

${ }^{1}$ Institute for Neurophysiology, Cologne, D

${ }^{2}$ Institute of Transfusion Medicine and Immune Hematology, DRK

Blutspendedienst Baden-Württemberg - Hessen gGmbH, Frankfurt/Main, D, ${ }^{3}$ Institute of Transfusion Medicine and Immune Hematology, DRK Blutspendedienst Baden-Württemberg - Hessen gGmbH, Frankfurt/Main, D, ${ }^{4}$ Institute for Neurophysiology, Cologne, D

Background and Objective: The sufficient supply of red blood cells is currently under strain in many places worldwide, resulting from an increasing number and complexity of exclusion criteria for blood donors, increasing difficulty in motivating and mobilizing enough donors, and increasing costs for the blood donation process. One alternative strategy is to exploit a relatively donor/donation-independent blood supply e.g. by manufacturing mature blood in culture from stored stem cells. We here report on an approach using embryonic stem cells (ESCs), which we aimed to commit to hematopoietic development and erythrocytic cells using the D3 and CCS murine ESC lines. Methods: In our two-step differentiation approach, undifferentiated ESCs were first induced to form embryoid bodies (EBs) in an Iscove's Modified Dulecco's Medium supplemented with non-heat inactivated serum, ascorbic acid, iron-saturated transferrin, protein-free hybridoma medium and monothioglycerol but without hematopoietic growth factors to obtain stage 1 cells. These cultures were performed either in the presence (small scale culture) or absence of methylcellulose in a mass culture. After 6-7 days, single cell suspensions were prepared and directly re-seeded into a serum-free Stem Cell Differentiation medium containing Stem Cell Factor, Insulin-Like Growth Factor I, Dexamethason and Erythropoietin. At days 13 of cultivation, suspension cells were collected to obtain stage 2 cells. Results: We assessed cell suspensions for the presence of erythrocytic colony-forming progenitors, TER119 (Glycophorin A-associated) antigen positive cells and benzidine-positive cells to detect haemoglobin. Cell numbers amplified approximately 2 logs during EB formation. We detected 15 45 erythrocytic colonies per 30,000 seeded cells, and between 5-38\% (CCE) and $2-13 \%$ (D3) TER119-positive cells, with similar results in either small scale or mass culture conditions. Moreover, staining for benzidine already revealed hemoglobinization after either step. The maintenance of cells in the second stage was possible only for short-term and resulted in further increase of cell numbers and generation of both BFU-E/CFU-E colonies and Ter119 expressing cells. Conclusions: Erythrocytic cells of various maturation stages can be derived from murine ES cells using a two-step protocol under small scale and, similarly, mass culture conditions. Their functionality and ability to terminally differentiate remain to be shown. Analogous differentiation of conventional human ESCs or patient-specific pluripotent stem cells may pave the way for substitution of red cells or immediate progenitors useful for transfusion therapy.

\section{P 12.04 \\ Blood Components in the Topical Treatment of Ocular Surface Defects: Regenerative Capacity of Human Albumin versus Serum: An In-vitro Study}

Blumenstein P. ${ }^{l}$, Frank B. ${ }^{2}$, Kasper K. ${ }^{3}$, Geerling G. ${ }^{3}$, Dibbelt L. ${ }^{2}$, Seyfarth $M .^{2}$, Hartwig $D .^{2}$

${ }^{1}$ Universitätsklinikum Schleswig-Holstein Campus Lübeck, Institut für Klinische Chemie, Lübeck, D, ${ }^{2}$ Universitätsklinikum Schleswig-Holstein Campus Lübeck, 3Julius-Maximilian-University, Würzburg, D

Objectives: Autologous serum has been successfully used for the topical treatment of persistent corneal epithelial defects and severe dry eye. Its positive effect on the regeneration of corneal epithelium is thought to be due to its high content of growth factors, nutritive agents and vitamins. Recently heterologous human albumin (HA) preparations, that are easily available standard blood products, are advocated as an alternative therapeutic agent in patients with ocular surface disease. In this in-vitro study HA and serum were comparatively tested for their regenerative impact on corneal epithelial cells. Design and Methods: Serum was prepared from healthy volunteers $(\mathrm{n}=10)$ under standardised conditions. HA was purchased as a standard $20 \%$ solution originally designated for intravenous application from Baxter. Serum and HA were diluted with Balanced Salt Solution to final concentrations of $100,50,25,12.5$ and $6.25 \%$. SV40-immortalized human corneal epithelial cells were incubated with both test substances for 6, 24 and 48 hours. Cell growth was quantified by means of a luminescence-based-ATPassay. Cell migration was assessed in a colony dispersion assay. The concentrations of EGF, TGF-beta, fibronectin, vitamin A and vitamin E were evaluated with ELISA or HPLC, respectively. Results: Serum was found to be considerably superior to HA regarding cell growth and migration supporting capacity at all time points and independently of concentration. The best results were obtained with undiluted serum. Concentrations of growth factors and vitamins were higher in serum than in HA: EGF: serum $0.82+/-0.16$ $\mathrm{ng} / \mathrm{ml}$, HA not detectable (n.d.); fibronectin: serum $153.0 \mathrm{ng} / \mathrm{ml}+/-52.6$ ng/ml, HA $10.6+/-0.01 \mathrm{ng} / \mathrm{ml}$; TGF-beta: serum $32.0+/-4,6 \mathrm{ng} / \mathrm{ml}$, HA n.d.; Vitamin A: Serum $3.0+/-0.6 \mathrm{micromol} / 1$, HA $0.13+/-0.01$ micromol/1; vitamin E: serum $23.5+/-3.7$ micromol/1, HA n.d. Conclusions: Migration and proliferation play a major role in tissue repair. In the cell culture model used, serum was clearly superior to HA in supporting cell migration and proliferation of corneal epithelial cells. This may be due to its higher content of growth factors, fibronectin and vitamins. The results of this in vitro study suggest the use of serum eye drops rather than HA in the treatment of patients with ocular surface diseases. For definite proof of the supremacy of autologous serum controlled clinical trials will be necessary. 


\section{P 12.05}

\section{Differential Effects of Human Alternative Supplements Replacing FCS on Mesenchymal Stem Cells from Different Human Tissues}

Hecker A. ${ }^{1}$, Lannert $H^{2}{ }^{2}$, Kocaömer A. ${ }^{3}$, Klüter $H^{3}{ }^{3}$, Bieback $K^{3}{ }^{3}$ ${ }^{1}$ Institute of Transfusion Medicine and Immunology, German Red Cross Blood Donor Service Baden-Württemberg - Hessen, Mannheim, D, ${ }^{2}$ Medical University Hospital Heidelberg Dept. V (Hematology, Oncology and Rheumatology), University of Heidelberg, D, ${ }^{3}$ Institute of Transfusion Medicine and Immunology, German Red Cross Donor Service BadenWürttemberg - Hessen, Mannheim, D

Mesenchymal Stromal Cells (MSC) are in focus regarding their clinical potential in cell therapy, tissue engineering and immune regulation. To enable clinical-scale manufacturing, human alternative supplements replacing fetal calf serum (FCS) for MSC expansion are under thorough investigation. We already demonstrated the superiority of pooled human serum (HS) as well as thrombin-activated platelet releasate in plasma (tPRP) on MSC derived from adipose tissue (AT) [1]. Subsequently we investigated their effects on MSC from human bone marrow (BM) and cord blood (CB). MSC from BM ( $\mathrm{n}=14)$ were isolated and cultured in basal medium supplemented with either $10 \%$ a) FCS (as control), b) AB-HS, c) tPRP or d) human Platelet Lysat (PL). Due to extremely low MSC frequencies in CB, it was not possible to perform paired analysis. Up to now, each two $\mathrm{CB}$ units were processed using $\mathrm{HS}-\mathrm{AB}$ or $\mathrm{PRP}$ and four using PL. In addition three primary CB-MSC cultures established using FCS were subjected in $\mathrm{p} 1$ to the four different supplements. For all culture conditions, long-term expansion capacity as well as the differentiation capacity into osteogenic and adipogenic lineage was tested. Cell surface marker expression was analyzed by flow cytometry.

Primary isolation and expansion of BM-MSC was possible in all culture conditions. However BM-MSC cultured with AB-HS or tPRP showed reduced proliferation compared to FCS, contradicting the data obtained using AT-MSC. Only medium supplemented with PL yielded clinically relevant cell numbers within the first 2-3 passages. Retesting PL in AT-MSC, in vitro gel-formation prevented further expansion in passage 1 cultures. None of 2 $\mathrm{CB}$ units tested using $\mathrm{AB}-\mathrm{HS}$ or tPRP gave rise to MSC, which however barely suggests anything due to the low numbers processed. However, efficacies of $50 \%$ ( 2 from 4 units tested using PL) seem to be encouraging. Strikingly, CB-MSC initially cultivated using FCS, and then subjected to the 4 different supplements, showed absolutely no growth in AB-HS and tPRP, but expansion in PL. For all MSC cultures, quality control assays revealed no impact on differentiation as well as marker expression.

Human MSC derived from the three sources CB, BM and AT respond differently to human alternatives replacing FCS. Identifying the biological basis for the different susceptibility of MSC derived from different tissues will be mandatory to define optimal protocols for clinical-scale manufacturing.

1 Kocaoemer A, Kern S, Kluter H, Bieback K: Human AB serum and thrombin-activated platelet-rich plasma are suitable alternatives to fetal calf serum for the expansion of mesenchymal stem cells from adipose tissue. Stem Cells 2007;25:1270-1278.

\section{P 13 Animal Models}

\section{P 13.01}

\section{Theraflex UV-Platelets: Influence of UVC-Irradiation on} Canine Platelet Concentrates

\section{Pohler P. ${ }^{l}$, Kohn B. ${ }^{2}$, Weingart C. $^{2}$, Mohr H. ${ }^{3}$, Mueller T.H. ${ }^{3}$}

${ }^{1}$ DRK-Blutspendedienst NSTOB, Forschung und Entwicklung, Springe, D, ${ }^{2}$ Klinik für Kleine Haustiere, Fakultät für Tiermedizin, Freie Universität Berlin, ${ }^{3}$ DRK-Blutspendedienst NSTOB, Springe, D

Background: The Theraflex UV-System uses UVC light for pathogen inactivation in platelet concentrates. As preparation for preclinical safety studies in dogs, the effects of UVC light on platelet parameters and storage stability on canine platelet concentrates (cPC) were investigated. Materials and Methods: Single cPC in storage medium SSP+ were prepared from 14 donor beagle dogs. The cPC, weight $94 \pm 4 \mathrm{~g}$, platelet concentration $3.8 \pm 0.6$ $\times 10 \mathrm{E} 8 / \mathrm{mL}$, protein content $20.2 \pm 2.2 \mathrm{mg} / \mathrm{mL}$, were filled into UVtransparent plastic bags and irradiated under agitation on a device emitting UVC light (wavelength: $254 \mathrm{~nm}$ ) at a dose of $0.4 \mathrm{~J} / \mathrm{cm}^{2}$. Influence of UVC on platelet parameters was investigated the day after UVC treatment and after storage at $22{ }^{\circ} \mathrm{C}$ for 6 days. As control, untreated cPC were used. Results: The influence of the UVC treatment on the examined PC parameters was, with exception of the p-LCR values, not very pronounced. Statistical analysis by paired t-test between UVC-treated and untreated cPC, however, showed clearly significant differences between UVC-treated cPC and the untreated controls, mainly after a storage period of 4 and 6 days. Like human PC after UVC treatment, UVC-treated cPC showed a higher meta- bolic activity, indicated by increases in $\mathrm{CO}_{2}$ content, a higher lactate accumulation and a significantly increased collagen-induced aggregation on day 6 (untreated: $22.8 \% \pm 1.5$, UVC-treated: $30.8 \% \pm 3.06$ ). In contrast to human $\mathrm{PC}, \mathrm{UVC}$ treated $\mathrm{cPC}$ exhibited a proportional increase in the percentage of large platelets (p-LCR value) after 4 and 6 days of storage in the UVC group (day 6: untreated: $15.1 \% \pm 1.8$, UVC: $21.3 \% \pm 3.1$ ). Conclusion: The influence of UVC light on in vitro parameters and on storage stability of the treated $\mathrm{cPC}$ is minimal up to 4 days after treatment. The UVC effects on $\mathrm{cPC}$ exhibit close similarities to those encountered on human PC.

This study was supported by the Forschungsgemeinschaft der Blutspendedienste des Deutschen Roten Kreuzes e.V. and MacoPharma International GmbH.

\section{P 13.02 \\ Blockade of Maternal Anti-HPA-1a-Mediated Platelet Clearance in a in vivo Mouse Model by an HPA-1a- Epitope-Specific $\mathrm{F}(\mathrm{ab})^{\prime} 2$}

Bakchoul T. ${ }^{1}$, Boylan B. ${ }^{2}$, Sachs . $^{3}$, Bein G. ${ }^{3}$, Santoso S. ${ }^{3}$, Newman $P{ }^{2}$

${ }^{1}$ Justus-Liebig University Giessen, Institute for clinical Immunology and Transfusion medicine, Giessen, D, ${ }^{2}$ BloodCenter of Wisconsin, Milwaukee, USA, ${ }^{3}$ Justus-Liebig University, Giessen, D

Objective: Neonatal alloimmune thrombocytopenia (NAIT) is most commonly caused by transplacental passage of maternal anti-HPA 1a antibodies. SZ21, a monoclonal antibody (mab) directed against platelet glycoprotein (GP) IIIa, competitively inhibits binding of anti-HPA-1a antibodies to HPA1a positive platelets in vitro. Therefore, mab SZ21 could be a potential therapy for NAIT through blockade of binding of maternal HPA-1a alloantibodies to fetal platelets. Design and Methods: Resting human platelets from HPA-1ab donors were injected into the retro-orbital plexus of non-obese diabetic/severe combined immunodeficient (NOD/SCID) mice. Circulating platelets were exposed to IgG from anti-HPA-1a sera obtained from NAITmothers or AB sera from healthy donors. Purified $\mathrm{F}(\mathrm{ab})^{\prime} 2$ fragment of mab SZ21 or control mouse IgG were injected 1 hour prior to human HPA-1a antibodies. Mouse blood samplings were taken over time and analyzed by flow cytometry. The percentage of human platelet circulating in the living mice were determined to evaluate the ability of mab SZ21 to prevent antiHPA-1a- mediated platelet clearance. Results: Human platelets circulate for up to 24 hours in NOD/SCID mice in the absence of platelet antibodies. In contrast, anti-HPA-1a antibodies derived from NAIT-mothers were able to efficiently clear HPA-1a positive platelets from the mouse blood circulation. Administration of SZ21 F(ab)'2 Fragment prevented anti-HPA-1a- mediated platelet clearance. This mab fragment did not influence either platelet circulation time or platelet function. Conclusion: In this study, we demonstrated that the $\mathrm{F}(\mathrm{ab})^{\prime} 2$ fragment of mab SZ21 could be an effective inhibitor of anti-HPA-1a-mediated clearance of human platelet circulating in an in vivo NOD/SCID mouse model, indicating a new therapeutic approach for NAIT. Further, our NOD/SCID mouse model system allows the study of the effect of human polyclonal antibodies on human cells circulating in a living organism under circumstances similar to those seen in human allo/ auto immune diseases.

\section{P 14 Laboratory Tools and Techniques}

P 14.01

\section{NOD2/CARD15 SNP Genotyping by Luminex and Impact} on the Outcome of Unrelated Stem Cell Transplantation

Vigh A. ${ }^{1}$, Putzbach $\mathrm{J}^{2}$, Schrezenmeier $\mathrm{H}^{2}$, Mytilineos $\mathrm{J.}^{2}$

${ }^{1}$ Institute for Clinical Transfusion Medicine and Immunogenetics UIm, German Red Cross Blood Donor Service Baden-Württemberg-Hessen, Department of Transplantation Immunology, Ulm, D, ${ }^{2}$ Institute for Clinical Transfusion Medicine and Immunogenetics Ulm, German Red Cross Blood Donor Service Baden-Württemberg-Hessen, UIm, D

Introduction: Studies on the impact of NOD2/CARD15 gene single nucleotide polymorphisms (SNP8, 12, 13) in unrelated HSCT revealed conflicting results regarding patient survival and acute or chronic graft versus host disease incidence. The principally used method for SNP typing is PCR-SSP (Sequence Specific Primer). A low turnover with high expenditure of time are disadvantages of this method in studies with high sample sizes. The aim of this study was to determine whether certain polymorphisms have an independent effect of NOD2/CARD15 mutations in the outcome of unrelated HSCT and to design a time saving method for genotyping. Methods: To assess the contribution of NOD2/CARD15 mutations in the outcome of unrelated HSCT we retrospectively tested 297 adult transplant patients with the diagnosis of AML, ALL, and CML, as well as their donors. The donor/recipient pairs were part of a previously well-characterized HLA-A, -B 
low and DR, DQ high resolution matched cohort with a follow-up of 5 years Transplant related mortality at one and at 5 years (TRM 1 yr, TRM 5yr) as well as overall survival at 5 years (OS 5yr) were analyzed in relation to NOD2/CARD15 genotypes. The individuals were genotyped for the NOD2/CARD15 SNPs rs206684 (SNP8), rs2066845 (SNP12) and rs5743293 (SNP13). To accomplish genotyping we designed a system based on 'xMap Multi-Analyte $\mathrm{COOH}$ (=Beads)' technology from the company Luminex. After establishing a multiplex PCR (MPCR), unassigned colorcoded beads were specifically linked to each of the SNP through CaptureOligonucleotides and subsequently hybridized with the MPCR products. Amplification success and specificity of the hybridisation were verified by sequencing in 43 DNA samples from healthy related individuals. Results: NOD2/CARD15 mutations occurred with a frequency of $18.4 \%$ in patient and $19.1 \%$ in donors. Mutant allele frequencies for SNP 8, 12, 13 were found in $5.4 \%, 1.7 \%, 2.5 \%$ of donors, and $4.2 \%, 1.2 \%$ and $4.2 \%$ of patients, respectively. The frequencies of the NOD genotypes were in Hardy Weinberg equilibrium and confirmed the results of other studies on Caucasian individuals. There were no significant differences in TRM at $1 \mathrm{yr}, 5 \mathrm{yr}$, as well as OS 5yr for transplants with and without SNP8, SNP12, and SNP13 mutations. The sequencing of the additional 129 tests revealed a $100 \%$ match to the results of the in house Luminex assay. Conclusions: The preliminary analysis of our data did not show an independent effect of NOD2/CARD15 mutations in the outcome of unrelated HSCT. With the Luminex technique we established a method for reliable, high throughput NOD2/CARD15 typing.

P 14.02

Quality Control of Leukocyte Reduced Blood Components: Overestimation of WBC Content Due to Nucleated Red Blood Cells

Fischer J.C. ${ }^{1}$, Moog R. ${ }^{2}$, Giers G. ${ }^{3}$

${ }^{1}$ University Hospital Düsseldorf, Institute for Transplantation Diagnostics and Cell Therapeutics, Düsseldorf, D, ${ }^{2}$ Institut für Transfusionsmedizin, Universitätsklinikum, Essen, D, ${ }^{3}$ Institut für Hämostaseologie und Transfusionsmedizin, Universitätsklinikum, Düsseldorf, D

Background: and Objectives Since several years leukocyte (WBC) filters are introduced in routine blood bank practice. For quality control flow cytometric methods for counting residual WBC are well established and widely used. Especially the commercial availed kits are based solely on DNA staining for WBC detection. We hypothesized that nucleated red blood cells (NRBCs) could impact these numbers. Methods: We developed a flow cytometric method for threshold detection of nucleated cells (NC) and leukocyte detection using simultaneously antibody $(\mathrm{AB})$ and DNA nuclei staining. In brief $100 \mu \mathrm{l}$ sample was stained with CD45 (AB, specific for WBC) and DRAQ5 (DNA stain). Measurement was done applying a single platform setting using flow count beads. In parallel a commercial available kit based only on DNA staining (PI) was used. CD45positive DRAQ5 positive cells were assumed as WBCs. CD45 negative DRAQ5 positive cells were classified as NRBCs, NCs as the sum of WBCs and NRBCs. For proving that these cells are really NRBCs, they were flow cytometric sorted on slides and evaluated using Wright Giemsa staining. Results: We investigated pre storage filtered erythrocyte concentrates ( $E C, n=128)$, plasma (FFP, $n=5$ ) and platelet concentrates ( $\mathrm{PC}, \mathrm{N}=42$ ) as well as 10 whole blood samples. For all samples a good concordance between the commercial kit and the detected NC count was seen. Microscope evaluation of the sorted DRAQ5 positive CD45 negative cells revealed that $95 \%$ of these cells were NRBC. Within the blood products EC $30.5 \%$ of all NCs were NRBCS (SD 23.5\%), in PC $22.6 \%$ (SD 14.1\%), in FFP 4\% (SD3.8\%) whereas in WB only $0.3 \%$ (SD0.4\%). Conclusion: Solely DNA based counting methods overestimate residual WBC content of leukocyte reduced blood components due the missing discrimination between NRBCs and WBCs.

\section{P 14.03}

\section{Dual Anti-Platelet Therapy with Aspirin and Clopidogrel Might Be Ineffective in Cardiologic Patients Regarding the Flow-Cytometric Platelet Reactivity Index}

\section{Prüller F. ${ }^{l}$, Ramschak H. ${ }^{\text {, }}$ Hödl R. $^{2}$, Kainz J. ${ }^{3}$, Metzler H. ${ }^{3}$, Truschnig $M$.}

${ }^{1}$ Medical University of Graz, Clinical Institute of Medical and Chemical Laboratory Diagnostics, Graz, A, ${ }^{2}$ Medical University of Graz, Department of Medicine, Division of Cardiology, Graz, A, ${ }^{3}$ Medical University of Graz, University Clinic of Anaesthesia and Intensive Care Medicine, Graz, A

Objective: Combination therapy with aspirin and clopidogrel is standard treatment for either patients presenting with acute coronary syndrome or with planned percutaneous coronary stent implantation. In these patients it would be advisable to have a confident parameter of the in-vivo platelet function for both to control therapeutic efficacy and to forecast bleeding complications e.g. in cases of emergency or urgent surgery. So far clopidogrel usually has to be stopped at least eight days before the procedure in these cases. Platelet function testing in anti-platelet treated patients would allow a more differentiated management of cardiologic patients in surgical settings. Methods: We prospectively tested 20 healthy volunteers, 21 surgical patients not on any anti-platelet treatment and 24 cardiologic patients on dual anti-platelet therapy with aspirin and clopidogrel. Platelet rich plasma $(110 \mathrm{~g})$ and platelet poor plasma $(2800 \mathrm{~g})$ was obtained by centrifugation with a GS-15 centrifuge (Beckman). Then light transmission aggregometry of ADP stimulated platelets (maximum Aggregation - $\mathrm{mA}$ ) was performed using a 4 channel Chronolog 700 (Chronolog). Platelet Reactivity Index (PRI) was determined in whole blood, using the flow-cytometric assay kit PLT VASP/P2Y12 (Biocytex, France) on a FACS Calibur (Becton Dickinson) flow cytometer. The Vasodilator Stimulated Phosphoprotein (VASP) phosphorylation correlates with the P2Y12 receptor inhibition on platelets. Data were statistically analysed using SPSS 14.0 software (SPSS Inc.). Results: PRI and mA are presented as mean \pm SD. 13 out of 24 cardiologic patients presented with a PRI $>52 \%$. The minimum PRI in the groups of healthy volunteers and surgical patients was $52.3 \%$

Student's t-test showed significant difference between the cardiologic group (respectively subgroups) and the control groups $\left({ }^{*+} \mathrm{p}<0.0001\right)$

\begin{tabular}{|l|l|l|}
\hline Platelet Reactivity & $\begin{array}{l}\text { Index }(\mathbf{\%}) \\
\text { Mean } \pm \text { SD }\end{array}$ & $\begin{array}{l}\text { maximum Aggregation (\%) } \\
\text { Mean } \pm \text { SD }\end{array}$ \\
\hline Healthy $(\mathbf{n}=\mathbf{2 0})$ & $83.5 \pm 14.0^{*}$ & $70.2 \pm 10.4^{*}$ \\
\hline Surgical $(\mathbf{n}=\mathbf{2 1})$ & $76.8 \pm 9.7^{+}$ & $73.8 \pm 19.8^{+}$ \\
\hline Cardiologic $(\mathbf{n}=\mathbf{2 4})$ & $51.8 \pm 20.0^{*+}$ & $30.6 \pm 17.0^{*+}$ \\
\hline Subgroup $>52 \%(\mathrm{n}=13)$ & $66.8 \pm 10.4$ & $40.3 \pm 15.8^{*+}$ \\
\hline Subgroup $<52 \%(\mathrm{n}=11)$ & $34.1 \pm 12.2 *^{+}$ & $19.2 \pm 10.2^{*^{+}}$ \\
\hline
\end{tabular}

Conclusion: Our findings underline both the problems of nonresponsiveness to anti-platelet therapy as well as the risk of bleeding complications in urgent surgical settings of cardiologic patients. Larger studies are needed to find standard diagnostic tools that show clear correlation to thrombotic events or bleeding complications in order to monitor anti-platelet therapy.

None of authors has any financial interests or any affiliations with funding organisations or with commercial supporters of the session.

\section{P 14.04}

\section{Multicenter Study of Roche Cobas TaqScreen MPX Test on the Cobas s 201 Platform for Donor Screening in Pools of 96}

Jork C. ${ }^{l}$, Pichl L. ${ }^{2}$, Schmidt M. ${ }^{3}$, Hourfar M.K. ${ }^{3}$, Schottstedt V. ${ }^{2}$, Wagner F. ${ }^{4}$, Seifried $E^{3}{ }^{3}$, Bux J. ${ }^{2}$, Müller T. ${ }^{4}$

${ }^{1}$ German Red Cross Transfusion Service NSTOB, NAT-Lab, Springe, D, ${ }^{2}$ German Red Cross Transfusion Service West, Hagen, D, ${ }^{3}$ German Red Cross, Frankfurt/Main, D, ${ }^{4}$ German Red Cross Transfusion Service NSTOB, Springe, D

Objectives: A multicenter study was done by three German blood banks, Hagen, Springe and Frankfurt, to evaluate the feasibility of routine testing of blood donor samples in pools of 96 using the Roche automated, cobas s 201 platform and the cobas TaqScreen MPX test, which were recently CE-IVD approved. At present, these blood banks test samples in pools of 96 using either a diagnostic or in-house test. Methods: Samples were pooled offline and the pools of 96 were run as individual samples on the cobas s 201 system. The analytical sensitivity for HBV, HCV and HIV-1 was evaluated using WHO International Standards and the 95\% LOD values were determined by Probit analysis. The reproducibility and cross contamination of the system (robustness) was evaluated by testing replicates of low positive samples of HBV, HCV and HIV-1 $(<=30 \mathrm{IU} / \mathrm{ml}, 50 \mathrm{IU} / \mathrm{ml}$ and $160 \mathrm{IU} / \mathrm{ml}$ respectively) and testing of chessboard panels of alternating high positive (10e6 IU/ml for HCV and HIV-1 and $10 \mathrm{e} 7 \mathrm{IU} / \mathrm{ml}$ for HBV) and negative samples, respectively. Genome inclusivity was evaluated using genotype panels for HCV, HIV-1 and HBV. To test the clinical performance and specificity, more than 62,000 routine donations were screened in pools of up to 96 donations at each test site, both by the cobas TaqScreen MPX Test and the test of record. Results: The analytical sensitivities at all test sites were between1.6 and 3.6 IU/ml, 4.9-10.9 IU/ml and 14.7-26.6 IU/ml for $\mathrm{HBV}$, $\mathrm{HCV}$ and HIV, respectively. The robustness of the cobas s 201 system was satisfying with all low positive replicates testing reproducibly reactive and only minor cross contamination rates. According to the panels tested the genotypes 1 to 6 for HCV, A to G for HBV and A to H, N and O for HIV-1 are detected by the cobas TaqScreen MPX Test with the same efficiency for 
all genotypes. The clinical performance data showed a specificity of the $96-$ pool testing from $99.38 \%$ to $100.00 \%$ while the sensitivity of the MPX Test varied from $99.79 \%$ to $100.00 \%$. No window cases were detected during the study but one MPX-only reactive pool sample that tested negative with the routine COBAS AmpliPrep/COBAS TaqMan HIV-1 Test. Conclusions: The cobas s 201/cobas TaqScreen MPX system is a fully automated NAT system suitable for routine blood donor screening. Amplification of HIV-1 is designed in the highly conserved 5'LTR region which might also improve blood safety. The analytical and diagnostic sensitivity of the cobas TaqScreen MPX Test fulfill all requirements of the Paul Ehrlich Institute for blood donor screening in mini pools up to 96 donations.

\section{P 14.05}

\section{Detection of Anti-Lea and Anti-Leb Antibodies in the Lymphocyte Cytotoxicity Assay}

\section{Richter R. ${ }^{l}$, Geisen C. $^{l}$, Scheuermann E. ${ }^{2}$, Seifried E. ${ }^{3}$, Seidl C. ${ }^{l}$}

${ }^{1}$ Institut für Transfusionsmedizin und Immunhämatologie, Frankfurt/Main, D, ${ }^{2}$ Goethe Universitätsklinkum, Zentrum der Inneren Medizin - Nephrologie, Frankfurt/Main, D, ${ }^{3}$ Institut für Transfusionsmedizin und Immunhämatologie - EuBIS Project Management, Frankfurt/Main, D

Objective: Frequently non-HLA-specific cytotoxic antibodies are detectible in lymphocyte cytotoxicity assays (LCT). Whereas HLA-specific antibodies are known to be of clinical relevance in renal transplantation leading to hyperacute and acute organ rejection the relevance of cytotoxic antibodies with other specificities is still under consideration. Antibodies against MICA- or MICB, angiotensin II receptor type 1 (AT1), vimentin, 100-kDa antigen, $38-\mathrm{kDa}$ antigen are suggested to be involved in early graft loss, acute and hyperacute renal graft rejection. Design, Method and Results: In our waiting list for cadaver kidney transplantation we found a patient (serum A) who was positive for non-HLA specific lymphocytotoxic antibodies. His blood transfusion history revealed immunisation against Lewis antigens, with the presence of anti-Lea (titer 32) and anti-Leb (titer 8) antibodies. In the LCT the patient was positive over five successive screening periods (15 month) for cytotoxic antibodies. The peak-PRA value based on LCT was $16 \%$ in the second period (month 3-6) and finally decreased to $0 \%$ in the fifth period. During the peak-PRA period lymphocytotoxic reactions were present with and without DTT, indicating the presence of IgM and IgG antibodies, whereas in the subsequent screening periods DTT abolished the cytotoxic reactivities. Antibody preabsorption of the sera using Lea and Leb positive erythrocytes significantly reduced the cytotoxic activity with a consistent reaction pattern against a selected donor panel. To confirm the cytotoxic activity of Lewis antibodies we subsequently screened two othe Le-positive sera (serum B and serum C) for cytotoxic reactivity. In the investigated sera no HLA-specific antibodies were detected in the ELISAscreening using LAT Mixed Class I\&II screening plates (OneLambda) Serum B contained Anti-Leb with a titer of 32 and serum C contained a weak titer of Anti-Lea. In the LCT serum B showed polyspecific reactions with PRA value of $52 \%$, whereas serum $\mathrm{C}$ did not show cytotoxic reactivity. After addition of DTT the serum B became negative in the LCT demonstrating the IgM nature of the anti-Leb antibodies. Conclusion: In conclusion our result indicate that - among non-HLA antibodies - anti-Lea and anti-Leb antibodies display cytotoxic reactivity in the LCT. Since clinical investigation suggest that Le-antibodies are related to a reduced long term survival of the renal graft, Le-antibodies detected in the LCT are of clinical relevance. Serum sample exchange and prospective crossmatching of these patients will be a necessary requisite to prevent transplantation of Le+ grafts against these lymphocytotxic Le-antibodies.

\section{P 14.06}

Characterization of New HLA Class I Alleles Using GroupSpecific Sequencing Primers (GSSPs) and HaplotypeSpecific Extraction (HSE)

\section{Enczmann J. ${ }^{1}$, Tillmann G. ${ }^{1}$, Ogrzewalla K. ${ }^{2}$, Lauber J. ${ }^{2}$}

${ }^{1}$ University Hospitals Düsseldorf, Institute for Transplantation Diagnostics and Cell Therapeutics, Düsseldorf, D, ${ }^{2}$ QIAGEN GmbH, Hilden, D

Objectives: This study analyzed the feasability of GSSP and HaploPrep to define new HLA-alleles. Design and Methods: During routine tissue typing the presence of new alleles was initially detected by either reverse hybridisation or simultaneous sequencing of both alleles in heterozygous samples. In order to identify and define these new alleles, two different strategies were applied. Group-specific sequencing primers (GSSPs) were used to obtain homozygous sequence information of the region of interest. Furthermore, the new alleles were isolated using haplotype-specific extraction (HSE) and subsequently analysed by sequence-based typing (SBT) covering exons 1 to 5. In addition, the complete sequence information of introns 1, 2, 3 and 4 was obtained in all cases. Results: 13 new HLA class I alleles (6 HLA-A, 6 HLA-B and 1 HLA-C) were identified using both methods and analyzed extensively in order to present a comprehensive characterization that enables a better classification of these new alleles into the HLA system. HLA alleles can be successfully separated from diploid samples using HaploPrep extraction prior to HLA typing with sequencing based typing. Therefore, new alleles of heterozygous samples can easily be characterized without any additional cloning. Group-specific sequencing primers (GSSPs) serve not only for resolving genotype ambiguities but can also facilitate the identification of HLA alleles with nucleotide exchanges in heterozygous samples. Conclusions: The combined use of GSSPs and HaploPrep extraction speeds up the characterization of new alleles since only the 'new' allele needs to be separated and analyzed selectively, thus ultimately reducing the number of HaploPrep extractions and sequencing reactions. The complete sequence information covering exons $1-5$, including introns $1-4$, largely defines the new alleles helping to further characterize the polymorphism of the HLA system. This knowledge is not only important for scientific questions, but also for technical aspects of HLA-typing.

\section{P 14.07 \\ Initial Results of the BD Thrombo Count Assay for Enumeration of Residual WBCs and RBCs in Platelet Concentrates Using a BD FACSCalibur Flow Cytometer}

Brys B. ${ }^{l}$, Spengler H.-P. ${ }^{2}$, Baumann-Baretti B. ${ }^{l}$, Krause K.-P. ${ }^{l}$ ${ }^{1}$ Haema AG, BIO CITY LEIPZIG, Leipzig, D,

${ }^{2}$ BD Biosciences, Scientific Affairs Europe, Heidelberg, D

Objectives: Enumeration of residual leucocytes (WBCs) and red blood cells (RBCs) is a mandatory part of the quality control (QC) of platelet concentrates (PCs). While flow cytometric enumeration of residual WBCs (e.g. using BD Leucocount) is increasingly replacing microscopic counting, RBCs are counted usually by microscopy. The BD Thrombo Count Assay claims to offer enumeration of both cell types, WBCs and RBCs, in one test tube by automated flow cytometry. Our objective was to obtain initial test results of selected PC samples comparing the Thrombo Count Assay with currently employed QC methods, microscopic counting of residual RBCs and/or WBCs, and Leucocount. Design and Methods: Selected PC samples $(n=72)$ were tested under routine conditions in our quality control lab (Haema AG) using the BD Thrombo Count Assay. For comparison, residual WBCs were also enumerated using the BD Leucocount test and manual counting using a Nageotte chamber, and residual RBCs enumerated by manual microscopic counting using a Fuchs-Rosenthal chamber. Flow cytometry and analysis was done with a FACSCalibur instrument and CellQuest Pro software. Results: Residual WBC analysis by Leucocount and Thrombo Count showed a wide cell range of $0-775 \mathrm{WBC} / \mu \mathrm{L}$. Calculated values resulted in a fair correlation $(\mathrm{r} 2=0.877)$ and median values of 0.79 vs. $0.81 \mathrm{WBC} / \mu \mathrm{L}$. In contrast, values of residual RBCs counted using the Thrombo Count Assay were considerably higher and did not correlate with the values obtained by microscopy. The flow cytometry analysis showed different populations of residual RBCs based on their relative size (FSC) and side scattered light (SSC). Conclusions: These initial results confirm the utility of the BD Thrombo Count Assay for enumerating residual cells in PC samples: The WBC results correlated well with those using the Leucocount test. The BD Thrombo Count Assay gave higher residual RBC counts compared to microscopic counting that has to be discussed. In further studies we are investigating the use of commercially available control materials, i.e. the BD Leucocount Control for residual WBCs and an internal QC sample for residual RBC.

\section{P 14.08}

Performance Validation of BD Thrombo Count Assay for Flow Cytometric Enumeration of Residual WBC and RBC in Platelet Concentrates: Single Site Results of a Multi Center Study

Brys $B .{ }^{l}$, Spengler H.-P. ${ }^{2}$, Baumann-Baretti B. ${ }^{l}$, Nauwelaers $F .{ }^{3}$, Krause K. $-P$.

${ }^{1}$ Haema AG, BIO CITY LEIPZIG, Leipzig, D, ${ }^{2}$ BD Biosciences, Scientific Affairs Europe, Heidelberg, D, ${ }^{3}$ BD Biosciences, Scientific Affairs Europe, Erembodegem, B

Objectives: The BD Thrombo Count Assay has been developed for residual cell enumeration in platelet concentrates (PCs). As part of a multi center study to validate the performance of Thrombo Count, we evaluated PC samples spiked with residual cells regarding linearity, precision, and accuracy according to NCCLS EP10-A and ICH Q2 guidelines. In addition, sample stability and staining stability were analyzed. Furthermore, selected 
aphaeresis PC samples were analyzed by Thrombo Count and results were compared with those obtained by manual microscopic counting (for RBCs) and using the BD Leucocount test (for WBCs). Design and Methods: PC samples collected from daily routine QC testing were spiked with defined cell numbers resulting in 7 different target concentrations covering a range of $0.5-9.5 \mathrm{WBC} / \mu \mathrm{L}$ and $600-11400 \mathrm{RBC} / \mu \mathrm{L}$. They were then evaluated using the Thrombo Count Assay, i.e. staining WBCs by propidium iodide and RBCs by PE-labeled anti-glycophorin A. Selected PC samples $(n=31)$ were also analyzed by microscopic RBC counting, using a Fuchs-Rosentha chamber, and by flow cytometric WBC enumeration, using the Leucocount test. Flow cytometry was done with a BD FACSCalibur and BD CellQuest Pro Software. Results: The linearity of cells in the analyzed concentration range was calculated at $\mathrm{r} 2=0.992$ for $\mathrm{WBC}$ and $\mathrm{r} 2=0.992$ for $\mathrm{RBC}$. Imprecision $(\% \mathrm{CV})$ of mean values from 10 -fold measurements of three selected cell concentration levels (low, medium, high) was calculated. WBC/ $\mu \mathrm{L}: 0.58$ (33\%), 5.75 (12\%), 10.98 (7.8\%); RBC/ $\mu \mathrm{L}$ : 633 (2.0\%), $5670(2.0 \%), 10095$ $(2.1 \%)$. A theoretical $\mathrm{CV}$ of $<20 \%$ was estimated at $>1.28$ cells $/ \mu \mathrm{L}$. In the cell ranges analyzed accuracy ranged from $91-112 \%$ for WBC and $87-105 \%$ for RBC. In transported PC samples, residual cell counts were found stable after additional $0-24 \mathrm{~h}$ of storage. Counts of stained samples were found stable for up to $3 \mathrm{~h}$. On selected PC samples, values of residual WBCs correlated well with those obtained using the Leucocount test. For RBCs, the values found by Thrombo Count were consistently higher than those obtained by microscopy. Conclusions: The results from this site of the mult center study verify that the Thrombo Count Assay is a rapid, simple and reliable test for flow cytometric enumeration of residual cells in PC samples. In samples spiked with RBCs and WBCs, Thrombo Count values calculated after background correction compared well with expected values and those using the Leucocount test. The fact that the values for RBCs in PC samples were consistently higher when using Thrombo Count compared to microscopic counting needs to be further examined, as is being done in a separate investigation

\section{P 14.09}

\section{Point-of Care Thrombelastometry - How to Centralize without Loosing Benefits?}

Weber D., Kelsch R., Glasmeyer S., Sibrowski W.

University Hospital Münster, Institute of Transfusion Medicine and

Transplantation Immunology, Münster, D

Some studies show that the management of hemostatic therapy with the support of 'point-of-care' thrombelastometry (TEM) could significantly decrease the use of red cells and platelets and will have an effect on the use of other blood products in intensive-care units and cardiac surgery. However the introduction of TEM at 'points-of-care' involved problems concerning the local availability of educated personnel, quality control and proper performance of tests. Objectives: Validation and transfer of the test system (ROTEM) to a central blood bank laboratory without substantial loss of immediate availability of test results through rapid sample transport by a blood carrier and online submission of analysis screens. Design and Methods: Measurement system analysis of the TEM-system (ROTEM) through Minitab 'Gage R\&R Study (Nested) protocol': three technicians each measured 'INTEM' and 'EXTEM' of three different samples (healthy blood donors) three times. To represent an extended measurement range we analysed both, undiluted and diluted samples $(1+1$ and $1+3$ with $\mathrm{NaCl} 0.9 \%)$ Influence of the 'pre-test' sample temperature, which could be modified by the transport on the results: one technician measured 'INTEM' of 8 samples (duplicates) under varying conditions. Incubation at $22{ }^{\circ} \mathrm{C}$ for $30 \mathrm{~min}$ was compared to $30 \mathrm{~min}$ at $4{ }^{\circ} \mathrm{C}, 30 \mathrm{~min}$ at $4{ }^{\circ} \mathrm{C}$ (insulating box) and $30 \mathrm{~min}$ at 37 ${ }^{\circ} \mathrm{C}$ (water bath). The results were analysed by 'Minitab Two sample T-test'. Results: The thrombelastometry system (ROTEM) is able to detect the three analysed samples as different measurement results with a part-to-part \% Study Variation of $98 \%$ (Minitab; Gage R\&R (Nested)). The influence of the person carrying out the test on the results was characterized by a Total Gage R\&R study variation of $18.9 \%$ (acceptable value). The 'individual value plots' of INTEM CT at different sample incubation temperatures showed significant differences comparing $30 \mathrm{~min} 22^{\circ} \mathrm{C}$ with $30 \mathrm{~min} 4{ }^{\circ} \mathrm{C}$ and $22{ }^{\circ} \mathrm{C}$ (see table below). Thus a sample preincubation at $37{ }^{\circ} \mathrm{C}$ (water bath) for about $10 \mathrm{~min}$ is recommended.

\begin{tabular}{|l|l|l|l|l|}
\hline Sample preincubation & $\mathrm{N}$ & Mean & StDev & $\mathrm{p}$ value \\
\hline $30 \min 22^{\circ} \mathrm{C}$ & 16 & 178.6 & 20.7 & \\
\hline $30 \min 4^{\circ} \mathrm{C}$ & 16 & 201.5 & 19.9 & 0.003 \\
\hline $30 \min 4^{\circ} \mathrm{C}$ (iso-box) & 15 & 196.3 & 14.6 & 0.01 \\
\hline $30 \min 37^{\circ} \mathrm{C}$ & 16 & 170.6 & 21.1 & 0.28 n.s. \\
\hline
\end{tabular}

Conclusions: The transfer of thrombelastometry by ROTEM from 'point-ofcare' to a central blood bank laboratory needs standardization and training of personnel. The advantages will be a sample transport coupled to rapid transfusion-related blood transports and online submission of data.

\section{P 14.10 Aggregation in Platelet Rich Plasma versus Shear- Dependent Analysis of Platelet Function in Whole Blood}

\section{Picker $S{ }^{1}$, Schneider V. ${ }^{2}$, Oustianskaja L. ${ }^{2}$, Gathof B. ${ }^{2}$}

${ }^{1}$ University of Cologne, Transfusion Medicine, Cologne, D,

${ }^{2}$ University of Cologne, D

Background: Platelet (PLT) function is an optional but desirable part for the initial screening of new PLT donors. For correct test interpretation, baseline values are needed. We therefore evaluated aggregation in PLT rich plasma (PRP) and a recently developed flow-dependent method, the cone and PLT analyzer (CPA) quantifying both adhesion and aggregation in the physiological environment of whole blood. Design: According to Born, turbidometric PLT aggregation was performed on the Apact 4Splus (Rolf Greiner Biochemica GmbH, Flacht, Germany) on citrated blood samples obtained from 100 healthy blood donors. Aggregation was assessed as maximal aggregation at $6 \mathrm{~min}$ after adding the agonist (arachidonic acid $1.5 \mathrm{mM}$, epinephrine $50 \mu \mathrm{M}$, collagen $10 \mu \mathrm{g} / \mathrm{mL}$, ADP $20 \mu \mathrm{M}$, ristocetin $1.5 \mathrm{mg} / \mathrm{mL}$, TRAP-6 $0.1 \mathrm{mM}$ ). Results were expressed as percent of baseline obtained in PLT poor plasma of the same donor. For CPA with the Impact R (Diamed $\mathrm{GmbH}$, Ottobrunn, Germany), $130 \mu \mathrm{L}$ of citrated blood of further 100 donors was placed in a polystyrene well and exposed to high shear stress $(2000 \mathrm{~s}-1)$ for $2 \mathrm{~min}$. After washing and staining, the wells were analyzed by the integrated light microscopy and results expressed as percent of the surface covered by PLTs (SC), aggregate average size (AS, $\mu \mathrm{m}^{2}$ ) and number of objects visualized (OB). Results: Except for epinephrine and ADP $(60 \pm 10 \%$, slightly higher in females) tubidometric aggregation averaged $83 \pm 2 \%$. The exact values were as follows: $83.8 \pm 10.4$ (arachidonic acid), $49.2 \pm 25.5$ (epinephrine), $80.7 \pm 8.9$ (collagen), $68.7 \pm 16.6$ (ADP), 85.1 \pm 8.1 (ristocetin), $85.7 \pm 6.3$ (TRAP-6). The higher the aggregation response the lower was the variation coefficient (VC). The CPA results depended slightly on gender and age (higher in females and elderly subjects), but, as observed with aggregation, were independent on ABO type. As seen from the high standard deviation $\left(14.4 \pm 4.1 \%\right.$ (SC), $62.2 \pm 16.4 \mu \mathrm{m}^{2}$ (AS), $1428 \pm 357$ (OB)), the VC ranged between 25 and $30 \%$. Conclusion: Both methods offered easy performance and reproducible results within 6 to $8 \mathrm{~min}$.

\section{P 15 Regulations, Legislation and Health Care Systems}

\section{P 15.01}

\section{Blood Transfusion in Europe: Differences and} Communalities Leading to Pan-European Standards and Criteria for the Inspection of Blood Establishments. The EuBIS Project

\section{Seidl C. ${ }^{l}$, Nightingale M. ${ }^{2}$, Costello ${ }^{3}{ }^{3}$, Sireis $W{ }^{4}$, Sobaga $L .{ }^{5}$,} De Wit J. ${ }^{6}$, Macmillan Douglas A. ${ }^{7}$, Delanay $F^{8}{ }^{8}$, Siegel W. ${ }^{9}$, Cermakova Z. ${ }^{10}$, Seifried E.

${ }^{1}$ Institut für Transfusionsmedizin und Immunhämatologie, EuBIS Project Management, Frankfurt/Main, D, ${ }^{2} \mathrm{NHSBT}$, Southhampton, UK, ${ }^{3} \mathrm{IMB}$, Dublin, IRL, ${ }^{4}$ Institut für Transfusionsmedizin und Immunhämatologie, Frankfurt/Main, D, ${ }^{5} \mathrm{EFS}$, Paris, F, ${ }^{6}$ Sanquin, Amsterdam, NL, ${ }^{7} \mathrm{AMD}$, Edinburgh, UK, ${ }^{8} \mathrm{FMD}$, Luxembourg, L, ${ }^{9} \mathrm{RPDA}$, Darmstadt, D, ${ }^{10} \mathrm{FNPO}$, Ostrava, CZ

Objectives: The specific objectives of the EU cofunded Project, EuBIS (www.eubis-europe.eu), are to define the current situation of standards and criteria used for inspections of blood establishment among the participating and collaborative institutions from 19 established, new, applicant and EFTA states in order to identify (A) international and national inspection guidelines in place and (B) the current inspection practice. Design and Methods: The Project develops a manual, defining requirements for the structure of quality management systems based on the directive 2002/98/EC and its technical annexes. Based on these requirements, inspection standards and criteria are developed to assist in the independent assessment of quality systems established by individual blood establishments in relation to the requirements of the EU-legislation on blood. Results and Conclusion: Transposition to national laws in EU member states of the Blood Directives has been completed. Following the national diversity generated during the last decades, implementation will need some additional effort. From the survey performed between the Project participants and collaborating partners, the majority of blood establishments responded that their current quality system will need at least minor improvements or modifications to be adapted to the EU Directive 
2005/62/EC. Modifications are required to reflect the individual structure of blood establishments and the background of their quality systems. Overall, modifications address all quality relevant sections defined by Annex of Directive 2005/62/EC. In case of individual blood establishments, the range is very large from no modification needed to several improvements required. Impressively, only a minority of blood establishments will need to perform major modifications or improvements (score 3-5). These improvements are focused on personnel and organisation, waste disposal, donor eligibility and storage and distribution. The results of the survey revealed several standards and guidelines, which are commonly used by blood establishments in European member states. About half of the participants use national standards in addition to European or international standards are either used in addition to the national standard and recommendations. With respect to the commonly used European or international standards, the EU GMP and CoE standards are the most commonly implemented standards for routine work processes. Based on the survey results the EuBIS expert group has developed guidelines based on Directive 2002/98/EC that include cross-references to the EU GMP standards, the PIC/S GMP for blood establishments, the CoE guide and the ISO 9000 series.

\section{P 15.02}

\section{Towards an European Specialist in Transfusion Medicine}

\section{Mueller M.M., Seifried E.}

Institute for Transfusion Medicine \& Immunohematology, Clinics of the JWG University \& GRC Blood Donor Service, Frankfurt/Main, D

Background: European directives 93/16/EEC, 2001/19/EC and 2005/36/EC deal with mutual recognition of professional qualifications of European medical doctors. Specialisations listed in the annexes of these directives not only comprise big medical subspecialities like internal medicine, surgery, etc., but also less frequent qualifications like immunology or tropcial medicine not common in all European member states. Transfusion medicine however, is not represented in these directives. Objectives \& Methods: In order to compile the current situation in European countries, a first questionnaire was sent out via the EBA (European Blood Alliance) platform to 15 European countries. The objective of this questionnaire was to evaluate the rate of qualifications in transfusion medicine already established in these countries. Results: Seven out of 15 European countries already have established a clearly defined speacialisation in transfusion medicine and immunohaematology/immunology. Since transfusion medicine is not listed in the annexes of the above mentioned European directives, automatic mutual recognition cannot take place even between European member states covering transfusion medicine as a national medical specialisation. A detailled and more complex questionnaire regarding specialisation in transfusion medicine has now been prepared by our group aiming at an analysis of different requirements and constituent parts of qualification in transfusion medicine in different countries. This questionnaire is currently distributed to transfusion medicine societies in all member states of the European Union. A joint working group consisting of members of the European network of transfusion medicine societies (EuroNet-TMS), DGTI and EBA will meet in order to define European standards for qualifications in transfusion medicine. Our final aim is first to jointly establish a consolidated European qualification in transfusion medicine and second, to introduce a European specialist in transfusion medicine into annex V of directive 2005/36/EC in order to facilitate automatic mutual recognition of qualifications in transfusion medicine throughout Europe.

\section{P 15.03}

Aseptic Manufacturing in Cellular Therapy: Investigation of Environmental Monitoring Programme Excursions

Wagner B. ${ }^{1}$, Bader L. ${ }^{2}$, Wittmann G. ${ }^{3}$, Grabein B. ${ }^{2}$, Schramm W. ${ }^{1}$ Klinikum der Universität München, Transfusionsmedizin \& Hämostaseologie, München, D,

${ }^{2}$ Max von Pettenkofer Institut der Ludwig-Maximilians-Universität, München, D, ${ }^{3}$ Abt. Transfusionsmed.\& Hämostaseologie des Klinikums der Universität München, D

Objectives: According to Annex 1 of the EC Guide to Good Manufacturing Practice (GMP) a detailed environmental monitoring programme (EMP) is dictated for the surveillance of aseptic manufacturing of cellular therapy products in a class 100 (A) cleanroom. Here we report an investigation of out of specification (OOS) results and the correcting measures in the absence of any microbial product contamination. Design \& Methods: EMP comprises of continous monitoring the pressure differences and particle counts and the periodical assessment of biological active particles (BAPs) with an air sampler, settle and contact plates. While preparing cells in the cleanroom settle plates are put in the working area and the gloves of the operators are moni- tored for microbial contamination with contact plates. According to the European Pharmacopoeia standards the plates are incubated, colony forming units (CFU) are counted and bacteria are identified. Results: On 7 subsequent occasions average CFU counts on gloves after the preparations were 1.43 (action limit 1.0) and prompted further investigations. Exclusively aerobic spore-forming bacteria (i.e. Bacillus spp. with alcohol-resistant spores) were cultured. Ventilation equipment defects were excluded and the alcoholic hand disinfectant dispenser in the cleanroom was changed. In addition, routine EMP was extended by the assessment of BAPs before preparation. During the following 8 episodes average CFU counts on gloves remained elevated before preparation (1.43), but were within the normal range after preparation (0.14). Different lots and sizes of gloves were involved and additional monitoring of the storage cabinet did not reveal significant results. So we changed the hand disinfectant dispenser in the lock at the entrance of the cleanroom. The examination of the alcoholic disinfectant taken through the nozzle of the dispenser removed revealed $0.34 \mathrm{CFU} / \mathrm{ml}$ culturing aerobic spore-forming bacteria. During the subsequent 8 occasions CFU counts on gloves before and after preparation were not elevated. The disinfectant taken from the dispenser in operation showed no microbial growth. Sterility testing of all manufactured cell products detected no microbial contamination throughout the whole period under review. Conclusions: Successful implementation of an EMP according to the EC-GMP Guide is demonstrated by its function as an 'early warning system': OOS results in EMP occurred without microbial contamination of all manufactured products. Culturing of spore-forming bacteria from gloves in cleanrooms should prompt investigations of the alcoholic disinfectant and its dispensers as a potential source for contamination with alcohol-resistant bacterial spores.

\section{P 15.04 \\ Authorized Persons for Hemotherapeutical Quality Assurance: An Important Element in the Quality Management System of Medical Institutions for the Benefit of the Patients}

\section{Markovic A. ${ }^{\text {I, }}$, Weinstock C.}

${ }^{1}$ DRK-Blutspendedienst West Zentrum für Transfusionsmedizin Bad Kreuznach gemeinnützige Gesellschaft mit beschränkter Haftung, Geschäftsführung, Bad Kreuznach, D,

${ }^{2}$ DRK-Blutspendedienst West Zentrum für Transfusionsmedizin Bad Kreuznach gemeinnützige Gesellschaft mit beschränkter Haftung, Bad Kreuznach, $D$

Purpose: Based on the german transfusion law the german hemotherapy guideline requests an according, well-defined quality management system in medical institutions. In this system a directive-independent, authorized person for hemotherapeutical quality assurance (PHQA, 'Qualitätsbeauftragter (QB) Hämotherapie') has to survey hemotherapy in medical facilities. Methods: The authors are externally assigned PHQA in various hospitals and great hematooncological ordinations in 2 german countries. With perennial experience the formal and practical aspects of hemotherapy are surveyed, and corrective recommendations help the institutions to improve their performance and to meet the requirements of the regulations. Results: A great accordance with the requirements can be denoted. Yet, due to frequent changes of structure and staff, there are some non-conformances which have to be corrected continuously to avoid damage for patients. Conclusions: PHQA are an important element in the quality management system of medical institutions. Their corrective recommendations, based on findings in systematic audits, help the institutions to improve hemotherapy for the benefit of their patients.

\section{P 15.05 \\ Processing of Comments / Complaints by a Central Complaint Management System}

Fischer $\mathrm{H}$.

DRK-Blutspendedienst West Zentrum für Transfusionsmedizin Bad Kreuznach gemeinnützige Gesellschaft mit beschränkter Haftung, Qualitätsmanagement, Bad Kreuznach, D

Purpose: In order to be able to process the comments and complaints of blood donors more quickly, a central complaint management system was introduced within the scope of quality assurance (QA) in 2001. Whereas the various modes of receiving the comments / complaints (by mail, e-mail, phone calls) had previously often resulted in a longer response time, centralizing the operation made it possible to streamline the flow and speed up the replies to the blood donors. Methods: All comments/complaints arrive centrally in QA. Using a standardized form, the comment / complaint is recorded, assigned to the competent department and forwarded to the person in charge. Tracking is also carried out by QA. Through a follow-up system a 
check after a specified period of time ascertains whether a reply has been given to the blood donor; if this is not the case, the competent department is reminded of the still pending response. Results: The continuous tracking undertaken through the central complaint management system ensures that blood donors receive an answer to their comments / complaints as quickly as possible. Conclusions: To the blood donor the speedy processing of his or her concern is of great importance. Only satisfied blood donors will come back. The continual improvement in the area of donor satisfaction will support the compliance with our stipulated supply mandate and will increase the commitment of blood donors to the blood donation service.

\section{P 16 Others}

\section{P 16.01}

\section{Lipids Apheresis. What We Can Say Today?}

\section{Pokrovsky S. ${ }^{1}$, Konovalov G. ${ }^{2}$, Adamova I. ${ }^{1}$, Afanasieva O. ${ }^{l}$,} Afanasieva M. ${ }^{l}$, Kipor S. $^{3}$

${ }^{1}$ Cardiology Research Center, Moscow, RUS, ${ }^{2}$ Medsi' Clinic, Moscow, ${ }^{3}$ POCARD Ltd, Moscow, RUS

The disorders of lipid metabolism usually result in serious pathology conditions, often inheritable. Familial hypercholesterolemia (FH) is associated with the disorder in the function of low density lipoprotein (LDL) receptors. Extracorporeal lipids elimination - LDL and/or Lp(a) apheresis can be treatment of choice for patients with homozygous; drug resistant heterozygous $\mathrm{FH}$; it's also helpful for the patients with drugs resistant lipids desorders patients after bypass surgery and also for patients with elevated Lp(a) level. Long-term LDL apheresis with antibodies containing columns 'LDL Lipopak $^{\circledR}$ (POCARD Ltd., Russia) provides significant decrease of LDL-C and increase of HDL-C level compared to baseline. Xanthomas decreases or completely disappears during the first years of treatment, improvement of myocardial function and significant regression of coronary atherosclerosis are observed. We have performed clinical follow up during 25 years of treatment by LDL apheresis.

Elevated Lp(a) level more than $30 \mathrm{mg} / \mathrm{dl}$ is associated with the development of atherosclerosis in coronary, carotid, peripheral arteries and early vein grafts occlusion after CABG. Patients with increased $\mathrm{Lp}(\mathrm{a})$ usually have severe coronary heart disease (CHD). For many patients with elevated Lp(a) and LDL, the LDL level can be effectively controlled by lipid lowering drug therapy, but target $L p(a)$ level can't be achieved. Currently there are practically no effective drugs for normalization of $\mathrm{Lp}(\mathrm{a})$ level. Because of that, we have designed specific $\mathrm{Lp}(\mathrm{a})$ apheresis with ${ }^{\prime} \mathrm{Lp}(\mathrm{a}) \mathrm{Lipopak}^{\circledR}$, immunosorbent columns. It is an unique approach for the treatment of patients with severe CHD. It's well known that all available systems for LDL apheresis (such as immunoadsorption, DS, HELP, DALI and other) can reduce Lp(a) But for specific removal of $L p(a)$ we have developed columns with sheep polyclonal antibodies against human $\mathrm{Lp}(\mathrm{a})$ - called ' $\mathrm{Lp}$ (a) Lipopak ${ }^{\circledR}$, (POCARD Ltd., Russia). Lp(a) Lipopak can reduced $\operatorname{Lp}(\mathrm{a})$ on $80 \%$, other parameters are practically constant during one $\mathrm{Lp}(\mathrm{a})$ apheresis procedure. Our experience with ' $L p(a)$ Lipopak $^{\circledR}$ ' columns demonstrated that the removal of $\mathrm{Lp}$ (a) from the patient's plasma up to the normal range by weekly $\mathrm{Lp}$ (a) apheresis results in the improvement of the patient's health status and quality of life. In all cases the progression of disease was terminated. The quantity of daily heart attacks was dropped and exercise tolerance test was improved after 20-30 treatments. The regression of atherosclerotic plaques in some segments of coronary arteries was observed. We postulate that $\mathrm{Lp}(\mathrm{a})$ apheresis could be used for some CHD patients with solo elevated $\mathrm{Lp}$ (a) to whom routine LDL apheresis can't be prescribed.

We have also proposed another opportunity - combined Lp(a) \& LDL apheresis that is a good method for the treatment of CHD patients, with elevated of the both $\operatorname{Lp}(\mathrm{a})$ and LDL levels. The apheresis procedures with one 'LDL Lipopak ${ }^{\circledR}$ ' and one ' $\mathrm{Lp}$ (a) Lipopak ${ }^{\circledR}$ ' column for the patient with elevated Lp(a) as well LDL levels were performed. The results show this combined apheresis technique to be effective and helpful for patients resistant to the lipids lowering drugs.

Design of new generation of the sorbents for the whole blood perfusion is currently in progress.

\section{P 16.02}

\section{Impact of Chronic Hepatitis C Infection in Patients with Haemophilia}

Vidovic N. ${ }^{1}$, Lochowski . $^{2}$, Grünhage $F^{3}{ }^{3}$, Goldmann ${ }^{2}{ }^{2}$,

Niemann B. ${ }^{2}$, Schröder J. ${ }^{2}$, Horneff S. ${ }^{2}$, Spengler U. ${ }^{2}$,

Sauerbruch $T^{2}{ }^{2}$, Oldenburg J. ${ }^{2}$

${ }^{1}$ University Clinic Bonn, Institute for Exp. Haematology and Transfusion

Medicine, Bonn, D,

${ }^{2}$ University Clinic Bonn, D, ${ }^{3}$ Saarland University Hospital, Homburg, D

Background: Chronic infection with hepatitis $\mathrm{C}$ virus (HCV) has turned out to be a major cause of morbidity and mortality in patients with haemophilia. Approximately $20 \%$ of patients with HCV develop cirrhosis over a 20 to 30 year period. As the percentage of haemophiliacs who exhibit end stage liver disease (ESLD) and hepatocellular carcinoma (HCC) is dramatically rising, means to assess those at highest risk for these complications are strongly recommended. Transient elastography by FibroscanTM is a novel technique to estimate the degree of hepatic fibrosis by measuring liver stiffness. Results: In our cohort of patients with haemophilia 315 are anti-HCV positive, indicating ongoing or previous infection with HCV. $61(20 \%)$ have spontaneously cleared HCV. 144 (45\%) patients underwent antiviral therapy which was successful in 80 patients. $174(55 \%)$ are still suffering from chronic hepatitis $\mathrm{C}$ because of treatment failure (64 patients), because antiviral therapy could not be performed ( 31 patients) e.g. conflict with other underlying diseases or has not been performed mainly due to fear of side effects, lack of clinical symptoms and expected low efficacy of treatment (78 patients). To date transient elastography was performed in 113 of the chronically HCV-infected patients. 57 (50.4\%) of them had no or mild fibrosis (Metavir F0/F1). 18 (15.9\%) exhibited moderate fibrosis (Metavir F2). Severe or cirrhotic fibrosis (Metavir F3 and F4) has been diagnosed in 49 $(43.4 \%)$ of these patients. In the virusnegative subcohort $31(81.6 \%)$ patients had no or mild fibrosis, 1 (2.6\%) had moderate fibrosis and 7 (18.4\%) patients showed severe or cirrhotic fibrosis. Conclusion: In order to assess liver fibrosis in our haemophilic patients and identify those eligible for antiviral therapy we used transient elastography which identified an unexpected high proportion of patients with severe or cirrhotic fibrosis of approximately $43 \%$. This finding persuaded a great percentage of them to finally start antiviral therapy. For patients with advanced fibrosis (Metavir F3 and F4) who are not eligible for virus eradication a close-meshed monitoring by ultrasonography and laboratory tests is recommended to prevent a fatal outcome by early therapeutic intervention.

\section{P 16.03 \\ Early Organ Rejection Caused by DP-Antibodies - a Case Report}

Monien S. ${ }^{1}$, Liefeldt L. ${ }^{2}$, Jacob $V_{.}{ }^{2}$, Salama A. ${ }^{2}$, Schönemann $C .{ }^{2}$ ${ }^{1}$ Charité, Institut für Transfusionsmedizin, Berlin, D, ${ }^{2}$ Charité, Berlin, D

Objectives: Relevant histocompatibility markers for kidney transplantation are HLA-A, -B, -DR. Humoral rejections are typically caused by antibodies (ab) against these antigens. The clinical significance of DP-antibodies is unclear. Design and Methods: Here we report on a second kidney transplantation in a 49-year-old patient. The first transplant (1998) had lost its function by humoral rejection after 30 months. HLA-ab have been detected by CDC, ELISA, and LUMINEX techniques. Second kidney transplantation was undertaken with a well-matched transplant (mismatch $\mathrm{A} / \mathrm{B} / \mathrm{DR} 1 / 0 / 0$ ) in 10/2006. The patient has never had ab against that incompatible antigen, even when tested by sensitive techniques. XM with blood and spleen lymphocytes and isolated T-cells were negative. Solely B-cell-XM was positive. Considering the negative T-cell-XM, good organ quality, and good match grade the patient was transplanted. Already the second postoperative day a rejection (Banff 2A) was diagnosed. We retyped the donor and found an additional DQ-mismatch. But no donor specific ab against these mismatches could be detected by sensitive Luminex testkits. So neither the positive Bcell-XM nor the early humoral rejection signs could be explained by HLA diagnostic tests. Only when tested by the new Luminex single antigen test a DP-antibody (DP11) was detected. The donor was typed for DP and found to be DP11 positive. The ab was also found in sera of the patient prior to the second transplantation. Immunizing event is most likely the first kidney transplantation. In the following course the DP-ab disappeared from the patients sera. We assume it to be absorbed by the transplanted kidney. Several immunosuppressive treatments and plasmapheresis could stabilize the kidney function only temporarily. Before completely loss of transplant function 7 months after transplantation occurred, DP-ab had reappeared in the patient's serum. Conclusions: This case confirms literature and own observations, which show that a positive B-cell-XM may be a risk factor in 
immunized re-transplant-patients. At least in these cases the non-classical HLA-markers should be included in diagnostic tests.

P 16.04

A Double-Edged Sword between Economics and High-
Standard Health Care: Calculating the Production Costs
of Stored Blood Components at a University Blood Center Vandercappelle U. ${ }^{l}$, Möller N. ${ }^{l}$, Herms B. ${ }^{2}$, Meier-Grothe S. ${ }^{2}$,
Scharf R.E.

${ }^{1}$ Heinrich Heine University Medical Center Düsseldorf, Department of Hemostasis and Transfusion Medicine, Düsseldorf, D,

${ }^{2}$ Heinrich Heine University Medical Center, Düsseldorf, D

Objectives: The costs for providing blood have increased as a result of the improved safety standards. On the other side hospitals are obliged to reduce expenditures. Methods: For the University Blood Center of the Dept. of Hemostasis, Hemotherapy and Transfusion Medicine at the Heinrich Heine University Medical Center Düsseldorf, different concepts such as 'mixed calculations', 'intramural cost allocation at the university hospital' and 'extramural benchmarking analyses' were prepared to provide the basics for optimized 'manufacturing' costs that correlate with the supply of highquality blood products. Therefore, a complete calculation of the actua expenditures was required. To achieve this goal, a clear assignment of the financial charges to each part of production (whole blood donation, apheresis etc.), a verification of these expenses by the Div. of Controlling and the Div. of Purchasing and Supply, the ascertainment of the real costs for human resources, and the detailed analysis of production data and consumption data were performed. Thereafter, a process flow model was developed describing all major steps involved in collecting, processing and transfusing blood. With these tools, it was possible to calculate the real entire expenses for donor recruitment and marketing, blood donation, manufacturing and preparation including material costs, human resources, administration overhead, costs for storage, disposition, handling, and transportation. To guide the intramural cost allocation process, it was necessary to differentiate between the various blood products, as their specific manufacturing causes distinct expenses. Results: Having established these tools, we performed calculations for the production costs in case of transfusing $100 \%$ of the blood products and compared these data with the real investment and expenses due to failure rates and expired products. These analyses allowed to identify cost intensive pitfalls and entrapments within the production and operator process flow. For the intramural cost allocation, the real financial charges of the different blood products were presented. In addition, a comparison between real 'in-house' and actual 'market' prices was provided. Conclusion: Analysis of blood components expenditures requires both (i) expert knowledge in production processes and their financial charges and (ii) competence in transfusion medicine and clinical hemotherapy.

\section{P 16.05}

\section{Eosinphils Enhance Anti-Tumor-Immunity by Sensing and Responding to Necrotic Tumor Cells}

Lotfi R. ${ }^{1}$, Herzog G. ${ }^{2}$, Rojewski M. ${ }^{2}$, Schrezenmeier . $^{\prime}{ }^{\prime}$

${ }^{1}$ Universitätsklinikum UIm, DRK Blutspendedienst Baden-Württemberg, Institut für Klinische Transfusionsmedizin und Immungenetik UIm, D, ${ }^{2}$ Universitätsklinikum Ulm, D

Objectives: Eosinophils are found at increased numbers within necrotic areas of tumor tissues. In case of colorectal cancer the so called tumorassociated-tissue-eosinophilia (TATE) is associated with a favourable prognosis. Nevertheless the pathophysiology of TATE and its impact is almost unknown. Necrotic cell death with subsequent release of damage associated molecular patterns (DAMPs) is a characteristic feature of tumor tissue DAMPs not only serve as alarmins inducing further tumor proliferation, but also induce a potent immune response including dendritic cell maturation and chemotaxis of leukocytes, specifically eosinophils. The chemotactic effect of DAMPs on eosinophils is well demonstrated in vivo and in vitro as well as in our own hands. High mobility group box 1 (HMGB1) is a prototypic member of DAMPs released following only necrotic but not apoptotic cell death. We sought to characterize the role of eosinophils within tumor microenvironment. Design and Methods: Human granulocytes were isolated by density centrifugation of whole blood followed by hypotonic lysis of remaining red cells. Eosinophils were negatively separated from other granulocytes using magnetic beads from Miltenyi. Lysates from a colorectal tumor cell line (HCT116) were generated by repeated freeze-thawing. Recombinan human HMGB1 was purchased from R\&D systems. Cytokine measuremen in supernatants was assessed using FlowCytomix (Bender MedSystems). Oxidative burst was assessed by flow cytometry using H2DCFDA (Invitro- gen) to detect intracellular peroxide. Results: We demonstrate that eosinophils - but not neutrophils - oxidative burst is enhanced when stimulated with DAMPs released from lysed tumor cells in a dose dependent manner. HMGB1 (a necrosis-specific DAMP) induced a similar dose dependent effect. Assessing released cytokine profile we could show that eosinophils challenged by DAMPs dose dependently released IL-8 while decreasing the release of Th2 cytokines, IL-4 and IL-10. Conclusions: Sensing DAMPs from necrotic tumor cells eosinophils produce peroxide which may be cytotoxic to tumor cells. In addition oxidation of DAMPs changes their biologic activity. Released IL-8 from eosinophils is a strong chemoattractant to granulocytes and may further enhance granulocytes infiltration into tumor tissue. DAMPs-challenged eosinophils decrease their IL-4 and IL-10 release thus paving the way for a Th1 response. We postulate an immune modulating role of eosinophils within tumor microenvironment. Our findings shed some light into the microenvironment of (necrotic) tumor tissue and open perspectives for immunotherapy of cancer.

\section{P 16.06}

Biospecific Sorbent with Synthetic Ligand for Removal of Anti-A and Anti-B Antibodies from Human Plasma

\section{Levashov $P^{1}{ }^{1}$, Klesareva E. ${ }^{1}$, Korchagina $E^{2}{ }^{2}$, Bovin $\mathrm{N}^{2}$,} Afanasieva O. ${ }^{l}$, Adamova I. ${ }^{\prime}$, Pokrovsky S.

${ }^{1}$ Cardiology Research Center, Moscow, RUS,

${ }^{2}$ Institute of Bioorganic chemistry, Moscow, RUS

The removal of specific antibodies from the plasma of patients is promising method for solving many of transplantology problems. One of the causative factors in the graft rejection, selected by the antigens of histocompatibility, is incompatibility on the groups of the blood according ABO system. Extracorporeal immunoabsorption for removal of anti-A and anti-B antibodies from patients' plasma transplantation is considered as a major prophylactic procedure in order to avoid hyperacute and acute vascular rejections. The synthetic oligosaccharides (A-trisaccharide, Atri) and (B-trisaccharide, Btri), covalently linked to agarose by different methods with and without polymer spacer. Five types of prepared sorbents were applied to the samples of human plasma of $\mathrm{O}$ blood group with high titer of specific antibodies. It was found that $1 \mathrm{ml}$ of Atri-sorbents or Btri-sorbents allows remove $70-91 \%$ of corresponding specific immunoglobulins (IgG and $\operatorname{IgM}$ ) from sample of 20 $\mathrm{ml}$ human plasma. Specificity of developed sorbents was the same of active ingredient of commercially available column 'Glycorex' (Glycorex Transplantation AB). All samples of sorbents were of high stability during sterilization and could be reused many times without the loss of binding capacity and specificity.

New simple and practical technique has been developed for the specific sorbent preparation. To be sure, the sorbents with the low weight synthetic ligands can be very perspective for the development of the new columns generation for the elimination of immunoglobulins with the therapeutic apheresis techniques.

\section{P 16.07 \\ Perioperative Alterations of Serum Erythropoietin Levels in Patients with and without Compensated Renal Insufficiency}

\section{Wenzel F. ${ }^{1}$, Gettmann $T^{2}{ }^{2}$, Klein M. $^{3}$, Giers G. $^{2}$}

${ }^{1}$ Salzburger Landesklinik, Univ.-Klinik für Transfusionsmedizin, Salzburg, A, ${ }^{2}$ Institut für Hämostaseologie und Transfusionsmedizin, Düsseldorf, D, ${ }^{3}$ Thorax und Kardiovaskularmedizin, Düsseldorf, D

Introduction: The hormone erythropoietin (EPO) is the main regulator of erythropoiesis and mainly produced by renal cells. Cell loss caused by operative procedures may alter serum levels of the hormone, resulting in an enhanced production, and one may speculate that a reduced increase of the hormone level could be observed in patients with a restricted renal function. Material and Methods: Blood samples from 12 patients (mean age $63 \pm 9$ years) with a normal renal function $(n=6)$ and with a compensated renal insufficiency $(n=6)$ were obtained before and on days 1, 5 and 10 after CABG. sEPO levels were determined by a commercially available ELISAKit (R\&D Systems, Germany). Results: Prior to CABG, sEPO (12.6 \pm 8.3 $\mathrm{mU} / \mathrm{ml})$ and $\mathrm{Hb}(9.3 \pm 1 \mathrm{mmol} / \mathrm{l})$ were within a normal range in all patients. At day 1 after surgery, $\mathrm{Hb}$ was significantly decreased to $6.7 \pm 0.8 \mathrm{mmol} / \mathrm{l}$. In contrast, sEPO was significantly elevated to $39.7 \pm 28.5 \mathrm{mU} / \mathrm{ml}$. At day 5 after CABG a significant difference in EPO levels could be observed between patients with normal renal function $(35.6 \pm 19.5 \mathrm{mU} / \mathrm{ml})$ and with compensated renal insufficiency $(20.9 \pm 15.4 \mathrm{mU} / \mathrm{ml})$ whereas at day 10 after surgery patients with compensated renal insufficiency reached again the range of the patients with normal renal function. Conclusions: Appropriate to the decrease in hemoglobin concentration, clear alterations of serum 
erythropoietin could immediate postoperatively be observed. In patients with compensated renal insufficiency a declined EPO level at day 5 could be observed recovering into a normal range at day 10 after surgery. Therefore the surgical exposure may lead to an aggravation of the restricted renal function especially in the first 5 days after surgery.

\section{P 16.08}

\section{Assessment of Blood Products Demand in the Treatment} of Adverse Drug Reactions in German Hospitals

\section{Rottenkolber D. ${ }^{I}$, Schmiedl S. ${ }^{2}$, Rottenkolber M. ${ }^{3}$, Hasford J. ${ }^{3}$}

${ }^{1}$ Ludwig-Maximilians-Universität München, Munich Center of Health

Sciences, Munich, D

${ }^{2}$ HELIOS Klinikum Wuppertal, Philipp Klee-Institut für Klinische

Pharmakologie, Universität Witten/Herdecke, Wuppertal, D, ${ }^{3}$ Department

of Medical Informatics, Biometry and Epidemiology, Ludwig-MaximiliansUniversität, Munich, D

Objective: Drug therapies combine progress in medicine with inevitable risks of adverse drug reactions (ADRs). The objective is to examine the demand for blood products in German hospitals induced by ADRs leading to admissions in departments of internal medicine. This paper is one of the first attempts to quantify the ADR-related economic burden and blood consumption in Germany. Methods: 4.444 patient records of ADRs leading to internal medicine hospitalisation were surveyed in 4 regional pharmacovigilance centres in Germany within the years 2000-2007. ADRs must have been induced by at least one drug which causality was qualified as 'likely' or 'very likely' according to Begaud et al. (1985). Incidence for ADRs was estimated (approx. 3.25\%). Market prices for blood products and statistical data on hospitalisation were evaluated by literature and desktop research Results: Treatment of 741 patients $(16.7 \%)$ requiring blood products resulted in total consumption of 2,726 (mean 3.76 per patient) erythrocyte concentrates (ECs) and 267 (mean 3.38 per patient) fresh frozen plasma unit (FFPs). The mean age of treated patients was $72.9(\mathrm{SD}=12.4)$ years, 412 $(55.6 \%)$ were female and $567(76.5 \%)$ were $\geq 65$ years old. Drugs most frequently associated with ADRs were acetylsalicylic acid (281), phenprocoumon (274), and diclofenac (118). In most cases, gastrointestinal tract was affected (SOC 'gastrointestinal disorder', $\mathrm{n}=623$ ). Matching statistical data of hospitalisation in Germany with our findings a total demand of 100,934 ECs and 9,882 FFPs units can be estimated resulting in total cost of approx. $€ 9.1 \mathrm{~m}$ per year for all German hospitals. According to a literature review on average $51 \%$ of ADRs are preventable [see Grandt et al., Dt. Arztebl 2005 ; 102]. Prevention of these ADRs could lead to a decreasing annual demand of blood products (ECs -51.981, FFPs -5.089 units) resulting in a saving potential of approx. $€ 4.68 \mathrm{~m}$ per year for German hospitals. Conclusions: Blood products are given in one sixth (mainly gastrointestinal bleeding) of al ADRs leading to hospital admissions in departments of internal medicine resulting in serious cost and provision burden for the respective hospitals. Both blood demand and hospital procurement costs can be reduced by half by preventing ADRs. Therefore, improving medication safety is not only essential for the health of the invidual patient but should also be one of the essential concerns for medical and public health decision makers in terms of cost reduction.

\section{P 16.09}

\section{Thrombopoietin Levels are Different in Plasma and} Serum Samples

Wenzel F. ${ }^{l}$, Günther $W^{2}{ }^{2}$, Hassan $S^{2}{ }^{2}$, Baertl $A .^{2}$, Kafka I. ${ }^{2}$, Wiedamann $\mathrm{H}^{3}$, Giers $\mathrm{G}^{2}$

${ }^{1}$ Salzburger Landesklinik, Univ.-Klinik für Transfusionsmedizin, Salzburg, A, ${ }^{2}$ Institut für Hämostaseologie und Transfusionsmedizin, Düsseldorf, D, ${ }^{3}$ Institut für Transfusionsmedizin, Salzburg, A

Introduction: The hormonethrombopoietin (TPO) is the main regulator thrombopoiesis. Especially in thrombocytopenic diseases TPO seems to be a helpful diagnostic marker. But it should be considered that platelets could influence TPO levels during the preanalytic period by clearing with TPO receptor followed by internalization as well as by release of TPO after platelet activation. Therefore we determined TPO levels under different sampling techniques, storage conditions and platelet counts. Methods: Blood samples of seven healthy blood donors, ten thrombocytopenic patients and eight patients with thrombcytosis were collected in tubes without additives and in EDTA- or citrate-filled tubes. TPO levels were determined by a commercially available ELISA-Kit (R\&D Systems). Results: In healthy blood donors and in patients with thrombocytosis TPO levels in plasma samples were found to be in a normal range $64 \pm 32 \mathrm{pg} / \mathrm{ml}$ and $59 \pm 42 \mathrm{pg} / \mathrm{ml}$, respectively. In contrast, in thrombocytopenic patients TPO plasma levels were elevated to $3024 \pm 347 \mathrm{pg} / \mathrm{ml}$. In the respective serum samples TPO showed a significant increase at normal and high platelet count to $136 \pm 56 \mathrm{pg} / \mathrm{ml}$ and $145 \pm 53 \mathrm{pg} / \mathrm{ml}$, respectively, whereas at low platelet counts no significant difference to the plasma values could be obeserved. Conclusions: Influences of preanalytic conditions on TPO levels could be observed when TPO levels reached a low range (especially in healthy volunteers and in patients with thrombocytosis). In thrombocytopenic patients with TPO at a high range no differences between TPO levels of plasma and serum samples could be observed. These influences should be considered by the determination and evaluation of TPO concentrations under different pathophysiological conditions.

\section{P 16.10 \\ Allogeneic Peripheral Stem Cell Apheresis: Ankara University Experience}

\section{Arat M., Ayyıldız E., Bay M., Bakanay S., Arslan O., Ilhan O.}

Ankara University Medical School Department of Hematology, Hemapheresis Unit, Ankara, TR

Introduction: Significant progress has been achieved in the clinical utilization of hematopoietic stem cells in the last 20 years. Allogeneic peripheral blood stem cell (PBSC) transplantation, which is transplantation of stem cells from healthy donors, has been increasingly performed in hematologic diseases, solid tumors, metabolic diseases and various immunodeficiency syndromes. Currently more than $75 \%$ of the allogeneic transplants in the world are performed with PBSC Stem cells are collected via cell separators by a one or more apheresis procedure following cytokine only priming of the donor. The advantages over BM collection are higher CD34 counts, omitting of general anesthesia and risks of operation, and ambulatory work-up and procedure. Patients and Methods: Between March 1998 and May 2008, 413 allogeneic PBSC collections (170 AML, 80 CML, 51 ALL, 20 Lymphoma, 16 Aplastic Anemia ,10 Thalassemia, 6 MDS, 4 myelofibrosis, 4 Renal cell cancer, $2 \mathrm{PNH}, 1$ plasma cell leukemia, 1 pure red cell aplasia) on 365 healthy donors were performed. Stem cell mobilisation of the donors were performed by administration of granulocyte colony stimulating factor (GCSF) $5 \mathrm{mcg} / \mathrm{kg}$ every 12 hours for 5 days and subsequent continuous flow apheresis on the 5th day. Donor characteristics were: F/M: 168/197, median age: 34 (range, 8-87) years, median body weight: $70 \mathrm{~kg}$ (range, 18-112). The targeted CD34+ cell number was $4 \times 10 \mathrm{e} 6 / \mathrm{kg}$ recipient weight. Results: Pre and post apheresis variables of the donor, apheresis procedure's characteristics and product data were summarized in Table 1. The median CD34+ count was $5.25 \times 10 \mathrm{e} 6 / \mathrm{kg}(0.94-44.4)$ The median number and the duration of apheresis procedure were $1(1-2)$ ve 258 (95-434) minutes, respectively. While sufficient number of CD34+ cells could be collected in $86 \%$ by a single apheresis procedure, second apheresis was required in only 48 donors. All procedures were successfully completed without any significant complication, which results with morbidity or mortality of the donor or termination of the procedure. Conculsion: In the last decade our hemapheresis unit successfully completed more than 400 PBSC collections on 365 healthy donors. PBSC is replacing the crown of BM as the unique source of stem cells. The ease and safe proceedures, reliable stem cell counts are the main known reasons for this evolution in hematopoietic stem cell transplantations.

\begin{tabular}{|c|c|c|c|c|c|c|c|c|c|c|c|}
\hline & \multicolumn{2}{|c|}{ Pre-apheresis } & \multicolumn{4}{|c|}{ Apheresis procedure } & \multicolumn{3}{|c|}{ Product } & \multicolumn{2}{|c|}{ Post-apheresis } \\
\hline & $\begin{array}{c}\text { WBC } \\
\times 10^{6} / \mathrm{mm}^{3}\end{array}$ & $\begin{array}{c}\mathrm{CD} 34+ \\
\mathrm{mcl}\end{array}$ & $\begin{array}{l}\mathrm{N} \text { of } \\
\text { proce- } \\
\text { dures }\end{array}$ & time & $\begin{array}{c}\mathrm{TBV} \\
\text { processed }\end{array}$ & $\begin{array}{c}\text { ACD } \\
(\mathrm{ml})\end{array}$ & $\begin{array}{c}\mathrm{TNC} \\
\times 10^{8} / \mathrm{kg}\end{array}$ & $\begin{array}{c}\mathrm{MNC} \\
\times 10^{8} / \mathrm{kg}\end{array}$ & $\begin{array}{c}\mathrm{CD} 34 \\
\times 10^{6} / \mathrm{kg}\end{array}$ & $\begin{array}{c}\text { WBC } \\
\times 10^{6} / \mathrm{mm}^{3}\end{array}$ & $\begin{array}{c}\text { Plt } \\
\times 10^{6} / \mathrm{mm}^{3}\end{array}$ \\
\hline Median & 47.00 & 79 & 1 & 258 & 12500 & 1000 & 6.98 & 4.96 & 5.25 & 39.00 & 166.00 \\
\hline Min. & 5.00 & 3 & 1 & 95 & 3017 & 247 & 0.78 & 0.45 & 0.94 & 4.40 & 56.60 \\
\hline Max. & 96.00 & 366 & 2 & 434 & 17149 & 1467 & 18.08 & 16.63 & 44.4 & 85 & 252 \\
\hline
\end{tabular}


P 16.11

Palliative Haemotherapy for Paediatric Patients Outside of the Hospital $(\mathrm{OOH})-2$ Years Experience of a Home Transfusion Programme of the University of Muenster

Reinicke-Voigt $\mathrm{U}^{1}{ }^{1}$, Baumann-Köhler M. ${ }^{2}$, Jürgens $\mathrm{H}^{2}$, Sibrowski W.

${ }^{1}$ Universitätsklinikum Münster, Transfusionsmedizin, Münster, D,

${ }^{2}$ Universitätsklinikum Münster, D

About 1800 children in Germany aged under 15 are diagnosed to have a malignant disease annually. The number of disease-related deaths up to 5 years after diagnosis in this paediatric population is $300-400$ per year. Anemia and thrombocytopenia are relatively common symptoms in particular at the final phase of life of these children. Bleeding, especially when the blood loss is visible is a particulary distressing symptom for both the patient and the family. The discipline of paedriatric palliative care has emerged in Germany over the last years. The aim of this development was and still is to enable families to care for their children in their own home. At the University Children's Hospital Muenster, Department of Paediatric Haematology and Oncology, a multidisciplinary palliative care team was established in the last years. Based on our experiency caring for palliative patients at home it is absolutely essential and desirable to have the facility to provide blood products at home.

Although home transfusion programmes are relatively common in the USA and Great Britain, this type of treatment are not realised in Germany even in the palliative setting so far. Since July 1, 1998 a Transfusion Act ('Transfusionsgesetz') regulates the clinical use of blood products in Germany in accordance with the guidelines established by the German Medical Association and the Paul Ehrlich Institute, which are regulary revised and adapted on the basis of current professional knowledge and technology. The administration of blood products, whether in hospital or a doctor's office, must follow certain quality-assumed rules governing transfusions as stipulated by the Transfusion Act. The University of Muenster now has 2 years experience of a home transfusion programme operating for paediatric patients in palliative care. The transfusion of blood and platelets outside the hospital $(\mathrm{OOH})$ reduce the demand on acute services and the need for hospital admission.

The potential risks can be decreased through careful planning and design. For the new field of transfusion of blood and platelets outside the hospital and doctor's office there is a demand of legal provision.

P 16.12

Good Service and Strong Personal Ties to the Pheresis

Unit Are More Important for Many ThrombozytapheresisDonors than an Allowance - a Follow-up

Gross S. ${ }^{1}$, Markovic A. ${ }^{2}$

${ }^{1}$ DRK-Blutspendedienst West, Haemapheresis, Bad Kreuznach, D, ${ }^{2}$ DRK-Blutspendedienst West, Bad Kreuznach, D

Introduction: The transfusion law demands the gratuity of blood donation, however it accepts an allowance orientated at the expenditure for each kind of donation. Therefore the allowance for thrombocytapheresis-donors was lowered clearly and expenditure-referred. The already improved service was maintained. Method: The effect of the lowering was registered by comparison of the donor behaviour 1 year before and 1 year after sinking allowance (phase A and B) and compared to the already published provisional study. Results: At the end of phase B we had lost $36 \%$ of the donors registered in phase A. However this loss could be overcompensated by $44 \%$ remaining or newly accrued donors. The mean donation frequency remained nearly constant in both phases with 4.7 versus 4.6. However, the number of donated blood products per donor decreased by 0.9 to 7.1 blood products $(-12 \%)$ versus $-14 \%$ in the provisional study. Conclusions: The lowering of the allowance shows one year later mainly a change in the donor population, but no loss of donators at all. Compared to the results of our provisional study the strong personal ties to the pheresis unit and an attractive service are still motivating our donators. An increase of double donations is also confirming this fact.

\section{P 16.13}

\section{Implementation of a Peer Audit System for Blood Donor} Services

Müller-Kuller $T^{l}{ }^{1}$, Findhammer $S{ }^{2}$, Frenda $S{ }^{2}$, Hennicker $I^{2}$, Seifried $E^{2}{ }^{2}$, Sireis $W^{2}$

${ }^{1}$ DRK-Blutspendedienst Baden-Württemberg - Hessen, Frankfurt, QM, Frankfurt/Main, D,

${ }^{2}$ DRK-Blutspendedienst Baden-Württemberg - Hessen, Frankfurt/Main, D

Objectives: Internal audits represent an important instrument of an efficient quality assurance system. In order to guarantee a critical evaluation of the processes and to identify any weaknesses, it is important that the auditors are technical experts, who are independent in work and function of the audited departments. The audits are not exclusively to examine formal aspects of quality assurance but also to analyze the processes in respect of technical and scientific issues. For this purpose the integration of specialized experts of other institutes is suitable. Design: The system for internal audits introduced in 2007 contains two audits, which are parallel accomplished: In the so called 'system-audit' the elements of the classical quality assurance are examined and the conformity with regulations is verified. In the so called 'process-audit' the operational procedures are proven for their accordance to current conditions of science and technology. The department for quality assurance is responsible for the organization, execution and rework of each audit. The experts for the system audits are likewise members of the quality assurance department. The process audits are conducted by experienced colleagues with excellent knowledge of the processes. In a rotation procedure different auditors are used for the institutes in each case. The audit reports of the individual experts are combined into a common report for the institute and made available for all responsible persons. In regular intervals the status of the corrective measures is queried, until these are corrected finally. The results and the corrective and preventive actions are included in the so called management review in order to inform the responsible management personnel. Results and Conclusions: The introduced audit system with inclusion of specialized inspectors was very well accepted within the enterprise. The audits were noticed not only as control but also as chance to discuss problems and to solve these. Compared to the audit system of the past, now the treatment and correction of the found deviations was carried out more seriously. The technically exchange between the experts led to an improvement of the processes and an adaptation of quality standards. The new system for internal audits was also favoured by external assessors. 